\title{
Monitoring the reproductive success of naturally spawning hatchery and natural spring Chinook salmon in the Wenatchee River
}

\author{
Michael J. Ford \\ Kevin S. Williamson \\ National Oceanographic and Atmospheric Administration \\ National Marine Fisheries Service \\ Northwest Fisheries Science Center \\ Conservation Biology Division \\ 2725 Montlake Blvd. East \\ Seattle, WA 98112 \\ and \\ Andrew R. Murdoch \\ Travis W. Maitland \\ Washington Department of Fish and Wildlife \\ 600 Capitol Way North \\ Olympia, WA 98501-1091
}

BPA Project No. 2003-039-00, Contract No. 41346 and 41826

Performance Period March 1, 2008-February 29, 2009

May 2009 


\section{Executive Summary}

We investigated differences in the statistical power to assign parentage between an artificially propagated and wild salmon population. The propagated fish were derived from the wild population, and are used to supplement its abundance. Levels of genetic variation were similar between the propagated and wild groups at 11 microsatellite loci, and exclusion probabilities were $>0.999999$ for both groups. The ability to unambiguously identify a pair of parents for each sampled progeny was much lower than expected, however. Simulations demonstrated that the proportion of cases the most likely pair of parents were the true parents was lower for propagated parents than for wild parents. There was a clear relationship between parentage assignment ability and the degree of linkage disequilibrium, the estimated effective number of breeders that produced the parents, and the size of the largest family within the potential parents. If a stringent threshold for parentage assignment was used, estimates of relative fitness were biased downward for the propagated fish. The bias appeared to be largely eliminated by either fractionally assigning progeny among parents in proportion to their likelihood of parentage, or by assigning progeny to the most likely set of parents without using a statistical threshold.

We used a DNA-based parentage analysis to measure the relative reproductive success of hatchery- and natural-origin spring Chinook salmon in the natural environment. Both male and female hatchery-origin fish produced far fewer juvenile progeny per parent when spawning naturally than did natural origin fish. Differences in age structure, spawning location, weight and run timing were responsible for some of the difference in fitness. Male size and age had a large influence on fitness, with larger and older males producing more offspring than smaller or younger individuals. Female size had a significant effect on fitness, but the effect was much smaller than the effect of size on male fitness. For both sexes, run time had a smaller but still significant effect on fitness, with earlier returning fish favored. Spawning location within the river had a significant effect on fitness for both males and females, and for females explained most of the reduced fitness observed for hatchery fish in this population.

While differences have been reported in the relative reproductive success of hatchery and naturally produced salmonids Oncorhynchus spp., factors explaining the differences are often confounded. We examined the spawning site habitat and redd structure variables of hatchery and naturally produced spring Chinook salmon O. tshawytscha of known size that spawned in two tributaries of the Wenatchee River. We controlled for variability in spawning habitat by limiting our analysis to redds found within four selected reaches. No difference in the instantaneous spawner density or location of the redd in the stream channel was detected between reaches. Within each reach, no difference in the fork length or weight of hatchery and naturally produced fish was detected. While most variables differed between reaches, we found no difference in redd characteristics within a reach between hatchery and naturally produced females. Correlation analysis of fish size and redd characteristics found several weak but significant relationships suggesting larger fish contract larger redds in deeper water. Spawner density was inversely related to several redd structure variables suggesting redd size may decrease as spawner density 
increases. Results should be considered preliminary until samples size and statistical power goals are reached in future years.

Trends in relative reproductive success of hatchery and naturally produced spring Chinook salmon Oncorhynchus tshawytscha in the Wenatchee Basins suggest females that spawn in the upper reaches of the tributaries produced a great number of offspring compared to females that spawn in the lower reaches of the tributaries. To better understand this trend, redd microhabitat data was collected from spring Chinook salmon that spawned in the Chiwawa River and Nason Creek, the primary spawning tributaries in the Wenatchee Basin. The objective of the study was to examine the influence of habitat and spawner density on spawning site and redd structure characteristics. We analyzed 27 variables of redd microhabitat data collected from the upper and lower most reaches of each study stream. In both streams, we found redds in the upper most reaches to be significantly larger (length and width) and deeper (bowl depth). Spawner density was significantly greater in the lower Chiwawa River compared to the upper reach. No difference in spawner density was detected between reaches in Nason Creek $(\mathrm{P}=0.54)$. Data should be considered preliminary until sample size goals are achieved. In the interim, data from additional stream reaches will be collected to better understand the relationships observed. In the future, redds will also be classified by habitat type and substrate of redds in different habitat types will be compared.

All results and conclusions should be considered preliminary and subject to revision until published in a peer-reviewed journal. 


\section{Table of Contents}

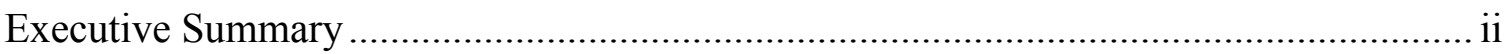

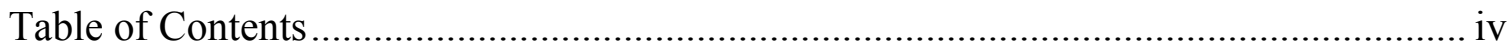

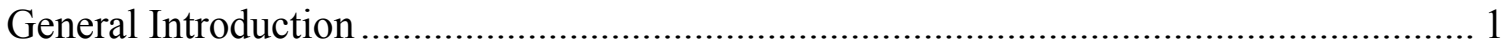

Chapter 1 - The Aunt and Uncle Effect Revisited: The Effect of Biased Parentage

Assignment on Fitness Estimation in a Supplemented Salmon Population ...................... 6

Chapter 2 - Factors influencing the relative fitness of hatchery and wild spring Chinook salmon in the Wenatchee River, Washington ............................................................... 25

Chapter 3 - Comparison of spawning site and redd characteristics of hatchery and naturally produced female spring Chinook salmon of known size in the Wenatchee River Basin

Chapter 4 - Influence of habitat and spawner density in the variation of redd microhabitat characteristics of spring Chinook salmon in the Wenatchee River Basin .... 67 


\section{General Introduction}

This project will quantitatively evaluate the relative reproductive success of naturally spawning hatchery and natural origin spring Chinook salmon Oncorhynchus tshawytscha in the Wenatchee River. Hatcheries are one of the main tools that have been used to mitigate for salmon losses caused by the construction and operation of the Columbia River hydropower system. In addition to harvest augmentation, hatcheries have recently been used in attempts to protect stocks from extinction and to enhance natural production (supplementation). Surprisingly, little is known about how much the investment in hatcheries benefits or harms natural production. Recent technological advances in genetics have enabled the empirical monitoring of the reproductive success of hatchery and natural spring Chinook salmon using a DNA-based pedigree approach. Specifically, this project will (1) directly measure the relative reproductive success of hatchery and natural-origin Chinook salmon in both natural and hatchery settings, (2) determine the degree to which any differences in reproductive success between hatchery and natural Chinook salmon can be explained by measurable biological characteristics such as run timing or size, and (3) estimate the relative fitness of hatchery-lineage Chinook salmon after they have experienced an entire generation in the natural environment. This report contains results from the fourth year of work on this project. The results from the previous years of work were addressed in Murdoch et al. 2007. The project is intended to last until 2012 in order to evaluate two entire spring Chinook salmon generations.

This project is collaboration between NOAA-Fisheries (Northwest Fisheries Science Center) and the Washington Department of Fish and Wildlife (WDFW). Results and progress are reported on jointly. This annual report is a joint authored report that has been split into four chapters in order to address important topics of the project. This project is an extension of the Chiwawa spring Chinook salmon supplementation program in the Wenatchee River operated by WDFW and funded by Chelan County Public Utility District (CCPUD).

\section{Description of Project Area}

Located in north central Washington, the Wenatchee River subbasin drains a portion of the eastern slope on the Cascade Mountains. The watershed is approximately $3,550 \mathrm{~km}^{2}$ with $383 \mathrm{rkm}$ of major creeks and rivers (Andonaegui 2001). Originating from Lake Wenatchee, the Wenatchee River flows 86.9 kilometers to its confluence with the Columbia River (rkm 754) near the town of Wenatchee (Figure 1). High mountainous regions of the Cascade crest are encompassed in the watershed, with numerous tributaries draining subalpine regions included in the Alpine Lakes and Glacier Peak Wilderness areas (Andonaegui 2001).

Historical river discharge monitored by the United States Geological Survey (USGS gauging station number 12462500 at river $\mathrm{km} \mathrm{9.4)} \mathrm{reported} \mathrm{a} \mathrm{41-year} \mathrm{mean} \mathrm{monthly}$ summer low discharge of $23 \mathrm{~m}^{3} / \mathrm{s}$ and a mean monthly spring peak discharge of $257 \mathrm{~m}^{3} / \mathrm{s}$. Of the total river discharge, the Little Wenatchee River (13\%) and White River (24\%) are 
the only tributaries that feed Lake Wenatchee (Mullan et al. 1992). Other primary tributaries of the Wenatchee River below the lake are Nason Creek (9\%), Chiwawa River (14\%) and Icicle Creek (19\%; Mullan et al. 1992).

The Wenatchee River basin supports self-sustaining populations of spring and summer Chinook, steelhead O. mykiss, and sockeye salmon O. nerka. Spring Chinook spawning occurs primarily in the upper Wenatchee River basin (upstream of rkm 57.3), although limited spawning does occur annually in lower elevation tributaries (i.e., Icicle and Peshastin creeks). Spawning subpopulations have been documented in all major tributaries in the upper Wenatchee River basin including the upper Wenatchee, Chiwawa, Nason, White and Little Wenatchee (Mosey and Murphy 2002). Andonaegui (2001) reported natural fish passage barriers, in the form of waterfalls, limit access in the Chiwawa River (53.3 rkm), Nason Creek (27.0 rkm), White River (23.0 rkm), and the Little Wenatchee River (12.6 rkm). Despite these barriers, spawning typically ends before these barriers. Increases in stream gradient and substrate size may limit spawning below barriers (Andonaegui 2001).

\section{History of Artificial Propagation}

Over harvest in the lower Columbia River and destruction of spawning habitat had significantly reduced Chinook populations in the Wenatchee River Basin by the 1930's (Craig and Suomeia 1941). As part of the Grand Coulee Fish Maintenance Project (GCFMP) during 1939 - 1943, salmon and steelhead were trapped at Rock Island Dam and redistributed into the Wenatchee, Entiat and Methow watersheds (Chapman et al. 1995). As a result, a mixed gene pool of fish originating from the Wenatchee, Entiat, Methow and Columbia River tributaries located upstream of the Grand Coulee Hydroelectric Project was created (Chapman et al. 1995). However, White River spring Chinook are genetically distinct from spring Chinook populations in the Chiwawa River and Nason Creek (Utter et al. 1995; Ford et al. 2001), and a low, but statistically significant level of genetic differentiation between Nason Creek and Chiwawa River populations was observed by Utter et al. (1995). Artificial propagation of spring Chinook in the Wenatchee Basin began in 1941. Leavenworth National Fish Hatchery (LNFH) released juvenile hatchery fish into Icicle Creek that were derived from broodstock collected at Rock Island Dam until 1944. Since 1948, hatchery spring Chinook have been released by the LNFH into Icicle Creek. Broodstock was collected in the Icicle River or transferred from other National Fish Hatcheries located in the lower Columbia River FH (Chapman et al. 1995). Currently, the spring Chinook program at LNFH released 1.6 million yearling smolts into the Icicle River, the purpose of which is harvest augmentation as part of the original mitigation for Grand Coulee Dam.

More recently, a supplementation program was initiated in 1989 on the Chiwawa River as part of the Rock Island Migration Agreement between Chelan County Public Utility District and the fishery management parties (RISPA 1989). The program is designed to mitigate for smolt mortality as a result of the operation of Rock Island Hydroelectric Project and has a production level goal of 672,000 yearling smolts. Currently, the 
program is operated under the Rock Island Habitat Conservation Plan and has established a goal for the program to increase the abundance of the naturally spawning population while maintaining the genetic integrity and long-term fitness of the stock (CCPUD 2002). However, low escapement to the Chiwawa River has limited smolt production and the mean number of hatchery smolts released since 1991 has been 199,309 (1989-2006 brood). Despite not meeting production goals, the number of hatchery fish on the spawning grounds has been greater than the number of naturally produced fish in most years since 2000 (Table 1).

Table 1. Summary of broodstock, spawner composition, and number of smolt released as part of the Chiwawa River spring Chinook hatchery program (WDFW, unpublished data).

\begin{tabular}{|c|c|c|c|c|c|c|c|c|c|}
\hline \multirow[b]{2}{*}{$\begin{array}{c}\text { Brood } \\
\text { Year }\end{array}$} & \multicolumn{2}{|c|}{ Broodstock } & \multicolumn{2}{|c|}{ Number of spawners } & \multirow{2}{*}{$\begin{array}{c}\text { Proportion } \\
\text { natural } \\
\text { influence (PNI) }\end{array}$} & \multicolumn{2}{|c|}{ Naturally produced } & \multicolumn{2}{|c|}{ Hatchery } \\
\hline & $\begin{array}{l}\text { Naturally } \\
\text { produced }\end{array}$ & Hatchery & $\begin{array}{l}\text { Naturally } \\
\text { produced }\end{array}$ & Hatchery & & $\begin{array}{l}\text { Number } \\
\text { of smolts }\end{array}$ & $\begin{array}{l}\text { Smolt-to- } \\
\text { adult }\end{array}$ & $\begin{array}{l}\text { Number } \\
\text { of smolts }\end{array}$ & $\begin{array}{c}\text { Smolt-to- } \\
\text { adult }\end{array}$ \\
\hline 1989 & 28 & 0 & 713 & 0 & 1.00 & & & 43,000 & $0.48 \%$ \\
\hline 1990 & 18 & 0 & 347 & 0 & 1.00 & & & 53,170 & $0.04 \%$ \\
\hline 1991 & 32 & 0 & 242 & 0 & 1.00 & & & 62,138 & $0.06 \%$ \\
\hline 1992 & 78 & 0 & 676 & 0 & 1.00 & 56,763 & $0.08 \%$ & 85,113 & $0.04 \%$ \\
\hline 1993 & 94 & 0 & 218 & 4 & 0.98 & 17,926 & $0.57 \%$ & 223,610 & $0.13 \%$ \\
\hline 1994 & 8 & 4 & 110 & 73 & 0.63 & 22,145 & $0.24 \%$ & 27,226 & $0.08 \%$ \\
\hline 1995 & 0 & 0 & 31 & 2 & & 5,230 & $0.92 \%$ & & \\
\hline 1996 & 8 & 10 & 33 & 25 & 0.51 & 17,922 & $0.91 \%$ & 15,176 & $0.52 \%$ \\
\hline 1997 & 32 & 79 & 54 & 128 & 0.29 & 39,044 & $2.10 \%$ & 266,148 & $0.99 \%$ \\
\hline 1998 & 13 & 34 & 39 & 47 & 0.34 & 24,953 & $1.32 \%$ & 75,906 & $1.54 \%$ \\
\hline 1999 & 0 & 0 & 63 & 31 & & 13,953 & $0.07 \%$ & & \\
\hline 2000 & 9 & 21 & 138 & 174 & 0.35 & 50,634 & $1.16 \%$ & 47,104 & $0.81 \%$ \\
\hline 2001 & 113 & 259 & 626 & 1,790 & 0.29 & 389,940 & $0.07 \%$ & 377,544 & $0.49 \%$ \\
\hline 2002 & 20 & 51 & 263 & 444 & 0.31 & 152,547 & $0.17 \%$ & 149,668 & $0.49 \%$ \\
\hline 2003 & 41 & 53 & 148 & 121 & 0.49 & 27,897 & & 222,131 & \\
\hline 2004 & 83 & 132 & 477 & 381 & 0.47 & 101,172 & & 494,517 & \\
\hline 2005 & 91 & 181 & 102 & 496 & 0.29 & 140,737 & & 494,012 & \\
\hline 2006 & 91 & 224 & 119 & 410 & 0.27 & 86,578 & & 552,482 & \\
\hline 2007 & 43 & 104 & 207 & 1,089 & 0.26 & & & & \\
\hline 2008 & 74 & 230 & 199 & 958 & 0.23 & & & & \\
\hline
\end{tabular}




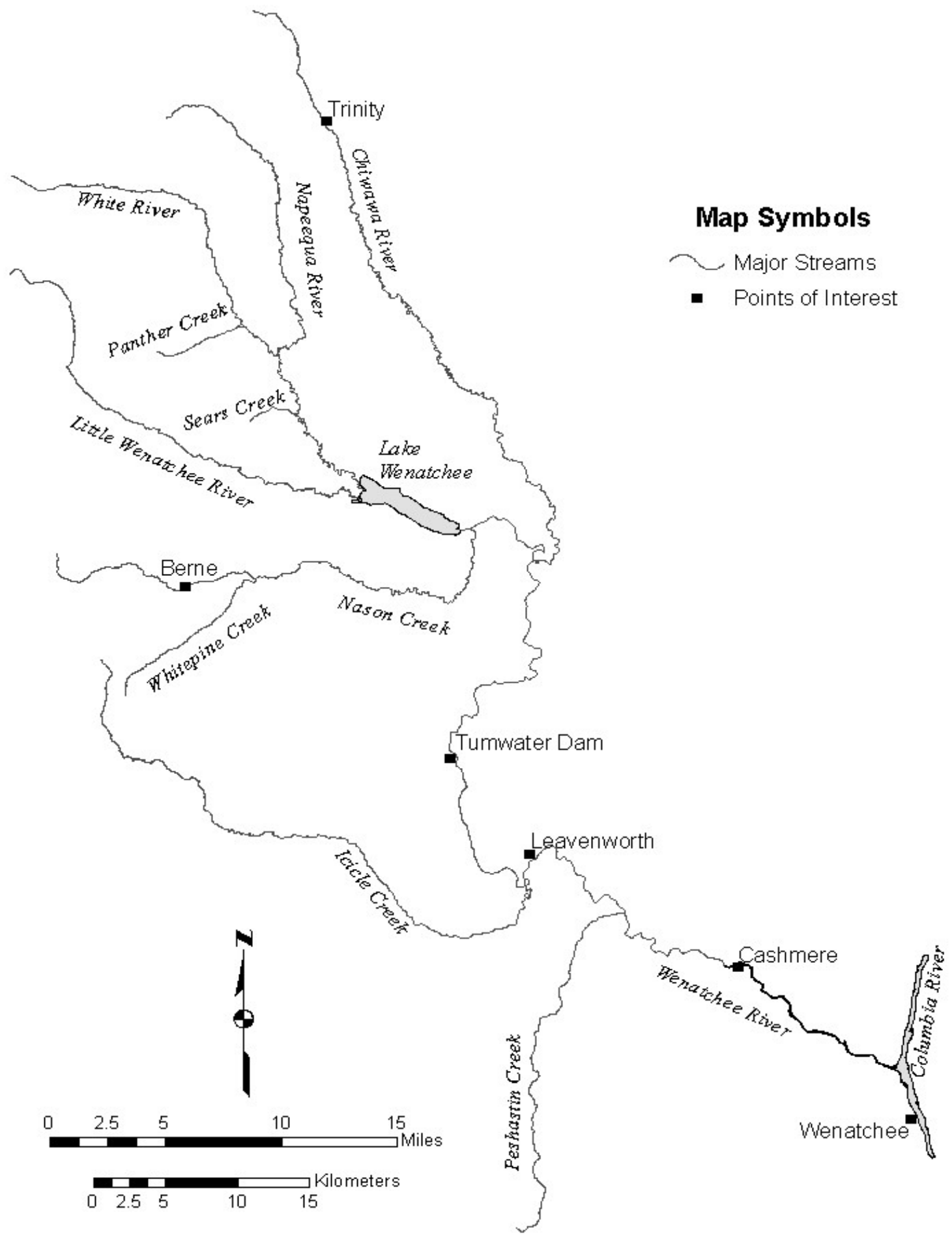

Figure 1. Map of Wenatchee River Basin and spring Chinook spawning tributaries. 


\section{References}

Andonaegui, C. 2001. Salmon, steelhead, and bull trout habitat limiting factors for the Wenatchee Subbasin (Water Resource Inventory Area 45) and portions of WRIA 40 within Chelan County (Squilchuck, Stemilt and Clockum drainages). Washington State Conservation Commission, Olympia, WA. $71-238$ p.

Chapman, D.W., C. Peven, A. Giorgi, T. Hillman, F. Utter. 1995. Status of spring Chinook salmon in the mid-Columbia region. Report to Chelan, Douglas, and Grant County Public Utility Districts, Washington. Don Chapman Consultants, Inc., Boise, Idaho.

CCPUD (Chelan County Public Utility District). 2002. Anadromous fish agreement and habitat conservation plan. Chelan County Public Utility District, Wenatchee, WA.

Craig, J. A. and A. J. Suomeia. 1941. Time of appearance of the runs of salmon and Steelhead trout native to the Wenatchee, Entiat, Methow and Okanogan rivers. United states Fish and Wildlife Service. 35 p. plus 18 affidavits and accompanying letters of corroboration.

Ford, M., and twelve coauthors. 2001. Upper Columbia River Steelhead and Spring Chinook Salmon Population Structure and Biological Requirements, Final Report, March 2001. Northwest Fisheries Science Center, National Marine Fisheries Service. Seattle, Washington.

Mosey, T. R., and L. J. Murphy. 2002. Spring and summer Chinook spawning ground surveys on the Wenatchee River basin, 2002. Chelan County Public Utility District, Wenatchee, Washington.

Mullan, J. W., K. R. Williams, G. Rhodus, T.W. Hillman and J.D. McIntyre. 1992. Production and habitat of salmonids in Mid-Columbia River tributaries. U.S. Fish and Wildlife Service, Monograph 1, Leavenworth, WA. 8 p.

Murdoch, A.R., T.N. Pearsons, T.W. Maitland, C.L. Deason, M.F. Ford, and K. Williamson. 2007. Monitoring the reproductive success of naturally spawning hatchery and natural spring Chinook salmon in the Wenatchee River. BPA Project No. 2003-039-00. Bonneville Power Administration, Portland, Oregon.

RISPA (Rock Island Project Settlement Agreement). 1989. Rock Island Project Settlement Agreement. Federal Energy Regulatory Commission and Chelan County Public Utility District Project No. 943, No. E-9569, Wenatchee, WA.

Utter, F.M., D.W. Chapman, and A.R. Marshall. 1995. Genetic Population Structure and history of Chinook salmon of the Upper Columbia River. American Fisheries Society Symposium 17: 149-68. 


\title{
Chapter 1 - The Aunt and Uncle Effect Revisited: The Effect of Biased Parentage Assignment on Fitness Estimation in a Supplemented Salmon Population
}

\begin{abstract}
We investigated differences in the statistical power to assign parentage between an artificially propagated and wild salmon population. The propagated fish were derived from the wild population, and are used to supplement its abundance. Levels of genetic variation were similar between the propagated and wild groups at 11 microsatellite loci, and exclusion probabilities were $>0.999999$ for both groups. The ability to unambiguously identify a pair of parents for each sampled progeny was much lower than expected, however. Simulations demonstrated that the proportion of cases the most likely pair of parents were the true parents was lower for propagated parents than for wild parents. There was a clear relationship between parentage assignment ability and the degree of linkage disequilibrium, the estimated effective number of breeders that produced the parents, and the size of the largest family within the potential parents. If a stringent threshold for parentage assignment was used, estimates of relative fitness were biased downward for the propagated fish. The bias appeared to be largely eliminated by either fractionally assigning progeny among parents in proportion to their likelihood of parentage, or by assigning progeny to the most likely set of parents without using a statistical threshold.
\end{abstract}

\section{Introduction}

The use of molecular markers to reconstruct pedigrees in natural populations has become a powerful tool in molecular ecology (reviewed by Jones \& Ardren 2003). For example, pedigree analysis of natural populations has been used to study breeding systems, the strength of natural selection, the genetic basis of phenotypic variation, and patterns of migration, among other problems (see reviews by Avise 1994; Garant \& Kruuk 2005).

One important application of pedigree analysis in conservation biology is estimating the reproductive contributions of captively reared organisms after they are released into the wild. Supplementation of wild populations with captively breed individuals is practiced for many species (Conway 1980; Olney et al. 1994), and is a particularly common management strategy for salmonid fishes (Hindar et al. 1991; Naish et al. 2008). Salmon management in much of North America and Europe is characterized by large-scale releases of juvenile fish that have been hatched and reared for up to a year in captivity. Most of these releases are intended to augment fisheries, but over the last 20 years many supplementation programs have also been initiated with the goal of increasing the abundance of wild salmon populations. Even in cases where a artificial propagation program is primarily intended to produce fish for harvest, strays from such programs often make up large fractions of natural salmon populations (reviewed by Naish et al. 2008).

A key biological uncertainty about the effects of hatchery production on natural salmon populations is the degree to which hatchery produced fish can reproduce in the natural 
environment (Reisenbichler \& McIntyre 1977; Ford 2002; Araki et al. 2008). Evaluating the relative reproductive success of hatchery produced salmon is therefore important for determining if the considerable investment society has made in hatchery supplementation programs is actually contributing to the recovery of salmon populations (Mobrand et al. 2005). By directly quantifying the reproductive success of stray hatchery fish in the natural environment relative to that of fish from the natural population they stray in to, the viability of natural populations receiving stray hatchery fish can also be more accurately evaluated (McClure et al. 2003). Similar problems exist for monitoring the effects of supplementation in other species (e.g., Jabbour et al. 1997).

A prerequisite for the successful use of parentage analysis to estimate relative fitness is the ability to construct a sufficiently accurate pedigree. Pedigree reconstruction using genetic markers has been subject of considerable study, and there are three types of commonly used methods of pedigree reconstruction: exclusion, identification of most the most likely set of parents, and fractional assignment of progeny among potential parents (reviewed by Jones \& Ardren 2003). The first two types of methods involve attempting to assign a specific pair of parents to each progeny of interest, either by using lack of allele sharing to exclude all but one possible pair of parents, or by using a statistical test to identify a pair of parents that is most likely to be the true parents. Fractional assignment, in contrast, does not attempt to identify a single pair of true parents, but instead divides each progeny among multiple parents (or pairs of parents) in proportion to their likelihoods.

Despite wide application, using pedigrees to estimate the fitness of individuals or the mean fitness of groups remains an evolving science, particularly in cases where the pedigree cannot be unambiguously described. In such cases, it is common to develop criteria such that a progeny is only assigned to a parent or pair of parents if some statistical threshold, such as the difference in log likelihood between the most likely and next most likely set of parents (e.g., Marshall et al. 1998) or a certain minimum number of loci at which alleles are shared (e.g. Araki et al. 2007b), is met. One consequence of such criteria is that there will typically be some progeny in a study that are not assigned to a set of parents.

Araki and Blouin (2005) discovered that the use of such assignment thresholds, and therefore the failure to assign some progeny to parents even when these parents are in fact present in the sample, can introduce bias into estimates of fitness by underestimating the true variance in fitness among individual parents or groups of parents. In particular, Araki and Blouin (2005) discovered that failure to assign progeny to parents that are in fact in the sample due to failure to meet a threshold for assignment (type A errors) can in some cases introduce greater bias into fitness estimates than incorrectly assigning progeny to parents due to a low stringency threshold for assignment (type B errors).

In principle, one should always be able to unambiguously describe a pedigree if all potential parents of the progeny in question are included in the analysis so long as data from a sufficient number of genetic markers are available. In practice, however, the number of genetic markers that can be scored is usually limited by logistical or financial 
constraints. In addition, there are often many reasons why pedigree reconstruction in natural populations often is less successful for a given number of genetic markers than expected from theoretical predictions. Scoring errors and failure to obtain genotypes from all potential parents are two common reasons for lower than expected parentage assignment (Jones \& Ardren 2003; Garant \& Kruuk 2005). In addition, natural mating systems often differ from idealized assumptions, which can affect parentage assignment. For example, Olsen et al. (2001) describe a pattern in which the true assignment rate of progeny to a set of known parents was much lower than predicted based on theoretical expectations. The lower than expected assignment rate was due to a high degree of familial relatedness among the true parents, a phenomenon they dubbed the 'aunt and uncle effect'.

In this paper, we describe an empirical study in which parental relatedness resulted in a biased estimate of the fitness of naturally spawning hatchery salmon. Unlike the phenomenon described by Araki and Blouin (2005), which tended to underestimate the degree of fitness differences among groups, the bias we found tended to exaggerate these differences. In addition to describing this phenomenon and exploring its causes, we also illustrate that fractional assignment is an effective way of producing unbiased estimates of relative fitness between groups that have different rates of parentage assignment.

\section{Material and Methods}

Study population - Our parental study population consisted of several thousand springrun Chinook salmon (Oncorhynchus tshawytscha) that were sampled during two separate spawning runs in 2004 and 2005. Migrating fish were captured at a fish trap at Tumwater Dam in the Wenatchee River, Washington as they returned to spawn in tributaries upstream of the dam. The fish trap is the only route upstream of the dam and $>99 \%$ of all adult spring-run Chinook salmon that passed the dam were sampled. There was also the potential for some unsampled parents in the form of earlier maturing parr that never migrated below the dam. A small portion of the caudal fin was clipped from each fish for DNA analysis. The origin (hatchery or wild) of each fish was determined by the presence (wild) or absence (hatchery) of an adipose fin clip. Several thousand progeny produced by these spawners were sampled in 2006 and 2007 as migrating smolts. More details about the study design and its overall goals can be found in a companion paper (Williamson et al., submitted).

Microsatellite genotyping -- Adult and juvenile fin-clip samples were collected, and genomic DNA was extracted from those samples according to the method of Lahood et al. (2008). All individuals were genotyped at 11 microsatellite loci: Ots3 (Banks et al. 1999), Ots104 (Nelson \& Beacham 1999), Ots201b, 211 and 213 (Greig et al. 2003), Ots2M and10M (Greig \& Banks 1999)), Ots519NWFSC (Naish and Park 2002), Oke4 (Olsen et al. 1998), Ogo4 (Olsen et al. 1998), and Ssa408 (Cairney et al. 2000). Microsatellite loci were amplified by Polymerase Chain Reaction (PCR), allele sizes were electrophoreticly resolved and scored according to the method of Winans et al. (2004). For each fluorescent phosphoamidite labeled primer set the annealing 
temperature used was $48{ }^{\circ} \mathrm{C}$ (Ots3 and 104), $54{ }^{\circ} \mathrm{C}$ (Oke4, Ots10M, 213, and 519NWFSC), and $60{ }^{\circ} \mathrm{C}$ (Ogo4, Ots2M, 201b, and 211, Ssa408).

Parentage assignment and simulations -- Assignment of progeny to parent pairs was conducted using the likelihood methods of Meagher and Thompson (1986) and Gerber et al. (2000) as implemented in the program FAMOZ (Gerber et al. 2003). Each individual in a sample of real or simulated (see below) progeny was tested against all potential pairs of parents and a log of odds (LOD) score was calculated for each potential parent pair/offspring combination as the log of the ratio of the probability of a parent pair/offspring relationship compared to the probability they were drawn randomly from the population. Progeny were either fractionally assigned to the 20 most likely parent pairs in proportion to their conditional probability of parentage (fractional assignment Devlin et al. 1988; Smouse \& Meagher 1994), were assigned to the parent pair with the highest likelihood (most likely assignment) or were assigned to the parent pair with the highest likelihood only if this log likelihood was $>2+$ the next highest log likelihood (threshold assignment).

In addition to analyzing the sampled progeny, we conducted three different types of simulations. First, we used the simulation function of the FAMOZ program to estimate the fraction of progeny for which the highest likelihood parent pair was the true parent pair. In this type of simulation, progeny were generated by random pairings drawn from the observed parental multi-locus genotypes and then the 'true' parents were compared to the parents with the highest likelihood for each progeny. These simulations were used to evaluate the effects of hatchery ancestry and parental effective population size on the power to correctly assign parentage. Second, in order to compare the assignment rates using the observed parental genotypes with those that would be expected if the parental genotypes has been drawn independently from an infinitely large population, we also conducted simulations in which parental genotypes were simulated in multi-locus HardyWeinburg equilibrium proportions using random draws from the observed alleles frequencies, and then progeny were created from these simulated parents as described above.

Third, we used the observed parental genotypes in a way similar to the first set of simulations to evaluate the effects of assignment errors on the estimates of the relative fitness of hatchery fish. In these simulations, we used a Mathematica (Wolfram Research) computer program to randomly assign fitness values to the observed parents, and then used these fitness values to generate simulated offspring as described above. These data (real parents with simulated offspring) were then used to conduct a parentage analysis and to compare the relative fitness estimates produced by the most likely, threshold, and fractional assignment methods. Observed distributions of relative fitness in salmon often appear approximately exponentially distributed (Seamons et al. 2004; Ford et al. 2006; Araki et al. 2007a), so fitness in the simulations was based on an exponential distribution. Specifically, each parent was assigned an initial fitness value drawn randomly from an exponential distribution with a mean of 1 . Within sexes, raw fitness was then converted to relative fitness by dividing each individual's fitness by the mean population fitness. The vectors of relative fitness for all individuals of each sex 
were then used as the parameters of two multinomial draws (one for each sex) that were used to assign each simulated progeny a mother and father. Genotyping errors were introduced at a rate of $1.5 \%$ per locus (a rate we have typically observed in our laboratory). For each individual at each locus, a uniform random number between 0 and 1 was drawn, and if the value was $<0.015$, the genotype at the locus was replaced with a random genotype drawn from the observed alleles at that locus.

Effective size and relative fitness calculation - The effective sizes of the spawning populations (hatchery and wild) that produced the spawning adults in 2004 and 2005 were estimated using the linkage disequibrium method (Hill 1981) utilizing the bias correction of Waples (2006) as implemented in the program LDNE (Waples \& Do 2008). The LNDE program estimates a sample size corrected estimate of composite linkage disequilibrium $\left(\hat{r}^{2}\right)$ which is used to estimate effective population size as described in Waples (2006). We also used the family partitioning method of Smith et al. (Smith et al. 2001) as implemented in the program PEDIGREE 2.2

(http://herbinger.biology.dal.ca:5080/Pedigree/) to estimate the number of family groups within the 2004 and 2005 spawners, broken down by origin and age. The Smith et al. (2001) method of partitioning samples into family groups uses a Markov Chain Monte Carlo search process to identify the most likely configuration of family groups (either full sib only or combinations of full and half-sibs) within a sample. Finally, the mean fitness of groups of fish was estimated as the average number of progeny assigned to individuals within that group, and the significance of group differences was evaluated using $t$-tests.

\section{Results and Discussion}

Assignment success -- Across the 11 loci, both hatchery and wild fish were characterized by high and approximately equivalent levels of variation (Table 1). The overall level of genetic differentiation among the four origin $\mathrm{x}$ year combinations was low $\left(\mathrm{F}_{\mathrm{ST}}=\right.$ 0.0039), but exact tests of differentiation among all pairs of populations defined by origin and sample year were highly significant $(\mathrm{p}<0.00001$ for all comparisons). Expected two parent exclusion probabilities were very high $->0.999999$ for both hatchery and wild origin parents, reflecting the high levels of variation and the large number of alleles in the samples. Consistent with these high exclusion probabilities, the assignment success for simulated, randomly mating, unrelated individuals was also close to 1 (Table 2). In contrast, the overall assignment success in which simulated progeny were generated from the observed parental genotypes was only $80-84 \%$ (Table 2 ). If a LOD threshold of 2 was employed to reduce the rate of incorrect assignment to $\sim 1 \%$, the total proportion of simulated progeny that could be assigned to parents dropped to only $\sim 60 \%$ (Table 2 ). The proportion of actual progeny that met this threshold was even lower (Table 2), perhaps due to non-migratory parents.

In order to explore the causes of the lower than expected rate of successful assignments of progeny to parents, we conducted simulations separately on each hatchery and wild fish and on each age class (Table 3). The origin-age classes had different sample sizes, so we conducted the simulations by first randomly drawing either 91 or 200 parents from each origin-age class. The value of 91 was chosen because this was the size of the 
Table 1. Levels and patterns of variation.

\begin{tabular}{ccccccc}
\hline Year & Origin & Sample size & No. Loci & $\mathrm{H}_{\mathrm{e}}{ }^{1}$ & $\mathrm{H}_{\mathrm{o}}{ }^{2}$ & No. alleles $^{3}$ \\
\hline 2004 & Hatchery & 1,772 & 11 & 0.77 & 0.77 & 19.7 \\
& Natural & 812 & 11 & 0.77 & 0.75 & 20.3 \\
2005 & Hatchery & 3,294 & 11 & 0.77 & 0.77 & 20.6 \\
& Natural & 473 & 11 & 0.77 & 0.76 & 18.4
\end{tabular}

${ }^{1}$ Expected heterozygosity calculated from allele frequencies assuming random mating, averaged over loci (Nei 1987).

${ }^{2}$ Observed proportion of heterozygotes, averaged over loci.

${ }^{3}$ Average number of allele per locus.

smallest origin-age class (2005 wild fish), and the value of 200 was chosen because we wanted to evaluated a larger sample size and this allowed comparisons among 7 of the 9 origin-age classes.

In evaluating assignment success (proportion of time the highest likelihood parent pair was the true parent pair) of the different origin-age groups, there was a clear difference between the hatchery and wild groups, particularly in the simulations with 200 potential parents (Table 3). When only wild fish were used in the simulations, assignment success was always at least $99 \%$. In contrast, when only hatchery fish were used in the simulations, assignment success ranged from $80-98 \%$ when 200 parents were used and $85-98 \%$ when 91 parents were used. This difference was not due to lower levels of variation (Table 1) or exclusion probabilities for hatchery fish, as these were similar for both groups, suggesting that the difference was due to greater correlation of variation among loci (linkage disequilibrium) in hatchery fish compared to wild fish.

One potential contributor to higher levels of linkage disequilibrium in hatchery produced fish could be lower effective population size in the hatchery than in the wild. Although hatchery fish made up a majority of the potential spawners in both 2004 and 2005, they were produced by a relatively small number of fish that had been spawned in the hatchery in 2000 - 2002 (Table 3). We will refer the fish that spawned in 2000-2002 as 'grandparents', the adults sampled in 2004 and 2005 as 'parents', and the smolts sampled in 2006 and 2007 as 'progeny'. The total number of grandparents ranged from 30 fish spawned in the hatchery in year 2000 to 4130 spawning fish in the wild in 2001 (Table 3). In total, the hatchery fish that returned in 2004 and 2005 were produced by 1012 spawners, and the wild fish that returned in the same years were produced by 5506 spawners, suggesting the hatchery parents may have consisted of a smaller number of family groups than the wild parents.

We conducted two additional analyses to test the hypothesis that the hatchery parents were more related to each other than were the wild fish, and therefore had lower assignment success rates. First, we used levels of linkage disequilbrium to estimate the 
Table 2. Summary of assignment success from different types of simulations and analyses

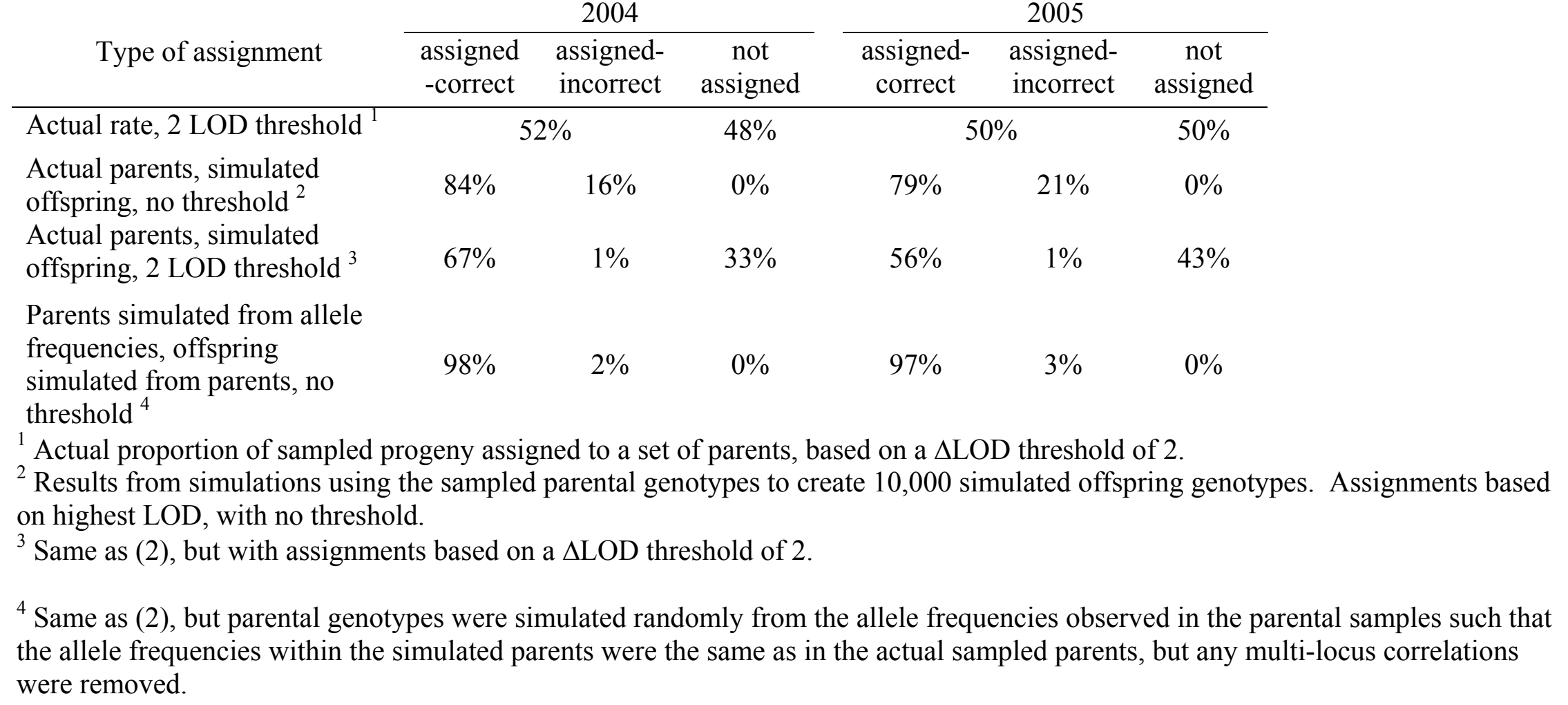


Table 3 - Simulated assignment success by cohort, effective population size of grandparents, and number of parental kin groups

\begin{tabular}{|c|c|c|c|c|c|c|c|c|c|c|c|c|}
\hline & & & assignmer & ccess ${ }^{4}$ & $\mathrm{Gr}$ & dpare & & grandparent $\hat{N}_{b}{ }^{6}$ & & & oups ${ }^{7}$ & \\
\hline Origin $^{1}$ & year-age $^{2}$ & $\mathrm{~N}^{3}$ & 91 parents & $\begin{array}{c}200 \\
\text { parents }\end{array}$ & female & male & total & $\hat{N}_{b}-\mathrm{LD}(95 \% \mathrm{CI})$ & $\begin{array}{l}\text { Half } \\
\text { or } \\
\text { Full }\end{array}$ & Full & $\begin{array}{l}\text { Average } \\
\text { size }\end{array}$ & $\begin{array}{l}\text { Max } \\
\text { size }\end{array}$ \\
\hline $\mathrm{H}$ & $2004-2$ & 594 & 0.88 & 0.82 & 43 & 27 & 70 & $14.5(12.4-16.7)$ & 33 & 83 & 0.03 & 0.14 \\
\hline $\mathrm{H}$ & 2004-3 & 707 & 0.97 & 0.94 & 241 & 133 & 374 & $50.8(45.3-56.8)$ & 87 & 153 & 0.01 & 0.07 \\
\hline $\mathrm{H}$ & 2004-4 & 328 & 0.87 & 0.80 & 11 & 19 & 30 & $16.4(13.8-19.3)$ & 55 & 84 & 0.02 & 0.15 \\
\hline W & $2004-4$ & 733 & 0.99 & 0.99 & 302 & 386 & 688 & $181.8(148.1-224.4)$ & 206 & 238 & 0.00 & 0.02 \\
\hline $\mathrm{H}$ & $2005-2$ & 279 & 0.87 & 0.77 & 46 & 48 & 94 & $10(7.7-12.4)$ & 33 & 49 & 0.03 & 0.21 \\
\hline $\mathrm{H}$ & 2005-3 & 134 & 0.85 & -- & 43 & 27 & 70 & $12.7(10.4-15.2)$ & 30 & 35 & 0.03 & 0.26 \\
\hline $\mathrm{H}$ & $2005-4$ & 988 & 0.98 & 0.98 & 241 & 133 & 374 & No estimate ${ }^{8}$ & 126 & 258 & 0.01 & 0.04 \\
\hline W & $2005-4$ & 449 & 0.99 & 0.99 & 2888 & 1242 & 4130 & $598.8(418.8-965.9)$ & 167 & 239 & 0.01 & 0.02 \\
\hline $\mathrm{W}$ & $2005-5$ & 91 & 0.99 & -- & 282 & 406 & 688 & $82.5(57.5-130.3)$ & 50 & 54 & 0.02 & 0.05 \\
\hline
\end{tabular}

${ }^{1} \mathrm{H}=$ hatchery, $\mathrm{W}=$ wild

${ }^{2}$ Sample year and age of the subgroup of parents analyzed. For example, 2004-2 indicates 2-year-old spawners sampled in 2002.

${ }^{3}$ Sample size of the subgroup of parents analyzed.

${ }^{4}$ Proportion of simulated assignments in which the most likely parent pair was the true parent pair. Simulations were performed using a random subset of either 91 or 200 from each age-origin group. Each simulation used sampled parental genotypes to create 10000 simulated progeny. The proportion assigned is the average across 5 simulations.

${ }^{5}$ Census size of the grandparental generations that produced each of the year-age cohorts. For example, the 2-year-old hatchery fish that returned to the Wenatchee River in 2004 were produced by breeding 43 females with 27 males.

${ }^{6}$ Estimate of the effective number of breeders in the grandparental generation, using the linkage disequilibrium method of Waples and Do (2008).

${ }^{7}$ Estimated number of kin groups within each year-age cohort, either combined full and half sib families or just full sib families, using the method of Smith et al. (2001). Average size refers to the average size of the kin groups divided by the population (year-age cohort) size. Max size is the size of the largest kin group divided by the population size.

${ }^{8}$ Sample variance explains the total amount of linkage disequilibrium. 
effective number of grandparents that produced each origin-age class the returned in 2004 and 2005 (Table 3). For hatchery fish, estimates of the effective number of grandparents ranged from 10 for the two-year old spawners in 2005 to 51 for the three-year old spawners in 2004, and were generally very low ( 4 of the 6 estimates were $<20$ ). For wild fish, the estimates were considerably larger, and ranged from $\sim 80$ to $\sim 600$. For both wild and hatchery fish, there were in some cases two separate effective size estimates of the same grandparental group (e.g., two year-olds in 2004 and three year-olds in 2005). We report both estimates, however, because there is an additional year of mortality that occurs between sampling years that could lead to differences in estimated effective size.

There is a non-linear relationship between the estimates of grandparental effective size and assignment success (Figure 1) and a linear relationship between the level of linkage disequilbrium and assignment success (Figure 2), indicating that the effective size of the grandparental generation clearly influences the assignment success of progeny to parents. The non-linear nature of the relationship between effective size and assignment success reflects the non-linear relationship between effective size and linkage-disequilbria (Hill 1981).

Second, in addition to estimated effective population size, we used the PEDIGREE program to estimate the number of full-sib families and number of kin groups (full and half-sib families) within each of the origin-age classes (Table 3). Consistent with the estimates of effective size and the observed number of grandparents, the hatchery origin fish tended to have fewer (and hence larger) family groups than did the wild fish. In addition to having larger average family sizes, the hatchery fish tended to have a few very large families. In particular, for hatchery fish the largest single kin group ranged from 7$26 \%$ of the population depending on the cohort sampled (Table 3 ). In contrast, the largest single family group for wild fish ranged from $2-5 \%$ of the population depending on the cohort sampled. There was a clear linear relationship between the proportion of the cohort contributed by the largest kin group and assignment success (Figure 3), suggesting the presence of close relatives among the parental population of hatchery fish leads to lower than expected assignment success. In other words, the aunt and uncle effect described by Olsen et al. (2001) is clearly apparent in the Wenatchee spring Chinook salmon population, and is more pronounced among hatchery fish than wild fish.

Fitness estimation -- A difference in assignment success between origin or age classes clearly has the potential to result in biased estimates of the differences in fitness among these groups. We evaluated the degree of this potential bias by using the observed adults sampled in 2004 and 2005 to simulate progeny and then to calculate the average number of progeny assigned to parents of hatchery versus wild origin. As expected, when a relatively stringent assignment threshold was used, we found highly significant differences between hatchery and wild fish (Table 4) when in fact such differences did not exist. In contrast, estimates made using either fractional assignment or the most likely method produced fitness estimates very close to the 'true' values, with no significant difference in fitness between hatchery and wild fish (Table 4). All three assignment methods produced a fitness distribution that was roughly similar to the true distribution, but the distribution produced by the threshold method was skewed toward a 
greater number of parents with no assigned progeny than either the true distribution or the distributions estimated using no threshold or fraction assignment (Figure 4). Simulations using a uniform fitness distribution instead of an exponential distribution produced essentially the same results (data not shown).

In the case where hatchery and wild fish are sampled from the same genetic background, Araki and Blouin (2005) developed a method for producing an unbiased estimate of relative fitness that corrects for errors in assignment. This correction resulted in only very minor (third decimal place) changes to the categorical fitness estimates in Table 4 (results not shown), mostly because type B assignment errors (assigning an incorrect pair of parents to a progeny) were relatively low in our simulations ( $\sim 1 \%$ for the $\Delta$ LOD threshold $>2$ assignments and $\sim 16 \%$ for the most likely assignments).

The difference in estimated relative fitness between the assignments based most likely and 2 LOD threshold methods illustrates the same issue that Araki and Blouin discovered, however. In particular, the threshold method reduces the type B error rate by increasing the statistical stringency for making an assignment. Lowering the type B error rate, however, has the direct result of increasing the type A error rate, which is the proportion of progeny who are not assigned a pair of parents even though the parents are in fact present in the sample. Araki and Blouin found when there is no genetic differentiation between the pair of groups who fitness are being compared, increasing the type A error rate produces estimates of relative fitness that are more biased toward 1 than an equivalent increase in the type B error rate. In this study, because the type A errors disproportionately affected hatchery produced fish, the resulting estimates of relative fitness were biased away from 1, even though the underlying cause of the bias was the same as described by Araki and Blouin. Araki and Blouin (2005) discuss how their method could be modified to allow for genetic differentiation between groups whose fitness is being compared, which would involve estimating separate assignment error rates for the two groups. Such an approach would be a potential alternative to fractional assignment for dealing with differences in assignment ability between groups. In addition, in some cases it may be advisable to simply score additional loci in order to increase the power to determine parentage even in the presence of levels of relatedness (Anderson \& Garza 2006).

In summary, in the population we studied, we found that there were clear differences in our ability to assign parentage to hatchery fish compared to wild fish. If a stringent threshold for accepting a parentage assignment was employed, these differences in assignment success created biased estimates of relative fitness. The bias was effectively eliminated by fractionally assigning progeny to parents, or by simply basing the assignments on the most likely pair of parents without using a statistical threshold for assignment. It is not uncommon for captive breeding programs, particularly those used to conserve threatened populations, to utilize relatively small numbers of breeders, so the phenomenon we observed is not likely to be specific to the particular population we studied. We suggest, therefore, that evaluation of differences in parentage assignment rates between groups of interest be routinely conducted when parentage analysis is used as a method of estimating relative fitness. 


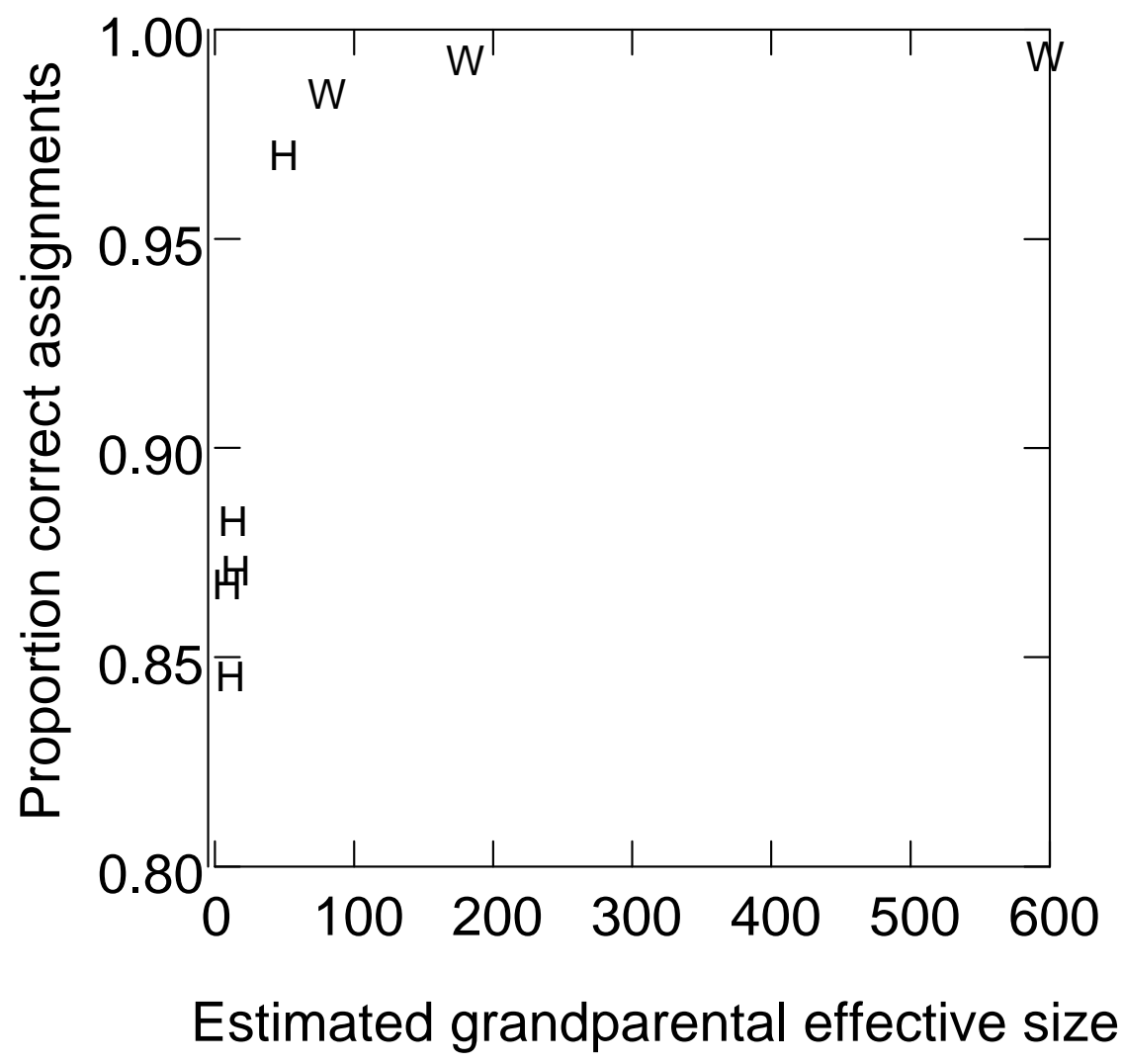

Figure 1. Relationship between number of effective grandparents and assignment success of progeny to parents, based on the 91-parent simulations described in Table 3. 


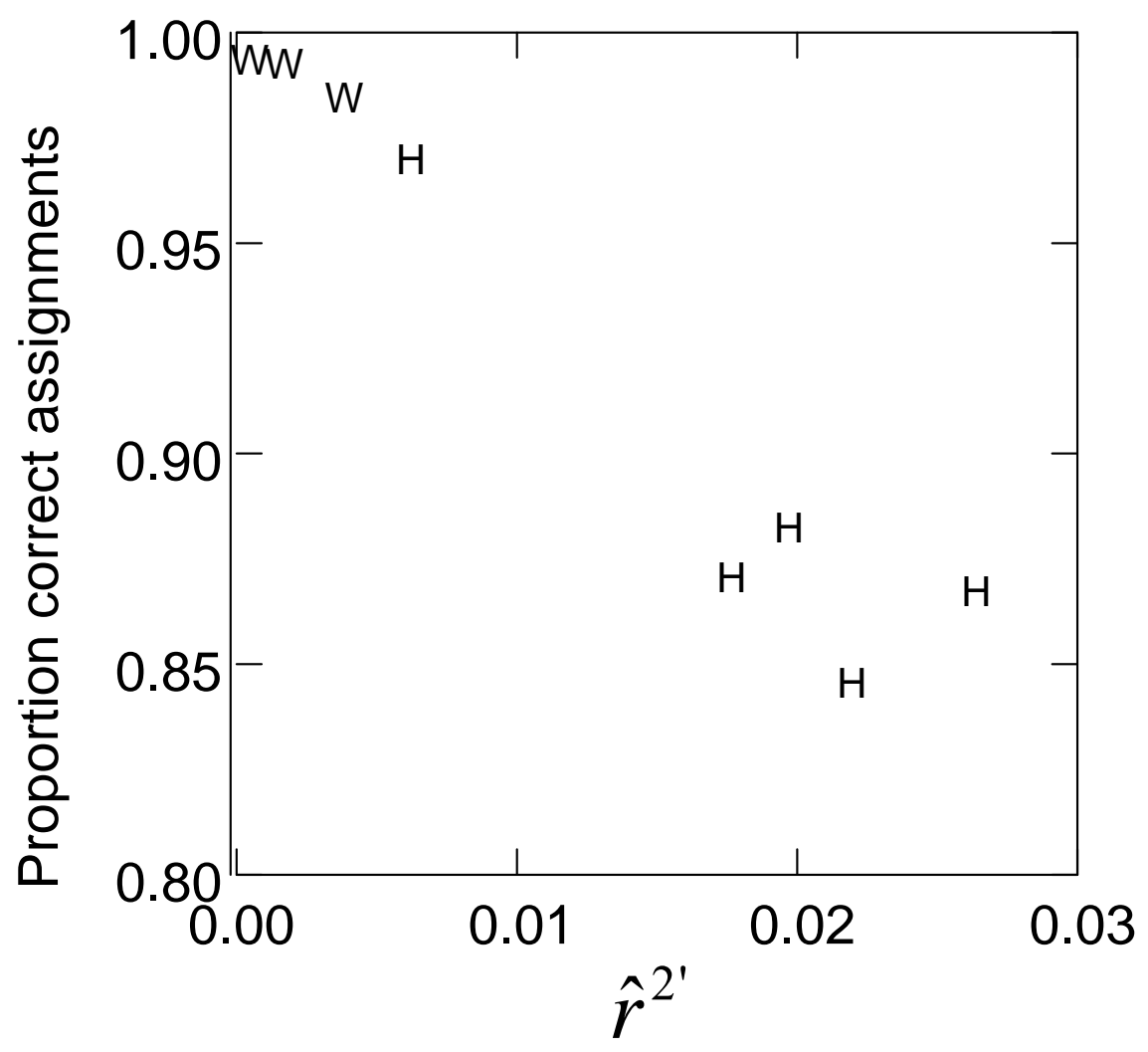

Figure 2. Relationship between corrected (for sample size) estimate of linkage disequilibrium $\left(\hat{r}^{2}\right)$ and assignment success of progeny to parents, based on the 91parent simulations described in Table 3 . The two quantities are negatively correlated $(r=$ $-0.968, p>0.0001)$. 


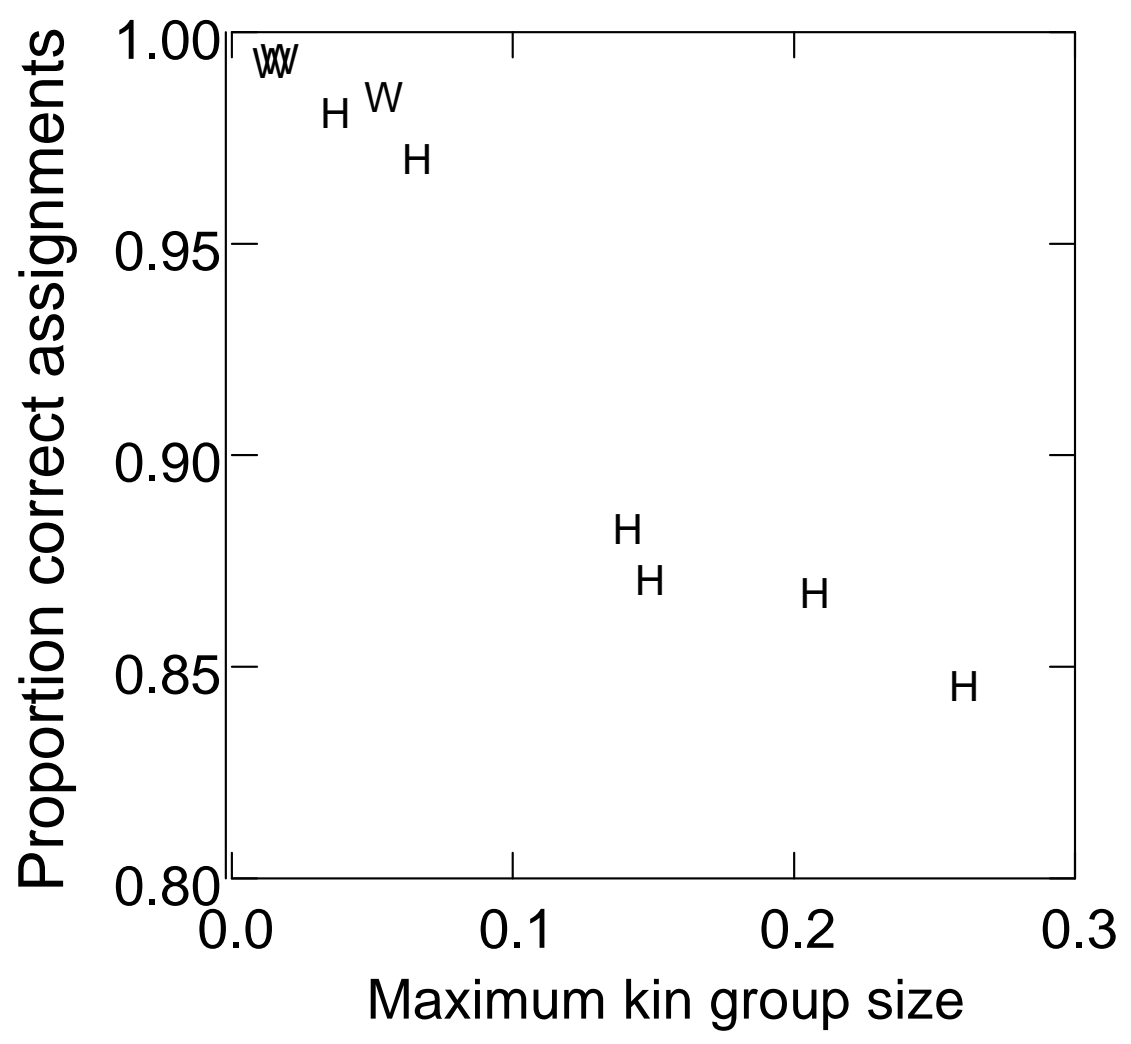

Figure 3. Relationship between the proportion of the cohort contributed by the largest single family group as estimated with the PEDIGREE program and assignment success of progeny to parents, based on the 91-parent simulations described in Table 3. The two quantities are negatively correlated $(r=-0.96, p<0.0001)$. 


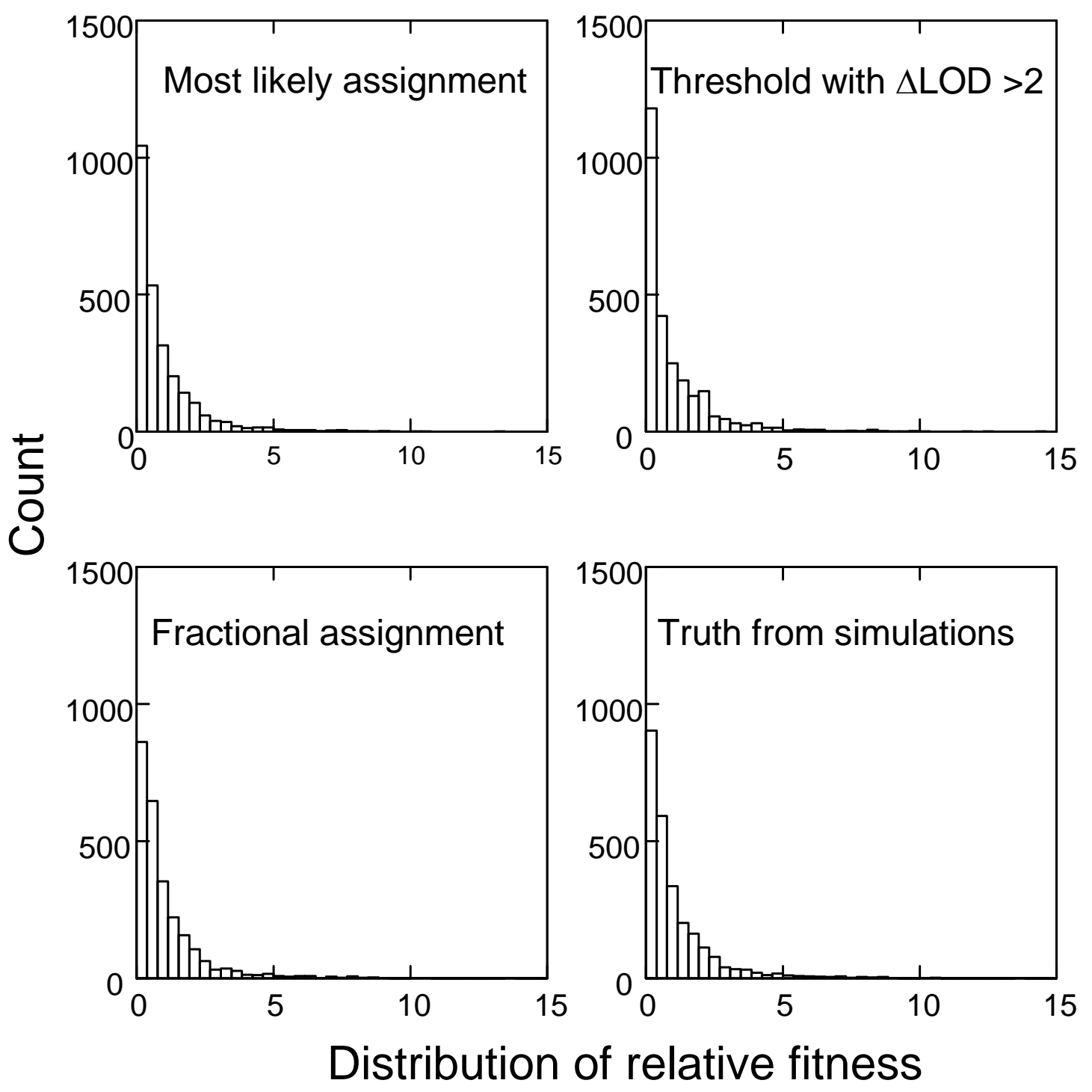

Figure 4. Comparisons of the 'true' (simulated) fitness distribution with those estimated using most likely assignment, most likely assignment with a threshold of $\Delta \mathrm{LOD}>2$, and fractional assignment. 
Table 4 - Comparison of simulated fitness estimates using alternative parentage assignment methods. Simulations involved creating simulated offspring from the sampled parental genotypes.

\begin{tabular}{|c|c|c|c|c|c|c|c|c|c|c|c|c|c|c|c|}
\hline \multirow[b]{2}{*}{ Sex } & \multirow[b]{2}{*}{ Age } & \multicolumn{5}{|c|}{ Wild means (SD) ${ }^{1}$} & \multicolumn{4}{|c|}{$\mathrm{H} / \mathrm{W}(\mathrm{p} \text {-value })^{2}$} & \multicolumn{5}{|c|}{ Hatchery means (SD) ${ }^{1}$} \\
\hline & & $\mathrm{N}$ & True & $\mathrm{T}_{0}$ & $\mathrm{~T}_{2}$ & Frac. & True & $\mathrm{T}_{0}$ & $\mathrm{~T}_{2}$ & Frac. & $\mathrm{N}$ & True & $\mathrm{T}_{0}$ & $\mathrm{~T}_{2}$ & Frac. \\
\hline $\mathrm{F}$ & All & 369 & $\begin{array}{c}16.13 \\
(15.19)\end{array}$ & $\begin{array}{c}16.20 \\
(15.25)\end{array}$ & $\begin{array}{c}12.70 \\
(12.23)\end{array}$ & $\begin{array}{c}15.84 \\
(14.81)\end{array}$ & $\begin{array}{c}0.89 \\
(0.16)\end{array}$ & $\begin{array}{c}0.89 \\
(0.16)\end{array}$ & $\begin{array}{l}0.74 \\
0.00\end{array}$ & $\begin{array}{c}0.88 \\
(0.96)\end{array}$ & 268 & $\begin{array}{c}14.37 \\
(15.86)\end{array}$ & $\begin{array}{c}14.46 \\
(15.26)\end{array}$ & $\begin{array}{c}9.36 \\
(11.71)\end{array}$ & $\begin{array}{c}13.88 \\
(14.50)\end{array}$ \\
\hline $\mathrm{M}$ & All & 435 & $\begin{array}{c}5.30 \\
(5.65)\end{array}$ & $\begin{array}{c}5.47 \\
(5.61)\end{array}$ & $\begin{array}{c}4.55 \\
(5.02)\end{array}$ & $\begin{array}{c}5.44 \\
(5.52)\end{array}$ & $\begin{array}{c}0.96 \\
(0.54)\end{array}$ & $\begin{array}{c}0.99 \\
(0.81)\end{array}$ & $\begin{array}{l}0.79 \\
0.00\end{array}$ & $\begin{array}{c}0.96 \\
(0.46)\end{array}$ & 149 & $\begin{array}{c}5.11 \\
(5.52)\end{array}$ & $\begin{array}{c}5.40 \\
(5.39)\end{array}$ & $\begin{array}{c}3.60 \\
(4.27)\end{array}$ & $\begin{array}{c}5.23 \\
(4.89)\end{array}$ \\
\hline & 2.00 & 0 & $\begin{array}{l}-- \\
--\end{array}$ & $\begin{array}{l}-- \\
--\end{array}$ & $\begin{array}{l}-- \\
--\end{array}$ & $\begin{array}{l}-- \\
--\end{array}$ & $\begin{array}{l}-- \\
--\end{array}$ & $\begin{array}{l}-- \\
--\end{array}$ & $\begin{array}{l}-- \\
--\end{array}$ & $\begin{array}{l}-- \\
--\end{array}$ & 626 & $\begin{array}{c}5.28 \\
(5.99)\end{array}$ & $\begin{array}{c}5.50 \\
(5.82)\end{array}$ & $\begin{array}{c}3.49 \\
(4.45)\end{array}$ & $\begin{array}{c}5.31 \\
(5.17)\end{array}$ \\
\hline & 3.00 & 28 & $\begin{array}{c}3.82 \\
(5.38)\end{array}$ & $\begin{array}{c}3.82 \\
(5.33)\end{array}$ & $\begin{array}{c}3.54 \\
(5.00)\end{array}$ & $\begin{array}{c}3.89 \\
(5.36)\end{array}$ & $\begin{array}{c}1.33 \\
(0.24)\end{array}$ & $\begin{array}{c}1.37 \\
(0.18)\end{array}$ & $\begin{array}{c}1.05 \\
(0.85)\end{array}$ & $\begin{array}{c}1.31 \\
(0.24)\end{array}$ & 740 & $\begin{array}{c}5.07 \\
(5.29)\end{array}$ & $\begin{array}{c}5.24 \\
(5.07)\end{array}$ & $\begin{array}{c}3.72 \\
(4.23)\end{array}$ & $\begin{array}{c}5.12 \\
(4.78)\end{array}$ \\
\hline & 4.00 & 403 & $\begin{array}{c}5.36 \\
(5.59)\end{array}$ & $\begin{array}{c}5.54 \\
(5.62)\end{array}$ & $\begin{array}{c}4.58 \\
(4.94)\end{array}$ & $\begin{array}{c}5.51 \\
(5.46)\end{array}$ & $\begin{array}{c}0.86 \\
(0.15)\end{array}$ & $\begin{array}{c}1.12 \\
(0.27)\end{array}$ & $\begin{array}{c}0.75 \\
(0.01)\end{array}$ & $\begin{array}{c}1.04 \\
(0.64)\end{array}$ & 96 & $\begin{array}{c}4.59 \\
(4.36)\end{array}$ & $\begin{array}{c}6.20 \\
(5.13)\end{array}$ & $\begin{array}{c}3.42 \\
(3.58)\end{array}$ & $\begin{array}{c}5.74 \\
(4.07)\end{array}$ \\
\hline
\end{tabular}

${ }^{1}$ Means and standard deviations for offspring per parent for wild or hatchery origin parents of different ages, using alternative methods of parentage assignment. True $=$ the actual known values from the simulations. $\mathrm{T}_{0}=$ parentage based on assigning the most likely parent pair as the true parents. $T_{2}=$ parentage based on assigning the most likely parent pair using a $\Delta$ LOD threshold of 2 . Frac $=$ parentage based on fractional assignment of a progeny to the 20 most likely pairs in proportion to their likelihoods.

${ }^{2} \mathrm{H} / \mathrm{W}$ is the mean number of offspring per hatchery parent divided by the mean number of offspring per wild parent, a measure of the relative fitness of hatchery origin parents. P-values are from $t$-tests comparing the wild and hatchery means. 


\section{Literature Cited}

Anderson EC, Garza JC (2006) The power of single-nucleotide polymorphisms for largescale parentage inference. Genetics 172, 2567-2582.

Araki H, Ardren W, Olsen E, Cooper B, Blouin M (2007a) Reproductive success of captive-bred steelhead trout in the wild: evaluation of three hatchery programs in the Hood River. Conservation Biology 21, 181-190.

Araki H, Berejikian BA, Ford MJ, Blouin MS (2008) Fitness of hatchery-reared salmonids in the wild. Evolutionary Applications 1, 342-355.

Araki H, Blouin MS (2005) Unbiased estimation of relative reproductive success of different groups: evaluation and correction of bias caused by parentage assignment errors. Molecular Ecology 14, 4097-4109.

Araki H, Cooper B, Blouin MS (2007b) Genetic effects of captive breeding cause a rapid, cumulative fitness decline in the wild. Science 318, 100-103.

Avise JC (1994) Molecular markers, natural history and evolution Chapman \& Hall, New York.

Cairney M, Taggart JB, Hoyheim B (2000) Atlantic salmon (Salmo salar L.) and crossspecies amplification in other salmonids. Molecular Ecology 9, 2175-2178.

Conway WG (1980) An overview of captive propagation. In: Conservation biology: an evolutionary-ecological perspective (eds. Soule ME, Wilcox BA), pp. 199-208. Sinauer, Sunderland, Massachusetts.

Devlin B, Roeder K, Ellstrand NC (1988) Fractional paternity assignment: theoretical development and comparison to other methods. Theoretical and Applied Genetics $76,369-380$.

Ford M, Fuss H, Boelts B, et al. (2006) Changes in run timing and natural smolt production in a naturally spawning coho salmon (Oncorhynchus kisutch) population after 60 years of intensive hatchery supplementation. Canadian Journal of Fisheries and Aquatic Sciences 63, 2343-2355.

Ford MJ (2002) Selection in captivity during supportive breeding may reduce fitness in the wild. Conservation Biology 16, 815-825.

Garant D, Kruuk LEB (2005) How to use molecular marker data to measure evolutionary parameters in wild populations. Molecular Ecology 14, 1843-1859. 
Gerber S, Chabrier P, Kremer A (2003) FaMoz: a software for parentage analysis using dominant, codominant and uniparentally inherited markers. Molecular Ecology Notes 3, 479-481.

Gerber S, Mariette S, Streiff R, Bodenes C, Kremer A (2000) Comparison of microsatellites and amplified fragment length polymorphism markers for parentage analysis. Molecular Ecology 9, 1037-1048.

Greig C, Banks MA (1999) Five multiplexed microsatellite loci for rapid response run identification of California's endangered winter Chinook salmon. Animal Genetics 30, 316-324.

Greig C, Jacobson DP, Banks MA (2003) New tetranucleotide microsatellites for finescale discrimination among endangered chinook salmon (Oncorhynchus tshawytscha). Molecular Ecology Notes 3, 376-379.

Hill WG (1981) Estimation of Effective Population-Size from Data on Linkage Disequilibrium. Genetical Research 38, 209-216.

Hindar K, Ryman N, Utter F (1991) Genetic effects of cultured fish on natural fish populations. Canadian Journal of Fisheries and Aquatic Sciences 48, 945-957.

Jabbour HN, Hayssen V, Bruford MW (1997) Conservation of deer: contributions from molecular biology, evolutionary ecology, and reproductive physiology. Journal of Zoology 243, 461-484.

Jones AG, Ardren WR (2003) Methods of parentage analysis in natural populations. Molecular Ecology 12, 2511-2523.

Marshall TC, Slate J, Kruuk LEB, Pemberton JM (1998) Statistical confidence for likelihood-based paternity inference in natural populations. Molecular Ecology 7, 639-655.

McClure MM, Holmes EE, Sanderson BL, Jordan CE (2003) A large-scale, multispecies status assessment: anadromous salmonids in the Columbia River Basin. Ecological Applications 13, 964-989.

Meagher TR, Thompson E (1986) The relationship between single parent and parent pair genetic likelihoods in genealogy reconstruction. Theoretical Population Biology 29, 87-106.

Mobrand LE, Barr J, Blankenship L, et al. (2005) Hatchery reform in Washington State: principles amd emerging issues. Fisheries 30, 11-33. 
Naish KA, Taylor JE, Levin PS, et al. (2008) An evaluation of the effects of conservation and fishery enhancement hatcheries on wild populations of salmon. In: Advances in Marine Biology, pp. 61-194. Elsevier Academic Press Inc, San Diego.

Nei M (1987) Molecular Evolutionary Genetics Columbia University Press, New York.

Nelson RJ, Beacham TD (1999) Isolation and cross species amplification of microsatellite loci useful for study of Pacific salmon. Animal Genetics 30, 225244.

Olney PJS, Mace GM, Feistner ATC (1994) Creative Conservation Interactive management of wild and captive animals. Chapman and Hall, London.

Olsen JB, Bentzen P, Seeb JE (1998) Characterization of seven microsatellite loci derived from pink salmon. Molecular Ecology 7, 1087-1089.

Olsen JB, Busack C, Britt J, Bentzen P (2001) The aunt and uncle effect: An empirical evaluation of the confounding influence of full sibs of parents on pedigree reconstruction. Journal of Heredity 92, 243-247.

Reisenbichler RR, McIntyre JD (1977) Genetic differences in growth and survival of juvenile hatchery and wild steelhead trout, Salmo gairdneri. Journal of the Fisheries Research Board of Canada 34, 123-128.

Seamons TR, Bentzen P, Quinn TP (2004) The effects of adult length and arrival date on individual reproductive success in wild steelhead trout (Oncorhynchus mykiss). Canadian Journal of Fisheries and Aquatic Sciences 61, 193-204.

Smith BR, Herbinger CM, Merry HR (2001) Accurate partition of individuals into full sib families from genetic data without parental information. Genetics 158, 13291338.

Smouse PE, Meagher TR (1994) Genetic analysis of male reproductive contributions in Chamaelirium luteum (L.) Gray (Liliaceae). Genetics 136, 313-322.

Waples RS (2006) A bias correction for estimates of effective population size based on linkage disequilibrium at unlinked gene loci. Conservation Genetics 7, 167-184.

Waples RS, Do C (2008) LDNE: a program for estimating effective population size from data on linkage disequilibrium. Molecular Ecology Resources 8, 753-756.

Winans GA, Paquin MM, Van Doornik DM, et al. (2004) Genetic stock identification of steelhead in the Columbia River Basin: An evaluation of different molecular markers. North American Journal of Fisheries Management 24, 672-685. 


\section{Acknowledgements}

The authors thank Robin Waples and Hitoshi Araki for comments on earlier versions of the manuscript. This study is part of a larger collaboration with Andrew Murdoch of the Washington Department of Fish and Wildlife, and was funded in part by a grant from the Bonneville Power Administration 


\title{
Chapter 2 - Factors influencing the relative fitness of hatchery and wild spring Chinook salmon in the Wenatchee River, Washington
}

\begin{abstract}
We used a DNA-based parentage analysis to measure the relative reproductive success of hatchery- and natural-origin spring Chinook salmon in the natural environment. Both male and female hatchery-origin fish produced far fewer juvenile progeny per parent when spawning naturally than did natural origin fish. Differences in age structure, spawning location, weight and run timing were responsible for some of the difference in fitness. Male size and age had a large influence on fitness, with larger and older males producing more offspring than smaller or younger individuals. Female size had a significant effect on fitness, but the effect was much smaller than the effect of size on male fitness. For both sexes, run time had a smaller but still significant effect on fitness, with earlier returning fish favored. Spawning location within the river had a significant effect on fitness for both males and females, and for females explained most of the reduced fitness observed for hatchery fish in this population.
\end{abstract}

\section{Introduction}

Artificial propagation is a commonly used tool to conserve a wide variety of threatened species (Mallinson 1995). Hatchery propagation, in which fish are bred and reared for part of their lives in captivity before being released into the wild, is widely used to supplement wild salmon populations (Naish et al. 2008). Indeed, in much of their range, salmonids are artificially propagated on a large scale. For example, over 4 billion anadromous juvenile salmon are released annually into the North Pacific Ocean from hatcheries in North America and Asia (Beamish et al. 1997). Similar hatchery programs and large-scale closed-pen fish farming operations exist for Atlantic salmon (Salmo salar) in the North Atlantic Ocean and Baltic Sea. Hatcheries are increasingly intended to contribute to conserving natural salmonid populations, as well as to continue to produce fish to mitigate for lost commercial, recreational, and tribal harvest opportunities (National Research Council 1996). In particular, supplementation projects, in which natural spawning by hatchery fish is intended to augment a natural population's abundance, have become common throughout the Pacific Northwest (Williams et al. 2003) and Europe (Fleming et al. 2000).

A key biological uncertainty about the effects of hatchery production on natural populations is the degree to which hatchery produced fish can reproduce in the natural environment (Reisenbichler \& McIntyre 1977; Ford 2002; Araki et al. 2008). Evaluating relative reproductive success is therefore critical for determining if the considerable investment society has made in hatchery supplementation is actually contributing to the recovery of salmon populations (Mobrand et al. 2005). Accurately measuring the biological causes of variance in reproductive success is important not only for determining the benefits of conservation hatcheries, but also for evaluating the risks from 
fish that stray from 'production' type hatcheries. The presence of large numbers of hatchery fish on spawning grounds can obscure the status of natural populations because their reproductive success is unknown (McClure et al. 2003), and may lead to reduced short and long-term natural productivity due to genetic deterioration of the natural population as a result of interbreeding between naturally produced fish and hatchery fish (Lynch \& O'Hely 2001; Ford 2002). By directly quantifying the reproductive success of hatchery fish in the natural environment relative to that of fish from the natural population, the viability of natural populations receiving hatchery fish can be more accurately evaluated.

Even when the relative reproductive success of hatchery produced fish is quantified, the biological or ecological causes of fitness differences between hatchery and wild fish often remain unknown. Conceptually, there could be a wide variety of reasons why hatchery fish might have lower fitness than wild fish spawning in the same stream. Even in cases where hatchery fish have low fitness, the management and conservation implications are likely to vary depending on exactly why the hatchery fish are less fit than wild fish in the same area. For example, if reduced fitness is largely due to environmental effects such as release location this would probably lead to fewer conservation concerns than if fitness reductions were due to genetic differences in behavior or physiology.

In a recent review, Araki et al. (2008) concluded that hatchery produced steelhead (Oncorhynchus mykiss) generally have lower reproductive success in the natural environment than wild steelhead. However, little direct data are available on the relative reproductive success of hatchery and wild Chinook salmon in the natural environment (O. tshawytscha) despite the extensive use of hatchery supplementation for this species (ISAB 2003; ISAB 2005; Araki et al. 2008), although recently several papers have reported on studies in laboratory or semi-natural environments (Fritts et al. 2007; Pearsons et al. 2007; Schroder et al. 2008).

We quantitatively assessed the relative reproductive success of naturally spawning hatchery and natural origin spring-run Chinook salmon in the Wenatchee River by employing a genetic pedigree analysis. Specifically, parentage analysis was performed to directly measure the relative reproductive success of hatchery and natural origin spring Chinook salmon in the natural environment, and determine the degree to which differences in reproductive success between hatchery and natural Chinook salmon can be explained by measurable biological characteristics such as run timing, morphology, and spawning location.

\section{Methods}

\section{Study population}

Our study population consists of the spring run Chinook salmon that spawn in the Wenatchee River, Washington (Figure 1). The population is listed as "endangered" under the Endangered Species Act (Federal Register 70:37160), and a variety of 
conservation strategies are being pursued to recover this population (www.nwr.noaa.gov). Starting in 1989, hatchery supplementation has been used in an attempt to increase population abundance and in recent years the hatchery program has produced $>50 \%$ of the individuals in the population that spawn naturally. The hatchery program's focus is primarily on the Chiwawa River, a major tributary of the Wenatchee River and one of the most important spring Chinook spawning areas in the watershed. Broodstock for the supplementation program are collected at a weir in the Chiwawa River, and the offspring of those fish are released back into the Chiwawa River as yearlings. Although juvenile fish are released only in the Chiwawa River, when they return as adults they spawn in all of the major spawning areas throughout the watershed (Murdoch et al. 2008).

The Wenatchee River spring-run Chinook salmon exhibit a 'stream-type' life-history pattern (Healey 1991) in which adults return to freshwater in the spring several months prior to when they spawn and juveniles migrate to the ocean during the spring one year following their emergence from the gravel (Healey 1983). In wild populations of Chinook salmon in the Columbia River, including the Wenatchee River, most anadromous males become sexually mature between age three to five and most females become mature at either age four or five (Meyers et al. 1998). Another characteristic of stream-type Chinook salmon is that some male fish mature at one or two years of age without migrating to the sea (Rich 1920; Burck 1967; Mullan et al. 1992), but little is known about the reproductive success of these early maturing males.

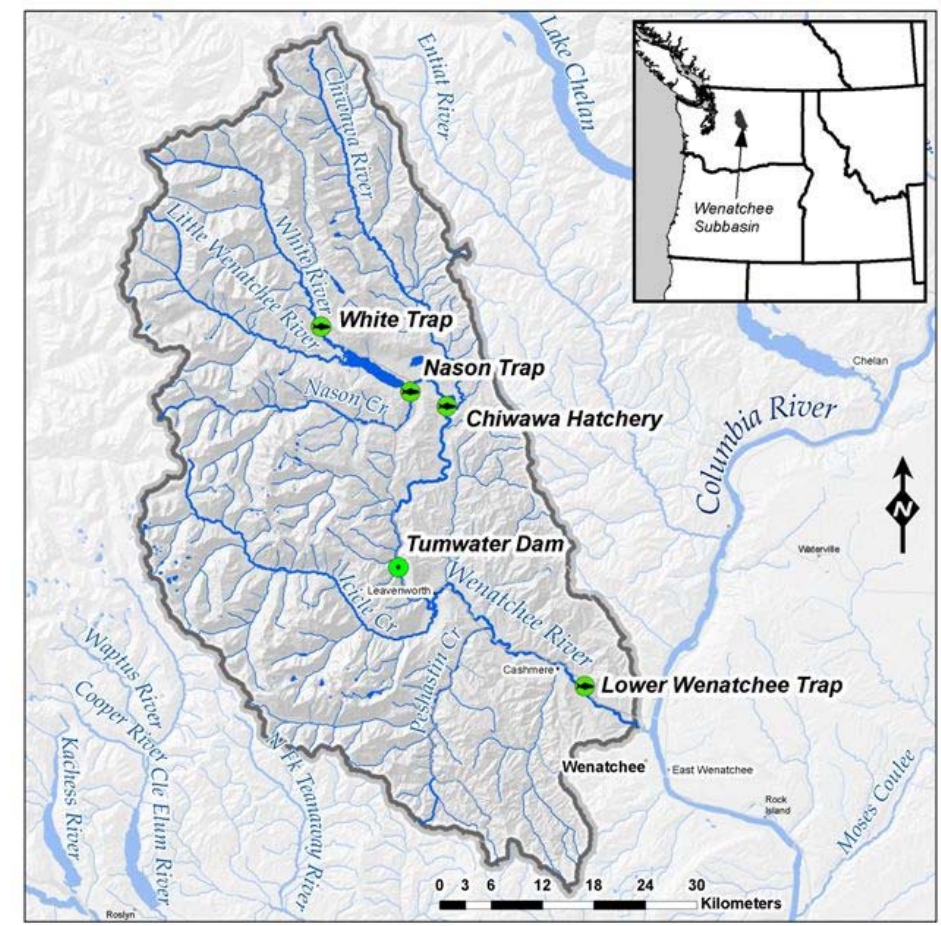

Figure 1. Map of study area. Major spring Chinook salmon spawning tributaries include the Chiwawa River, Nason Creek, White River, and Little Wenatchee River. 


\section{Adult and Juvenile trapping and sampling}

In 2004 and 2005, beginning in early April and ending in early August, essentially all migrating spring Chinook salmon were trapped and sampled (scales, caudal fin clip) at Tumwater Dam, located at river kilometer (rkm) 43.7 on the Wenatchee River in Tumwater Canyon (Figure 1, Table 1). Tumwater Dam is located below all of the major spring Chinook salmon spawning areas in the watershed, so we obtained samples from essentially all of the potential breeders migrating into the Wenatchee River drainage system, with the possible exception of those mature male parr that never migrated below Tumwater Dam and potentially a very small number of spring-run Chinook salmon that migrated after the trapping period ended. Biological data were collected from all adult spring Chinook salmon sampled (Table 1). Each fish was identified to gender, scanned for passive integrated transponder (PIT) tags and coded wire tags, and the presence or absence of the adipose fin. Fork and post orbital to hypural plate length were measured to the nearest $\mathrm{cm}$ and weight to the nearest $0.01 \mathrm{~kg}$. Subsequent identification of PIT tagged carcasses recovered on the spawning grounds permitted the comparison of carcass recovery distributions of hatchery and naturally produced fish.

Juvenile Chinook salmon samples (caudal fin clip) were taken from fish collected in rotary screw traps located on the Wenatchee River (rkm 9.6), Chiwawa River (rkm 1.0), and Nason Creek (rkm 0.8) (Table 1). All rotary traps were located downstream from the majority of spawning habitat in each respective watershed. The primary collection location was the Wenatchee River, which operated from early February through August, although most yearling smolts were captured prior to July 1 . Depending on river discharge levels one or two screw traps (1.5 m diameter) were operated and trap efficiency ranged between 1-3\%. Due to spring run off, traps operated $83 \%$ and $92 \%$ of the trapping period in 2006 and 2007, respectively. At tributary trap locations, yearling (age 1) juveniles were sampled approximately daily from early March to late June. In addition, separate samples of sub-yearlings (age 0) juveniles produced by the 2004 spawners were collected weekly from late September to early November on the Chiwawa River and Nason Creek in 2005 (Table 1). Trap efficiencies in the tributaries ranged between $5-10 \%$ in the spring and $20-40 \%$ during the fall.

Table 1. Summary of 2004 and 2005 adult and juvenile Chinook salmon samples.

\begin{tabular}{|c|c|c|c|c|c|c|c|c|}
\hline \multirow{3}{*}{ Year } & \multirow{3}{*}{ Origin $^{1}$} & \multirow{2}{*}{\multicolumn{2}{|c|}{ Adults }} & \multicolumn{3}{|c|}{ Yearling Juveniles } & Sub-yea & Juveniles \\
\hline & & & & \multicolumn{5}{|c|}{ Trap Location $^{2}$} \\
\hline & & Males & Females & $\mathrm{C}$ & $\mathrm{N}$ & LW & $\mathrm{C}$ & $\mathrm{N}$ \\
\hline \multirow[t]{2}{*}{2004} & $\mathrm{H}$ & 1,502 & 270 & & & & & \\
\hline & $\mathrm{W}$ & 437 & 376 & 738 & 194 & 558 & 574 & 401 \\
\hline \multirow[t]{2}{*}{2005} & $\mathrm{H}$ & 1,573 & 1,724 & & & & & \\
\hline & W & 235 & 238 & & & 831 & & \\
\hline
\end{tabular}

${ }^{1} \mathrm{H}=$ hatchery, $\mathrm{W}=$ wild

${ }^{2} \mathrm{C}=$ Chiwawa River, $\mathrm{N}=$ Nason Creek, and LW = Lower Wenatchee River. 


\section{Microsatellite genotyping}

Genomic DNA was extracted from fin clips according to the method of Lahood et al. (2008). All individuals were genotyped at 11 microsatellite loci: Ots3 (Banks et al. 1999), Ots104 (Nelson \& Beacham 1999), Ots201b, 211 and 213 (Greig et al. 2003), Ots2M and10M (Greig \& Banks 1999), Ots519NWFSC (Naish \& Park 2002), Oke4 (Olsen et al. 1998), Ogo4 (Olsen et al. 1998), and Ssa408 (Cairney et al. 2000). Microsatellite loci were amplified by Polymerase Chain Reaction (PCR) assays, allele sizes were electrophoreticly resolved and scored according to the method of Winans et al. (2004). For each fluorescent phosphoamidite labeled primer set the annealing temperature used was $48{ }^{\circ} \mathrm{C}$ (Ots3 and 104), $54{ }^{\circ} \mathrm{C}$ (Oke4, Ots10M, 213, and 519NWFSC), and $60^{\circ} \mathrm{C}$ (Ogo4, Ots2M, 201b, and 211, Ssa408). Genotyping error rate per locus was determined by re-amplifying and re-scoring microsatellite loci for a subset of individuals, and calculating the number of alleles mis-scored over the total number of alleles observed at each locus.

\section{Parentage assignment}

Assignment of parentage was calculated using the likelihood methods of Meagher and Thompson (1986) and Gerber et al. (2000) as implemented in the program FAMOZ (Gerber et al. 2003). Individuals with missing data at more than 1 locus were excluded from the analysis. In addition, a small number of summer run Chinook salmon, which are genetically distinct from the spring-run population (Utter et al. 1995; Schwenke et al. 2006), were excluded from the analysis on the basis of their genotypes. Each individual in a sample of progeny was tested against all potential pairs of parents and a log of odds (LOD) score was calculated for each potential pair of parents and offspring as the log of the ratio of the probability of a parent pair/offspring relationship compared to the probability they were drawn randomly from the population. Where multiple nonexcluded parent pairs occurred, progeny were fractionally assigned to parents in proportion to their likelihood of parentage (Devlin et al. 1988; Smouse \& Meagher 1994). In situations where multiple parent pairs are compatible with some offspring, fractional assignment methods provide a statistically robust way to estimate selection gradients (e.g., Morgan \& Conner 2001; Nielsen et al. 2001) and fitness differences between groups (Ford and Williamson 2008). In order to make the analyses computationally tractable, only the 20 most likely parent pairs for each offspring were included in the analysis.

\section{Selection and fitness analysis}

All statistical analyses were conducted using the SYSTAT v11 (Systat Software Inc) computer package. The significance of simple differences in mean fitness between two groups were calculated using t-tests, and models testing the effects of multiple traits on fitness were evaluated using ANOVA. We estimated the effects of the following traits on fitness: weight, run time, age, origin (hatchery or natural), hatchery ancestry, and spawning location. Spawning location was based upon location of carcass recovery and linked back to fish identity at Tumwater Dam by PIT tag information. Spawning ground 
surveys of all potential spawning habitat were conducted twice a week throughout the entire spawning season (Murdoch et al. 2008). Carcass recovery location of each PIT tagged fish was recorded using handheld GPS devices and converted to river kilometer using ArcView 9.2. To facilitate comparisons between sexes, traits and years, traits were standardized within each sex and year by subtracting the mean and dividing by the standard deviation. Weight was cube root transformed prior to standardization such that it was a more linear function of size, and run time was converted to ordinal days for ease of analysis and to permit comparison between years. Absolute fitness (progeny counts) within sexes and years was converted to relative fitness by dividing by the mean fitness. For calculation of $p$-values only, the relative fitness values were transformed by raising to the 0.2 power to improve normality. All effect estimates and comparisons between hatchery and wild fitness, however, are reported using the untransformed relative fitness values (Lande \& Arnold 1983). In order to test for the potential effect of non-random smolt trapping effort across the season, analyses were conducted using both the unweighted smolt counts and the counts after weighting each smolt in inverse proportion to the estimated trap efficiency on the day of capture.

\section{Results}

\section{Parentage assignment}

Based on computer simulations conducted using the FAMOZ program to simulate progeny from the observed parental genotypes, we determined that if the most likely parent pair were always selected as the true parent pair, $\sim 20 \%$ of the assignments would be to the wrong pair of parents. By incorporating an assignment threshold such that a progeny was only assigned to a pair of parents if the highest LOD score for that progeny was a least 2 LOD units higher than the next highest LOD score, the expected rate of assignment to incorrect parents could be reduced to $\sim 1 \%$, but at a cost of failing to assign $>40 \%$ of the progeny to any parents. Furthermore, we discovered a pattern of biased assignment failure, such that progeny of hatchery fish were less likely to be assigned to the correct pair of parents than progeny of wild fish. The cause of the difference in 'assignability' between hatchery and wild fish appeared to be due to higher levels of relatedness among the hatchery origin fish than the wild origin fish. These results are explored in detail in a another paper (Ford \& Williamson 2008).

To avoid biased estimates of relative fitness due to failure to assign hatchery fish to parents that were in fact present in the sample, we assigned progeny fractionally to the most likely 20 parent pairs in proportion to their likelihoods. For both the 2004 and 2005 spawning years, $\sim 43 \%$ of the progeny were assigned predominately $(>90 \%)$ to a single pair of parents, with the remaining progeny assigned in varying fractions to multiple sets of potential parents (Figure 2). Computer simulations in which the observed parents were used to generate simulated offspring in order to test alternative methods of fitness estimation indicated that fractional assignment of progeny produced unbiased estimates of relative fitness between hatchery and wild fish (Ford \& Williamson 2008). 
The fitness distribution estimated from the fractional offspring assignments was highly skewed, with a mode near zero and a tail of larger fitness values (Figure 3). Such a highly skewed fitness distribution is similar to what has been observed for other salmonid species, including coho salmon (Ford et al. 2006) and steelhead (Seamons et al. 2004; Araki et al. 2007a).

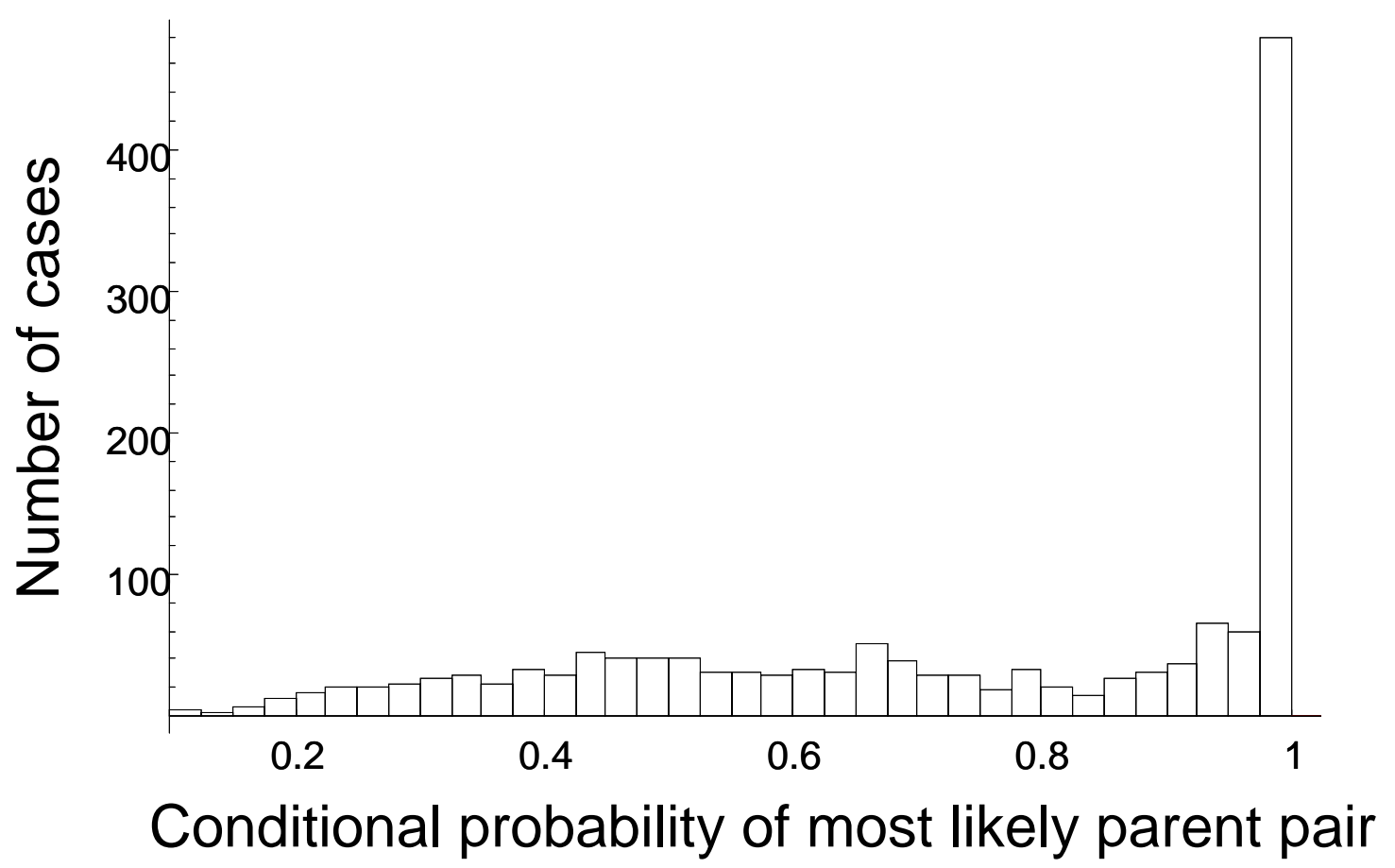

Figure 2. Distribution of likelihoods for the most likely parent pair for each progeny assigned to the 2004 parents (2005 distribution is similar - data not shown).

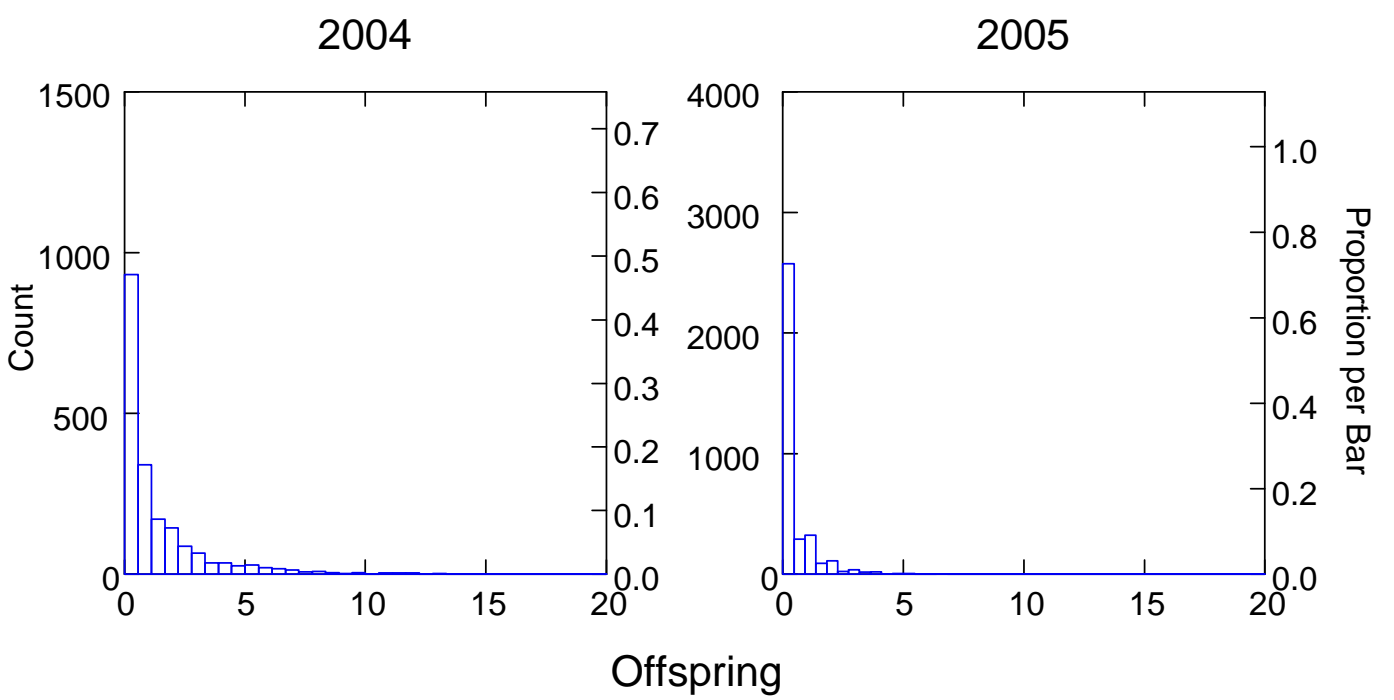

Figure 3. Distribution of estimated fitness (fractionally assigned offspring) for 2004 and 2005. 


\section{Differences between hatchery and wild fish}

Hatchery and wild fish differed in several characteristics (Table 2). In particular, in 2004 most of the hatchery males were 2 and 3-year-olds, whereas most of the wild males were 4-year-olds. For some comparisons within age, sex, and year, hatchery and wild fish differed significantly in run timing and weight, but these comparisons were not always consistent between the two years. For example, 4-year-old hatchery females returned significantly later than 4-year-old wild females in 2004, but significantly earlier in 2005.

One notable difference between hatchery and wild fish of both sexes was carcass recovery location. Within both the Chiwawa River and Nason Creek (the two largest spawning tributaries), hatchery fish were recovered significantly lower in the watersheds than wild fish (Table 2). There were also areas, such as the Wenatchee River mainstem, that had large numbers of hatchery carcass recoveries but few or no wild fish.

\section{Fitness of hatchery and wild fish in the stream environment}

The fitness estimates (standardized mean progeny counts per potential male or female spawner) are reported in Table 3. When progeny were counted as sub-yearlings (2004 brood year only), we found no significant difference in progeny per parent for hatchery and natural origin fish if the comparisons were made within age classes, although hatchery fish produced fewer sampled progeny/parent for all age classes except age 5 females. If male parents regardless of age were considered together, hatchery fish produced significantly fewer sub-yearlings per male parent than wild fish. When progeny were counted at the yearling stage, the 4-year-old (dominant) age class hatchery fish produced significantly fewer progeny per male and female parent in both 2004 and 2005. When all age classes were combined within each sex in either 2004 or 2005 , hatchery males and females produced significantly fewer yearling progeny per parent compared to their wild counterparts.

In addition to age, we evaluated two other traits measured on fish as they were sampled at Tumwater Dam: weight and run timing. We found effects of both traits on fitness in both sexes, with higher weight and earlier run timing associated with greater fitness (Figure 4, Table 4). For both sexes, hatchery origin continued to have a significant negative effect on fitness as well, after taking into account the effects of weight and run timing (Table 4).

We investigated the effect of an additional trait - carcass recovery location - that was measured on the spawning grounds rather than at Tumwater Dam. Only $\sim 10 \%$ of the fish sampled at Tumwater Dam were recovered as carcasses, so we combined data from both years for this analysis in order to increase sample size. Carcass recovery location is correlated with spawning location (Murdoch et al. 2008), and differed significantly between hatchery and wild fish for some of the major spawning tributaries (Figure 5, Table 2). Because only the Chiwawa River and Nason Creek had large numbers of both hatchery and wild spawners with a range of recovery locations, we limited our analysis to these two streams. For both sexes, carcass recovery location had a significant effect on fitness, with fish that spawned higher upstream producing more progeny than fish 
spawning downstream (Figure 5). For females, when carcass recovery location was included in the model, the magnitude of the hatchery origin effect dropped $4 \mathrm{X}$ from -0.19 to -0.03 compared to the case there recovery location was not included (Tables 5 and 6 ). In contrast, the effect of hatchery origin on males remained similar whether recovery location was included in the model or not (-0.56 versus -0.48 ; Tables 5 and 6$)$. Estimated model coefficients and $p$-values were very similar using both the weighted and unweighted smolt counts; only the weighted results are reported in Tables 4, 5 and 6. 
Table 2. Summary of trait variation in adult hatchery and wild spring Chinook salmon used in the parentage analysis.

\begin{tabular}{|c|c|c|c|c|c|c|c|c|c|c|c|c|c|c|c|c|}
\hline \multirow[b]{3}{*}{ Trait } & \multirow[b]{3}{*}{ Year } & \multirow[b]{3}{*}{ Age } & \multicolumn{7}{|c|}{ Males } & \multicolumn{7}{|c|}{ Females } \\
\hline & & & \multicolumn{3}{|c|}{ Hatchery } & \multicolumn{4}{|c|}{ Wild } & \multicolumn{3}{|c|}{ Hatchery } & \multicolumn{4}{|c|}{ Wild } \\
\hline & & & $\mathrm{N}$ & Mean & SD & $\mathrm{N}$ & Mean & SD & $\mathrm{p}$-value & $\mathrm{N}$ & Mean & $\mathrm{SD}$ & $\mathrm{N}$ & Mean & SD & p-value \\
\hline & 2004 & 2 & 626 & 0.12 & 0.11 & -- & -- & -- & -- & -- & -- & -- & -- & -- & -- & -- \\
\hline & & 3 & 747 & 1.79 & 0.64 & 28 & 1.44 & 0.50 & $<0.001$ & 3 & 3.27 & 0.46 & 0 & -- & -- & -- \\
\hline & & 4 & 96 & 5.60 & 1.29 & 403 & 5.32 & 1.30 & 0.06 & 252 & 5.50 & 0.97 & 362 & 5.28 & 0.81 & $<0.001$ \\
\hline & & 3 & 129 & 1.83 & 0.46 & 9 & 1.62 & 0.30 & 0.08 & 0 & -- & -- & 0 & -- & -- & -- \\
\hline & & 4 & 1111 & 6.05 & 1.30 & 185 & 5.16 & 1.30 & $<0.001$ & 1702 & 5.41 & 0.87 & 201 & 5.39 & 0.97 & 0.80 \\
\hline & & 5 & 6 & 8.10 & 2.20 & 39 & 9.23 & 1.93 & 0.28 & 8 & 7.23 & 1.41 & 44 & 7.99 & 1.31 & 0.19 \\
\hline
\end{tabular}

Run timing

$\begin{array}{cccccccccccccccc}2004 & 2 & 626 & 193.18 & 9.01 & -- & -- & -- & - & - & - & - & -- & -- & -- & -- \\ & 3 & 747 & 179.61 & 9.21 & 28 & 178.71 & 12.42 & 0.71 & 3 & 185.30 & 2.89 & 0 & -- & -- & -- \\ & 4 & 96 & 173.91 & 14.50 & 403 & 170.73 & 13.58 & 0.05 & 252 & 177.13 & 12.29 & 362 & 170.13 & 11.70 & <0.001 \\ & 5 & 2 & 167.00 & 2.83 & 4 & 160.00 & 6.22 & 0.13 & 3 & 169.00 & 14.73 & 7 & 178.71 & 12.65 & 0.39 \\ 2005 & 2 & 290 & 191.22 & 12.66 & -- & -- & -- & -- & -- & -- & -- & -- & -- & -- & -- \\ & 3 & 129 & 179.76 & 11.02 & 9 & 182.44 & 17.74 & 0.67 & 0 & - & - & 0 & -- & -- & -- \\ & 4 & 1111 & 171.79 & 12.66 & 185 & 175.46 & 15.84 & <0.001 & 1702 & 170.57 & 12.18 & 201 & 175.01 & 15.39 & <0.001 \\ & 5 & 6 & 166.33 & 16.71 & 39 & 166.97 & 18.91 & 0.93 & 8 & 164.88 & 16.34 & 44 & 168.39 & 17.03 & 0.59\end{array}$

Location (RKM), 2004

and 2005 combined

Chiwawa River

\begin{tabular}{ccccccccccccccc}
3 & 25 & 19.35 & 11.54 & 2 & 20.48 & 3.18 & 0.75 & 0 & - & -- & 0 & - & -- & -- \\
\hline 4 & 89 & 18.66 & 10.81 & 47 & 27.57 & 10.64 & $<0.001$ & 194 & 20.26 & 11.86 & 63 & 29.54 & 11.20 & $<0.001$
\end{tabular}




\begin{tabular}{|c|c|c|c|c|c|c|c|c|c|c|c|c|c|c|}
\hline 5 & 0 & -- & -- & 3 & 28.77 & 12.93 & -- & 0 & -- & -- & 8 & 28.83 & 8.77 & -- \\
\hline \multicolumn{15}{|l|}{ Nason Creek } \\
\hline 3 & 37 & 8.94 & 6.48 & 1 & 13.44 & -- & -- & 0 & -- & -- & 0 & -- & -- & -- \\
\hline 4 & 54 & 6.73 & 5.64 & 48 & 13.60 & 7.09 & $<0.001$ & 118 & 7.92 & 6.34 & 48 & 13.63 & 8.31 & $<0.001$ \\
\hline 5 & 0 & -- & -- & 1 & 13.46 & -- & -- & 1 & 13.37 & -- & 15 & 14.95 & 7.20 & -- \\
\hline \multicolumn{15}{|l|}{ White River } \\
\hline 3 & 0 & -- & -- & 0 & -- & -- & -- & 0 & -- & -- & 0 & -- & -- & -- \\
\hline 4 & 2 & 29.19 & 0.39 & 5 & 29.33 & 0.41 & 0.71 & 29 & 30.00 & 0.74 & 11 & 29.70 & 0.70 & 0.24 \\
\hline 5 & 0 & -- & -- & 0 & -- & -- & -- & 0 & & & 0 & -- & -- & -- \\
\hline \multicolumn{15}{|c|}{ Wenatchee River } \\
\hline 3 & 3 & 83.61 & 2.71 & 0 & -- & -- & -- & 0 & -- & -- & 0 & -- & -- & -- \\
\hline 4 & 37 & 83.76 & 1.90 & 1 & 78.27 & -- & -- & 60 & 83.25 & 2.36 & 1 & 85.52 & -- & -- \\
\hline 5 & 0 & -- & -- & & -- & -- & -- & 0 & & & 1 & 84.27 & -- & -- \\
\hline \multicolumn{15}{|c|}{$\begin{array}{l}\text { Little Wenatchee } \\
\text { River }\end{array}$} \\
\hline 3 & 0 & -- & -- & 0 & -- & -- & -- & 0 & -- & -- & 0 & -- & -- & \\
\hline 4 & 5 & 11.52 & 2.23 & 6 & 11.88 & 1.45 & 0.76 & 22 & 11.14 & 2.91 & 10 & 11.62 & 2.48 & 0.64 \\
\hline 5 & 0 & -- & -- & 0 & -- & -- & -- & 0 & -- & -- & 0 & -- & -- & -- \\
\hline
\end{tabular}


Table 3. Standardized progeny counts and relative fitness of hatchery and wild fish for the 2004 and 2005 spawning years.

\begin{tabular}{|c|c|c|c|c|c|c|c|c|c|c|c|c|c|c|c|c|c|c|c|c|}
\hline \multirow{4}{*}{ Sex } & \multirow{4}{*}{ Age } & \multicolumn{12}{|c|}{2004} & \multicolumn{7}{|c|}{2005} \\
\hline & & \multicolumn{7}{|c|}{ Sub-yearling } & \multicolumn{12}{|c|}{ Yearling } \\
\hline & & \multicolumn{3}{|c|}{ Wild } & \multicolumn{4}{|c|}{ Hatchery } & \multicolumn{2}{|c|}{ Wild } & \multicolumn{3}{|c|}{ Hatchery } & \multicolumn{3}{|c|}{ Wild } & \multicolumn{4}{|c|}{ Hatchery } \\
\hline & & $\mathrm{N}$ & Mean & $\mathrm{SD}$ & $\mathrm{H} / \mathrm{W}^{1}$ & $\mathrm{~N}$ & Mean & SD & Mean & SD & $\mathrm{H} / \mathrm{W}$ & Mean & SD & $\mathrm{N}$ & Mean & $\mathrm{SD}$ & $\mathrm{H} / \mathrm{W}$ & $\mathrm{N}$ & Mean & $\mathrm{SD}$ \\
\hline \multirow[t]{5}{*}{$\mathrm{M}$} & 2 & 0 & - & -- & -- & 626 & 0.22 & 0.50 & - & -- & -- & 0.32 & 0.50 & 0 & - & - & - & 290 & 0.20 & 0.50 \\
\hline & 3 & 28 & 1.06 & 2.03 & 0.68 & 740 & 0.72 & 1.32 & 0.84 & 1.19 & 0.83 & 0.70 & 1.01 & 9 & 2.03 & 2.32 & 0.36 & 129 & 0.74 & 1.34 \\
\hline & 4 & 403 & 2.48 & 3.44 & 0.81 & 96 & 2.00 & 2.50 & 2.50 & 3.12 & $0.55^{*}$ & 1.38 & 1.49 & 185 & 2.04 & 3.29 & $0.49 * *$ & 1111 & 1.00 & 2.10 \\
\hline & 5 & 4 & 1.15 & 1.40 & 0.68 & 2 & 0.78 & 1.07 & 4.50 & 7.33 & 0.02 & 0.07 & 0.07 & 39 & 2.05 & 3.32 & 0.66 & 6 & 1.36 & 2.60 \\
\hline & All & 435 & 2.38 & 3.37 & $0.25 * *$ & 1,491 & 0.59 & 1.26 & 2.42 & 3.17 & $0.24 * *$ & 0.58 & 0.92 & 233 & 2.04 & 3.25 & $0.40 * *$ & 1536 & 0.83 & 1.86 \\
\hline \multirow[t]{3}{*}{$\mathrm{F}$} & 4 & 362 & 1.04 & 1.37 & 0.86 & 252 & 0.89 & 1.14 & 1.24 & 1.37 & $0.55^{* *}$ & 0.69 & 0.10 & 201 & 1.80 & 2.90 & $0.49 *$ & 1702 & 0.88 & 1.70 \\
\hline & 5 & 7 & 0.32 & 0.35 & 2.15 & 3 & 0.69 & 0.58 & 0.54 & 0.47 & 0.70 & 0.38 & 0.34 & 44 & 1.97 & 2.34 & 0.78 & 8 & 1.72 & 2.53 \\
\hline & All & 369 & 1.04 & 1.36 & 0.88 & 271 & 0.91 & 1.17 & 1.23 & 1.36 & $0.55^{* *}$ & 0.68 & 0.96 & 245 & 1.83 & 2.80 & $0.48^{* *}$ & 1759 & 0.88 & 1.70 \\
\hline
\end{tabular}

${ }^{1} \mathrm{H} / \mathrm{W}=$ ratio of mean fitness between hatchery and wild fish. Significant differences in mean fitness between hatchery and wild fish are indicated as $* \mathrm{p}<0.05, * * \mathrm{p}<0.01$.

Table 4. Effects of origin, age, run timing, weight on male and female relative fitness.

\begin{tabular}{|c|c|c|c|c|c|c|c|c|}
\hline \multirow{3}{*}{ Effect } & \multicolumn{4}{|c|}{ Male } & \multicolumn{4}{|c|}{ Female } \\
\hline & \multicolumn{2}{|c|}{2004} & \multicolumn{2}{|c|}{2005} & \multicolumn{2}{|c|}{2004} & \multicolumn{2}{|c|}{2005} \\
\hline & Estimate & p-value & Estimate & p-value & Estimate & p-value & Estimate & $\mathrm{p}$-value \\
\hline constant & 0.93 & & 1.66 & & 0.96 & & 1.36 & \\
\hline hatchery origin & -0.32 & 0.006 & -0.60 & 0.013 & -0.23 & $<0.001$ & -0.47 & $<0.001$ \\
\hline Age 3 & 0.33 & 0.086 & 0.38 & 0.154 & & & & \\
\hline Origin $X$ age 3 & 0.15 & 0.959 & -0.10 & 0.561 & & & & \\
\hline run timing & -0.09 & 0.032 & -0.08 & 0.561 & -0.17 & $<0.001$ & -0.17 & 0.001 \\
\hline weight & 0.71 & $<0.001$ & 0.34 & $<0.001$ & 0.13 & 0.002 & 0.12 & 0.015 \\
\hline
\end{tabular}

Note -- Age 2 males were excluded and age 4 and 5 were combined for the analysis. 
Males

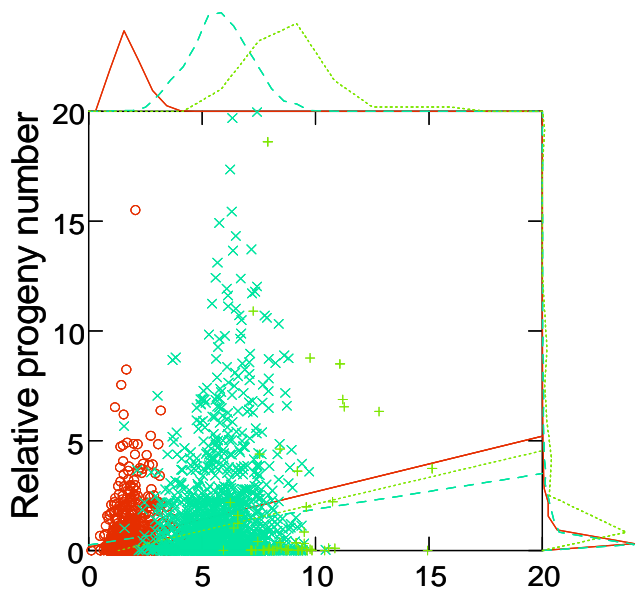

Females



Weight $(\mathrm{kg})$

Figure 4. Relationship between age, weight and relative fitness for the combined 2004 and 2005 data on naturally spawning fish. Relative fitness was estimated as standardized, fractionally assigned counts of yearling offspring. Weight and fitness distribution by age are illustrated on the margins.

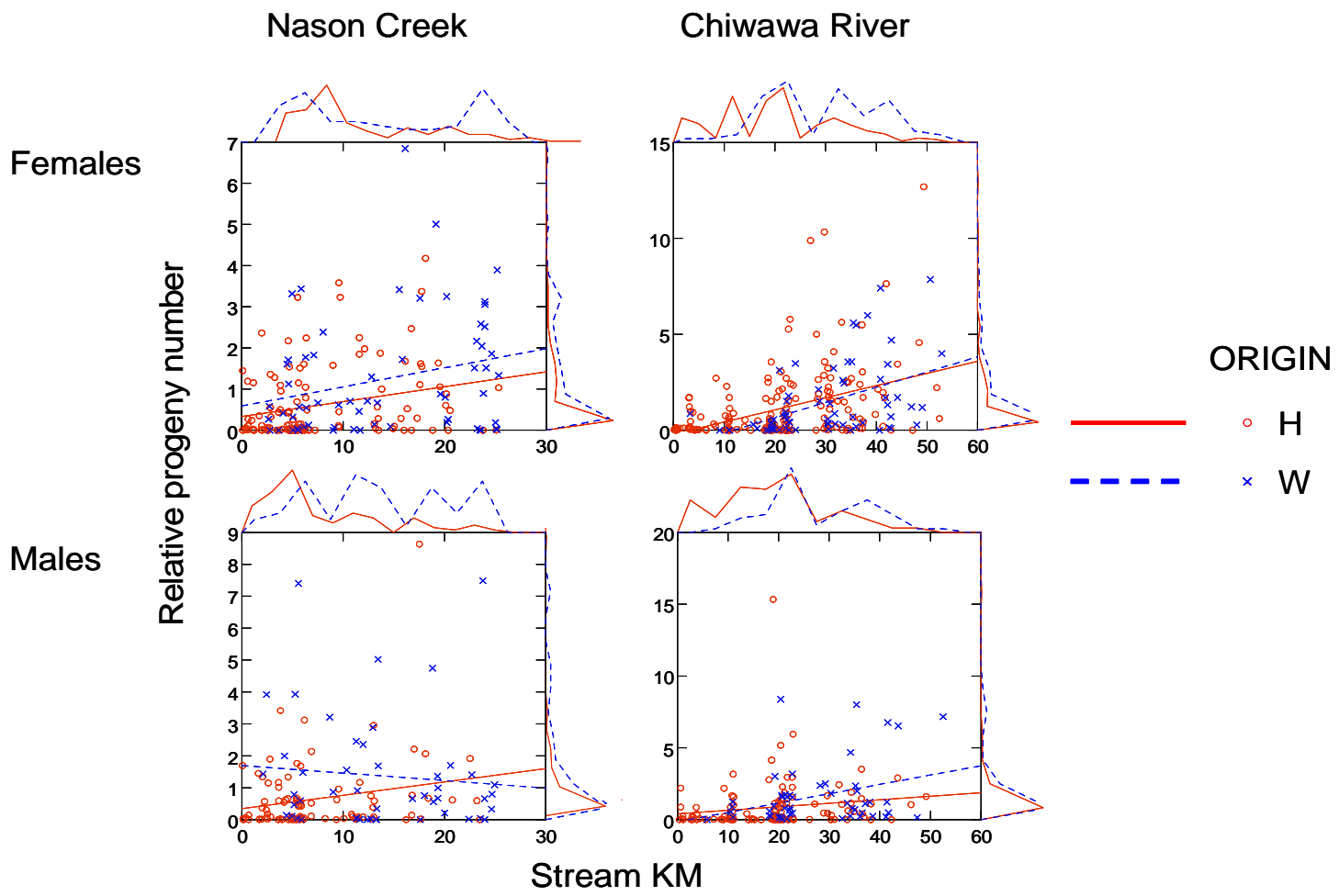

Figure 5. Relationship between female and male carcass recovery location and relative fitness for the Chiwawa River and Nason Creek. Relative fitness was estimated as standardized, fractionally assigned smolt counts. Recovery location by river kilometer $(\mathrm{rkm})$ and fitness distributions are illustrated on the margins. Data from both years are combined. 
Table 5. Effects of origin, age, run timing, weight and spawning location on male and female relative fitness. Data are from 2004 and 2005 combined. Age 2 males were excluded from the analysis and ages 4 and 5 were combined.

\begin{tabular}{|c|c|c|c|c|}
\hline \multirow{2}{*}{ Effect } & \multicolumn{2}{|c|}{ Males } & \multicolumn{2}{|c|}{ Females } \\
\hline & Estimate & p-value & Estimate & p-value \\
\hline Constant & 1.53 & & 1.013 & \\
\hline Hatchery origin & -0.48 & 0.009 & -0.03 & 0.052 \\
\hline Age 3 & 0.61 & 0.001 & -- & \\
\hline Origin $x$ age 3 & -0.35 & 0.180 & -- & \\
\hline Run timing & 0.13 & 0.156 & 0.03 & 0.197 \\
\hline Weight & 0.52 & $<0.001$ & 0.11 & 0.155 \\
\hline Location & 0.37 & 0.001 & 0.62 & $<0.001$ \\
\hline
\end{tabular}

Table 6. Effects of origin, age, run timing, weight on male and female relative fitness, using only fish recovered on the spawning grounds (same data as in Table 5). Data are from 2004 and 2005 combined. Age 2 males were excluded from the analysis and ages 4 and 5 were combined.

\begin{tabular}{|c|c|c|c|c|}
\hline \multirow{2}{*}{ Effect } & \multicolumn{2}{|c|}{ Males } & \multicolumn{2}{|c|}{ Females } \\
\hline & Estimate & p-value & Estimate & p-value \\
\hline Constant & 1.54 & & 1.08 & \\
\hline Hatchery origin & -0.56 & 0.004 & -0.19 & $<0.001$ \\
\hline Age 3 & 0.53 & 0.004 & & \\
\hline Origin $x$ age 3 & -0.32 & 0.219 & & \\
\hline Run timing & 0.05 & 0.459 & -0.10 & 0.819 \\
\hline Weight & 0.46 & $<0.001$ & 0.14 & 0.095 \\
\hline
\end{tabular}

\section{Discussion}

\section{Fitness distribution}

Like previous studies of salmon fitness, the estimated offspring numbers for Wenatchee River Spring Chinook salmon were highly skewed, with many parents having no sampled progeny assigned to them (Figure 3). There are several likely causes of this skewed distribution. First, the sample number of offspring used in our analysis constituted a small fraction of the total juvenile progeny produced. The shape of the fitness distribution is affected by progeny sample size (e.g., in the extreme case if no progeny were sampled the entire distribution would be on zero) and it's likely that if more progeny were sampled the distribution would move to the right. Second, many of the adults sampled at Tumwater Dam in fact produced no progeny, because pre-spawn mortality in this population has been estimated to be as high as 50\% (Murdoch et al. 2008). Finally, even among those fish that spawned, there appears to be a highly skewed distribution of progeny number, indicating a high variance in reproductive success. 
Both female and male hatchery origin adults had significantly lower mean fitness compared to their wild counterparts (Table 3), similar to what has been observed in other species (reviewed by Araki et al. 2008). In particular, for the dominant four-year-old age class, hatchery fish produced only about half as many progeny per parent as wild fish, similar to what has been observed in studies of hatchery steelhead (e.g., Leider et al. 1990; Kostow et al. 2003; e.g., Araki et al. 2007a; Araki et al. 2007b). This result is perhaps not too surprising, since like most steelhead hatchery programs, spring-run Chinook salmon in the Wenatchee River (and other Interior Columbia Basin streams) typically spend a full year rearing in the hatchery prior to release. If reduced fitness is in part due to the effects of rearing in the hatchery and if the severity of such effects is correlated with the length of time a fish spends rearing in the hatchery environment, then species that spend similar periods of time in hatchery rearing conditions might be expected to have similar reductions in fitness in the wild.

Schroder et al. (2008) used pedigree analysis to evaluate the relative reproductive success of spring Chinook salmon in the Yakima River that were challenged in a semi-natural spawning channel. That study found that eggs deposited by first generation hatchery females survived to be sampled as emergent fry to early parr 5.6 percentage points below that of eggs deposited by wild females. The authors also found subtle differences in behavior and spawning location that appeared to cause the survival difference. The fitness difference between hatchery and wild females (and males) in the Wenatchee River was much larger than 5.6\% (Table 3), and there could be several reasons for the greater differences in fitness we observed in this study. First, the Wenatchee River supplementation program was started in 1989 and returning hatchery fish have comprised $36-70 \%$ of the broodstock since 1994. The Yakima River program started in 1997 and uses only wild fish for broodstock, so the hatchery fish in the Wenatchee River have experienced more generations of domestication selection than the Yakima River fish. Second, we measured fitness over a longer period of the life-cycle (pre-spawning adult to yearling smolt), allowing for more opportunities for differences in fitness between wild and hatchery fish to manifest. Finally, the Wenatchee study was in a natural setting, compared to an artificial stream channel in Yakima. It is possible that the natural environment is less benign to hatchery produced fish than the stream channel, leading to greater differences in fitness. In support of the last two points, other studies in the Yakima Basin demonstrated that offspring of hatchery parents were more susceptible to predation mortality at the fry stage (Fritts et al. 2007) and less competitive in contest competition experiments at the parr stage (Pearsons et al. 2007).

\section{Fitness differences due to variation in other traits}

Part of the motivation for this study was to determine if differences in traits such as age, size, and spawning location could explain any observed differences in fitness between hatchery and wild origin fish. Hatchery and wild fish differed significantly in age structure (males) and spawning location (both sexes; Table 2), so these were obvious candidates for traits that may explain fitness differences. 
For males, the overall relative fitness of hatchery fish was much lower if all age classes were combined together than if analyzed separately (Table 3). This was due to the higher fraction of three-year-old males among hatchery fish compared to wild fish. Three-yearolds of either hatchery or wild origin produced less than half the progeny per parent than four-year-olds (Table 3), leading to large differences in relative fitness among fish of different origins if age structure was not taken into account. Indeed, if age structure were not taken into account in the analysis, hatchery males would have a relative fitness of only 0.25 in 2004, when most adult hatchery males were three-year-olds and most wild males were four-year-olds (Table 3). Hatchery fish have a tendency to mature at earlier ages than wild fish (Knudsen et al. 2006; Murdoch et al. 2008), but the difference is subtle and does not explain the differences in age structure in 2004 and 2005. Instead, these differences were due mostly to an increase in hatchery releases starting in 2003, and the three-year-olds that returned to spawn in 2004 were in high abundance due to this strong hatchery cohort (Murdoch, unpublished data). Wild and hatchery females both returned predominately as four-year-olds, and differences in age structure therefore did not contribute to fitness differences between hatchery and wild females.

Other than differences in age structure, carcass recovery location was the only measured trait to date that differed notably between hatchery and wild origin fish (Table 2). In the major spawning tributaries (Chiwawa River and Nason Creek), hatchery fish of both sexes were recovered on average lower in the watershed than wild fish (Table 2). Carcass recovery location also had a significant effect on fitness, such that fish that were recovered higher in the watersheds had higher average fitness than those that were recovered lower in the watersheds (Table 5, Figure 5). This difference in recovery location explained $\sim 80 \%$ of the difference in relative fitness between hatchery and wild females, but explained little of the difference for males (Tables 5 and 6).

Carcass recovery location is a good index of spawning location for female spring Chinook salmon (Murdoch et al. 2008), and the effect of recovery location on fitness is presumably due to differences in spawning location or subsequent juvenile rearing location rather than carcass recovery location per se. To our knowledge, this is the first direct estimate of the effect of general spawning location on fitness in a natural stream, although the result is consistent with previous indirect observations and there is a large literature on spawning site selection by salmon (reviewed by Quinn 2005). In another supplemented spring Chinook population in the Imnaha River, Oregon, Hoffnagle et al. (2008) also found that hatchery females were distributed lower in the watershed than wild females, and hypothesized that this could have a deleterious effect on the fitness of the population. Schroder et al. (2008) also found that small differences in spawning location within an artificial stream contributed to reduced fitness of hatchery spring Chinook salmon in the Yakima River.

The cause of the difference in spawning distribution between hatchery and wild Chinook salmon in the Wenatchee River is probably due to the rearing methods and release location of the hatchery fish. Hatchery juveniles are initially reared in an offsite facility until they reach 6-7 months of age, when they are transferred to a rearing pond near the mouth of the Chiwawa River (Figure 1). There, the fish are reared on a mixture of Chiwawa River and Wenatchee River water until they are volitionally released as smolts from early April to late May. Salmon are known to imprint on chemical cues in the water 
and to use these cues as a homing mechanism when they return to spawn as adults (Quinn 1984.; Quinn 1993). It is therefore not surprising that returning hatchery fish tend to spawn in the lower reaches of the Chiwawa River and areas nearby in Nason Creek and the Wenatchee River, since this is the area to which they imprinted as juveniles. Our results indicate that this rearing strategy has deleterious fitness consequences for the hatchery fish that are produced.

Our results do not directly address the mechanism by which spawning in the lower reaches of the Chiwawa River and Nason Creek leads to lower fitness, but there are two plausible factors. First, the density of spawners is higher in the lower reaches, due to the large number of hatchery fish produced by the supplementation program. It is possible that the population is closer to carrying capacity in these lower reaches, and the per capita fitness of fish in these areas is therefore less than in the upper portions of the watershed that have lower spawning densities. Second, the spawning and rearing habitat is generally considered to be of higher quality in the upper reaches of the watersheds which are located in protected U.S. Forest Service Lands, compared to the lower reaches which are more impacted by roads and development (UCSRB 2007). These factors are not mutually exclusive, however, and it seems likely that some combination of the two is responsible for the relationship between fitness and spawning location. Other aspects of the effect of spawning location remain to be explored. For example, relatively few wild fish but considerable hatchery fish spawned in the Wenatchee River proper (Table 2), and this choice of spawning location may also contribute to the overall reduction in hatchery fish fitness.

In addition to age and spawning location, we also examined the effects of weight and run timing, traits which generally did not differ among fish of different origin, on relative fitness. Similar to a previous study on coho salmon (Ford et al. 2006), selection for larger size was strong for males and significant but less strong for females (Figure 4, Table 4). Selection on run timing was for earlier timing for both males and females, and was weaker than selection for male size and similar in strength to selection on female size (Table 4). Neither weight nor run timing differed consistently between hatchery and wild fish, and not surprisingly neither of these traits explain the reduced fitness of hatchery fish compared to wild fish (Table 4).

Biological factors other than those examined in this study may also influence the reproductive success of hatchery Chinook salmon. In particular, there have been studies that have found differences between hatchery fish in a variety of behavioral (e.g., Riddell 1991; e.g., Fleming \& Gross 1992), morphological (e.g., Fleming \& Gross 1989) and physiological traits (e.g., Hill et al. 2006). Reduced courtship behavior or aggression exhibited by hatchery fish relative to wild fish has been demonstrated in Chinook salmon (Chebanov \& Riddel 1998), coho salmon (Fleming \& Gross 1992; Berejikian et al. 2001) and Atlantic salmon (Jonsson 1997). Subtle differences in behavior or physiology may explain the continued negative effect of hatchery origin on male reproductive success after the effects of the measured traits were accounted for (Table 5). 


\section{Conservation implications}

The low relative reproductive success of hatchery fish in our study and more generally (Araki et al. 2008) suggest that the hatchery supplementation, as it is currently carried out, may not be as effective as it could be at conserving natural salmon populations. In the case of Wenatchee spring Chinook salmon, the clustering of hatchery produced spawners in the lower reaches of the tributaries likely means that the capacity of the habitat becomes saturated more rapidly than would be the case if the hatchery fish were more evenly distributed throughout the watershed. If a supplementation program's goal is to produce fish that will return to spawn naturally and augment the productivity of a depressed wild stock, a sufficient quantity of high quality spawning and rearing habitat must be available (Cuenco et al. 1993; HSRG 2004; Goodman 2005). A tendency to return to a limited portion of the watershed, coupled with declines in fitness due to hatchery rearing (Araki et al. 2007b; Araki et al. 2008), may act synergistically to reduce reproductive success of naturally spawning hatchery salmon and limit the ability of supplementation to increase natural production. For females, but not for males, much of reduction in female hatchery fish fitness in the Wenatchee River appears to be due to spawning location, a rather malleable trait. This suggests that alternative acclimation and release strategies, such as acclimating and releasing fish in multiple locations and at locations higher in the tributaries, might potentially lead to better performance by the naturally spawning female hatchery fish. However, if the locations in the upper tributaries are already at or near capacity with wild fish alone, there would be no population level benefit from supplementing these areas even if it did result in higher relative fitness of the hatchery origin fish. This suggest that considerable care must be taken to match the size of a supplementation program to the capacity of the ecosystem.

Even though the low relative fitness of hatchery fish in our study meant that the supplementation program may not have been as effective as it could have been, the total demographic effect of the program may still have been positive due to the extremely low productivity of the natural population. The geometric mean adult spawner-to-spawner rate for the hatchery program was 2.52 for the 1989 to 2001 brood cycles, compared to 0.45 for the natural population (data from Table 5.35 of Hillman et al. 2008). The average relative fitness of hatchery fish compared to natural fish in 2004 and 2005 was 0.40 (weighted average of female and male values in Table 3). The net number of naturally produced grandchildren (measured at the smolt stage) expected to be contributed by a fish spawned in the hatchery compared to being left in the wild is therefore $(2.52 * 0.40) / 0.45=2.25$. Therefore, even though relative fitness of the hatchery fish was less than half that of the wild fish, in net the supplementation program may have provided a short term increase in the number of naturally produced fish in the population due to the much higher adult replacement rate for fish in the hatchery compared to the wild. Whether such short-term increases will translate into longer term benefits is unclear, however, and will depend in part on whether the presence of naturally spawning hatchery fish reduces the fitness of natural fish in the long term. In addition, this simple calculation does not take into account the effect of density on productivity, so the overall effect of the supplementation on natural population viability remains unknown. 
A recommendation provided by both the Hatchery Scientific Review Group (2004) and the USFWS Columbia Basin Hatchery Review Team (2005) is to provide productive habitat for all life history stages of hatchery and natural origin salmonid fishes since the fitness of the naturally-spawning population and the number of adult salmon (artificially or naturally produced) returning to the watershed ultimately depend on the quality of the natural habitat. Studies such as the one reported here may be useful not only for measuring the reproductive fitness of naturally spawning hatchery and wild origin fish, but also for assessing the efficacy of activities intended to improve spawning and rearing habitat or to improve the effectiveness of the supplementation program. For example, pedigree analysis could be used to monitor whether or not hatchery juveniles released higher within the Wenatchee River system would return to spawn in those areas, and to compare their reproductive fitness to that of hatchery fish that spawn lower in the watershed. This approach may also permit one to detect changes in the carrying capacity of the natural habitat to support salmon spawning and rearing following efforts to improve habitat.

\section{Acknowledgements}

Linda Park and Eric Iwamoto provided useful comments on earlier drafts of this manuscript, and Ewann Berntson assisted with data collection. This research was funded by contracts to M.J.F. and A.R.M from the Bonneville Power Administration.

\section{References}

Araki H, Ardren W, Olsen E, Cooper B, Blouin M (2007a) Reproductive success of captive-bred steelhead trout in the wild: evaluation of three hatchery programs in the Hood River. Conservation Biology 21, 181-190.

Araki H, Berejikian BA, Ford MJ, Blouin MS (2008) Fitness of hatchery-reared salmonids in the wild. Evolutionary Applications 1, 342-355.

Araki H, Cooper B, Blouin MS (2007b) Genetic effects of captive breeding cause a rapid, cumulative fitness decline in the wild. Science 318, 100-103.

Banks MA, Blouin MS, Baldwin BA, et al. (1999) Isolation and inheritance of novel microsatellites in chinook salmon. Journal of Heredity 90, 281-288.

Beamish RJ, Mahnken C, Neville CM (1997) Hatchery and wild production of Pacific salmon in relation to large-scale, natural shifts in the productivity of the marine environment. ICES Journal of Marine Science 54, 963-964.

Berejikian BA, Tezak EP, Park L, et al. (2001) Male competition and breeding success in captively reared and wild coho salmon (Oncorhynchus kisutch). Canadian Journal of Fisheries and Aquatic Sciences 58, 804-810.

Burck WA (1967) Mature stream-reared spring chinook salmon. Oregon Fish Commission Research Briefs 13, 128. 
Cairney M, Taggart JB, Hoyheim B (2000) Atlantic salmon (Salmo salar L.) and crossspecies amplification in other salmonids. Molecular Ecology 9, 2175-2178.

Chebanov NA, Riddel BE (1998) The spawning behavior, selection of mates, and reproductive success of Chinook salmon spawners of natural and hatchery originsunder conditions of joint spawning. Journal of Ichthyology 38, 517-536.

Cuenco ML, Backman TWH, Mundy PR (1993) The use of supplementation to aid in natural stock restoration. In: Genetic Conservation of Salmonid Fishes (eds. Cloud JG, Thorgaard GH), pp. 269-288. Plenum Press, New York.

Devlin B, Roeder K, Ellstrand NC (1988) Fractional paternity assignment: theoretical development and comparison to other methods. Theoretical and Applied Genetics 76, 369-380.

Fleming IA, Gross MR (1989) Evolution of adult female life history and morphology in a Pacific salmon (coho: Oncorhynchus kisutch ). Evolution 43, 141-157.

Fleming IA, Gross MR (1992) Reproductive behavior of hatchery and wild coho salmon ( Oncorhynchus kisutch ): does it differ? Aquaculture 103, 101-121.

Fleming IA, Hindar K, Mjolnerod IB, et al. (2000) Lifetime success and interactions of farm salmon invading a native population. Proceedings of the Royal Society, Series B Biology 267, 1517-1523.

Ford M, Fuss H, Boelts B, et al. (2006) Changes in run timing and natural smolt production in a naturally spawning coho salmon (Oncorhynchus kisutch) population after 60 years of intensive hatchery supplementation. Canadian Journal of Fisheries and Aquatic Sciences 63, 2343-2355.

Ford MJ (2002) Selection in captivity during supportive breeding may reduce fitness in the wild. Conservation Biology 16, 815-825.

Ford MJ, Williamson KS (2008) The aunt and uncle effect revisited. Molecular Ecology submitted.

Fritts AL, Scott JL, Pearsons TN (2007) The effects of domestication on the relative vulnerability of hatchery and wild origin spring Chinook salmon (Oncorhynchus tshawytscha) to predation. Canadian Journal Of Fisheries And Aquatic Sciences 64, 813-818.

Gerber S, Chabrier P, Kremer A (2003) FaMoz: a software for parentage analysis using dominant, codominant and uniparentally inherited markers. Molecular Ecology Notes 3, 479-481.

Gerber S, Mariette S, Streiff R, Bodenes C, Kremer A (2000) Comparison of microsatellites and amplified fragment length polymorphism markers for parentage analysis. Molecular Ecology 9, 1037-1048. 
Goodman D (2005) Selection equilibrium for hatchery and wild spawning fitness in integrated breeding programs Canadian Journal of Fisheries and Aquatic Sciences 62, 374-389.

Greig C, Banks MA (1999) Five multiplexed microsatellite loci for rapid response run identification of California's endangered winter Chinook salmon. Animal Genetics 30, 316-324.

Greig C, Jacobson DP, Banks MA (2003) New tetranucleotide microsatellites for finescale discrimination among endangered chinook salmon (Oncorhynchus tshawytscha). Molecular Ecology Notes 3, 376-379.

Healey MC (1991) The life history of chinook salmon (Oncorhynchus tshawytscha). In: Life history of Pacific salmon (eds. Groot C, Margolis L). University of British Columbia Press, Vancouver, B.C.

Hill MS, Zydlewski GB, Gale WL (2006) Comparisons between hatchery and wild steelhead trout (Oncorhynchus mykiss) smolts: physiology and habitat use. Canadian Journal of Fisheries and Aquatic Sciences 63, 1627-1638.

Hillman T, Miller M, Peven C, et al. (2008) Monitoring and evaluation of the Chelan County PUD hatchery programs. 2007 Annual Report. June 1, 2008. .

Hoffnagle TL, Carmichael RW, Frenyea KA, Keniry PJ (2008) Run timing, spawn timing, and spawning distribution of hatchery- and natural-origin spring Chinook salmon in the Imnaha River, Oregon. North American Journal of Fisheries Management 28, 148-164.

HSRG (2004) Hatchery Reform: Principles and Recommendations of the Hatchery Scientific Review Group.

ISAB (2003) Review of salmon and steelhead supplementation, pp. 1-205, Portland.

ISAB (2005) Monitoring and evaluation of supplementation projects.

Jonsson B (1997) A review of ecological and behavioural interactions between cultured and wild Atlantic salmon. 54, 1031-1039.

Knudsen CM, Schroder SL, Busack CA, et al. (2006) Comparison of life history traits between first-generation hatchery and wild upper Yakima river spring Chinook salmon. Transactions Of The American Fisheries Society 135, 1130-1144.

Kostow K, Marshall A, Phelps S (2003) Naturally spawning hatchery steelhead contribute to smolt production but experience low reproductive success. Transactions of the American Fisheries Society 132, 780-790.

Lahood ES, Miller JJ, Apland C, Ford MJ (2008) A rapid, ethanol-free fish tissue collection method for molecular genetic analyses. Transactions Of The American Fisheries Society 137, 1104-1107. 
Lande R, Arnold SJ (1983) The measurement of selection on correlated characters. Evolution 37, 1210-1226.

Leider SA, Hulett PL, Loch JJ, Chilcote MW (1990) Electrophoretic comparison of the reproductive success of naturally spawning transplanted and wild steelhead trout through the returning adult stage. Aquaculture 88, 239-252.

Lynch M, O'Hely H (2001) Captive breeding and the genetic fitness of natural populations. Conservation Genetics 2, 363-378.

Mallinson JJC (1995) Conservation breeding programmes: an important ingredient for species survival. Biodiversity and Conservation. 4:617-635.

McClure MM, Holmes EE, Sanderson BL, Jordan CE (2003) A large-scale, multispecies status assessment: anadromous salmonids in the Columbia River Basin. Ecological Applications 13, 964-989.

Meagher TR, Thompson E (1986) The relationship between single parent and parent pair genetic likelihoods in genealogy reconstruction. Theoretical Population Biology 29, 87-106.

Mobrand LE, Barr J, Blankenship L, et al. (2005) Hatchery reform in Washington State: principles amd emerging issues. Fisheries 30, 11-33.

Morgan MT, Conner JK (2001) Using genetic markers to directly estimate male selection gradients. Evolution 55, 272-281.

Mullan JW, Williams KR, Rhodus G, Hillman TW, McIntryre JD (1992) Production and Habitat of Salmonids in Mid-Columbia River Tributary Streams U.S. Fish and Wildlife Service.

Murdoch A, Pearsons T, Maitland T, Ford M, Williamson K (2008) Monitoring the reproductive success of naturally spawning hatchery and natural spring Chinook salmon in the Wenatchee River. BPA Project No. 2003-039-00. Bonneville Power Administration, Portland, Oregon. Available at http://pisces.bpa.gov/release/documents/documentviewer.aspx?doc=P106770. Department of Energy, Bonneville Power Administration.

Naish KA, Park LK (2002) Linkage relationships for 35 new microsatellite loci in chinook salmon Oncorhynchus tshawytscha. Animal Genetics 33, 316-318.

Naish KA, Taylor JE, Levin PS, et al. (2008) An evaluation of the effects of conservation and fishery enhancement hatcheries on wild populations of salmon. In: Advances In Marine Biology, pp. 61-194.

National Research Council (1996) Upstream: salmon and society in the Pacific Northwest National Academy Press, Washington DC. 
Nelson RJ, Beacham TD (1999) Isolation and cross species amplification of microsatellite loci useful for study of Pacific salmon. Animal Genetics 30, 225 244.

Nielsen R, Mattila D, Clapham P, Palsboll P (2001) Statistical approaches to paternity analysis in natural populations and applications to the North American humpback whale. Genetics 157, 1673 - 1682.

Olsen JB, Bentzen P, Seeb JE (1998) Characterization of seven microsatellite loci derived from pink salmon. Molecular Ecology 7, 1087-1089.

Pearsons TN, Fritts AL, Scott JL (2007) The effects of hatchery domestication on competitive dominance of juvenile spring Chinook salmon (Oncorhynchus tshawytscha). Canadian Journal Of Fisheries And Aquatic Sciences 64, 803-812.

Quinn TP (1993) A review of homing and straying of wild and hatchery-produced salmon. Fisheries Research 18, 19-44.

Quinn TP (2005) The behavior and ecology of Pacific salmon \& trout American Fisheries Society, Bethesda, Maryland.

Quinn TP (1984.) Homing and straying in chinook Salmon (Oncorhynchus tshawytscha ) from Cowlitz River hatchery, Washington. Can. J. Fish. Aquat. Sci. 41:10781082.

Reisenbichler RR, McIntyre JD (1977) Genetic differences in growth and survival of juvenile hatchery and wild steelhead trout, Salmo gairdneri. Journal of the Fisheries Research Board of Canada 34, 123-128.

Rich WH (1920) Early history and seaward migration of Chinook salmon in the Columbia and Sacramento Rivers. Bulletin of the Bureau of Fisheries 37, 78 p.

Riddell BE (1991) Competition between hatchery and wild coho salmon ( Oncorhynchus kisutch ): genetic variation for agonistic behaviour in newly-emerged wild fry. Aquaculture. 98:161-172.

Schroder SL, Knudsen CM, Pearsons TN, et al. (2008) Breeding success of wild and first-generation hatchery female spring Chinook salmon spawning in an artificial stream. Transactions of the American Fisheries Society 137, 1475-1489.

Schwenke PL, Rhydderch JG, Ford MJ, Marshall AR, Park LK (2006) Forensic identification of endangered Chinook Salmon (Oncorhynchus tshawytscha) using a multilocus SNP assay. Conservation Genetics 7, 983-989.

Seamons TR, Bentzen P, Quinn TP (2004) The effects of adult length and arrival date on individual reproductive success in wild steelhead trout (Oncorhynchus mykiss). Canadian Journal of Fisheries and Aquatic Sciences 61, 193-204. 
Smouse PE, Meagher TR (1994) Genetic analysis of male reproductive contributions in Chamaelirium luteum (L.) Gray (Liliaceae). Genetics 136, 313-322.

UCSRB (2007) Upper Columbia Salmon Recovery Board, Upper Columbia spring Chinook salmon and steelhead recovery plan. August 2007.

Utter FM, Chapman DW, Marshal AR (1995) Genetic population structure and history of chinook salmon of the Upper Columbia River. American Fisheries Society Symposium 17, 149-168.

Williams R, Lichatowich J, Mundy P, Powell M (2003) Integrating artificial production with salmonid life history, genetic, and ecosystem diversity: a landscape perspective. Trout Unlimited.

Winans GA, Paquin MM, Van Doornik DM, et al. (2004) Genetic stock identification of steelhead in the Columbia River Basin: An evaluation of different molecular markers. North American Journal Of Fisheries Management 24, 672-685. 


\title{
Chapter 3 - Comparison of spawning site and redd characteristics of hatchery and naturally produced female spring Chinook salmon of known size in the Wenatchee River Basin
}

\begin{abstract}
While differences have been reported in the relative reproductive success of hatchery and naturally produced salmonids Oncorhynchus spp., factors explaining the differences are often confounded. We examined the spawning site habitat and redd structure variables of hatchery and naturally produced spring Chinook salmon O. tshawytscha of known size that spawned in two tributaries of the Wenatchee River. We controlled for variability in spawning habitat by limiting our analysis to redds found within four selected reaches. No difference in the instantaneous spawner density or location of the redd in the stream channel was detected between reaches. Within each reach, no difference in the fork length or weight of hatchery and naturally produced fish was detected. While most variables differed between reaches, we found no difference in redd characteristics within a reach between hatchery and naturally produced females. Correlation analysis of fish size and redd characteristics found several weak but significant relationships suggesting larger fish construct larger redds in deeper water. Spawner density was inversely related to several redd structure variables suggesting redd size may decrease as spawner density increases. Results should be considered preliminary until sample sizes and statistical power goals are reached in future years.
\end{abstract}

\section{Introduction}

The breeding success of hatchery salmon and steelhead in the natural environment has been reported to be less than that of their naturally produced conspecifics (Ford 2002, Araki et al. 2008). Differences in breeding success or fitness between hatchery and natural origin salmonids has been linked to genetics effects resulting from domestication selection in the hatchery environment (Busack and Currens 1995, Lynch and O'Hely 2001). Domestication selection can manifest as differences in morphological (Fleming and Gross 1992; Knudsen et al. 2006; Busack et al. 2007) and behavioral (Fleming and Gross 1992; Schroder et al. 2008) traits between hatchery and naturally produced fish. Understanding how these differences influence the fitness of hatchery fish in the natural environment would assist in the modification of hatchery practices or programs intended to conserve or rebuild populations.

Quantifying differences in morphological traits of hatchery and naturally produced salmonids is a relatively simple task that may explain part of the observed difference in fitness. For example, if female hatchery fish have on average $80 \%$ of the number eggs of a wild female, the we would expect the relative reproductive success of hatchery fish to be no greater than $80 \%$ of naturally produced fish. Behavioral differences are more difficult to quantify, in part due to our inability to observe differences even in controlled environments. Furthermore, uncertainty does still exist as to which traits are the most important in terms of breeding success. Most studies examining the breeding behavior of hatchery and natural produced fish were conducted in artificial streams because a 
controlled environment provides opportunity to conduct extensive observations (Fleming and Gross 1992; Fleming and Gross 1993; Fleming et al. 1997; Schroder et al. 2008). Application of results from artificial or semi-natural environments to the natural environment does raise some concern because of the lack of natural variability of the habitat in these studies.

However, regardless of the species studied, consistency in the results of these studies create an ever increasing argument that the results are useful in making inferences regarding breeding behavior of hatchery and naturally produced fish in the natural environment. Common among these studies was the conclusion that at low densities most types of breeding behaviors (longevity, redd location, number of nests, digging frequency, and time required to cover eggs) were similar for hatchery and naturally produced fish (Fleming and Gross 1992; Fleming et al. 1997; Schroder et al. 2008). Fleming and Gross (1993) reported that as competition increased among male and female coho salmon Oncorhynchus kisutch increased, as a function of increasing density, hatchery males were less aggressive and hatchery females deposited a lesser proportion of her eggs in the nests than wild fish. Under competition, hatchery males and females experienced only $62 \%$ and $82 \%$ breeding success of wild fish, respectively. Fleming et al. (1997) found that male hatchery Atlantic salmon Salmo salar were also less aggressive under competition and were only $51 \%$ as reproductively fit as wild male Atlantic salmon, but found no difference for females. In that experiment, a single wild male versus multiple hatchery males tended to spawn with a single female. Schroder et al. (2008) also reported similar trends in egg retention of female spring Chinook salmon O. tshawytscha as the density increased within an artificial spawning channel.

One important difference among these studies was the life stage at which reproductive success was evaluated. Schroder et al. (2008) estimated reproductive success at the fry stage and found wild female spring Chinook salmon had a 5.6\% advantage over hatchery females. Studies with coho salmon (Fleming and Gross 1992) and Atlantic salmon (Fleming et al. 1997) at low densities estimated breeding success at the eyed egg stage and found no difference among hatchery and naturally produced females. Schroder et al. (2008) suggested that subtle differences in redd abandonment, egg burial, and redd location may be responsible for the observed difference in fry survival. The cumulative effect of those differences over a greater time period (i.e., fry versus eyed egg) may have resulted in differences in breeding success that were simply not expressed at the eyed eggs stage.

Spawning site selection is a critical behavior exhibited by female salmonids. Studies examining the breeding behavior often try to minimize much of the environmental variability (substrate, water depth, and water velocity) so that inferences made about behavior differences and any effect on survival would not be confounded. Given the large variability of potential spawning sites in the natural environment, it is not unreasonable to expect the subtle differences in behavior observed in artificial environments are more accentuated in natural environments (Schroder et al. 2008). Following that logic, the culmination of breeding results in a construction of one or more egg pockets containing fertilized eggs, otherwise referred to a redd. If a redd is the end result of breeding before senescence, then examining differences among redds may provide insight to differences in breeding behavior in the natural environment. 
Quantifying differences in spawning site selection and redd characteristics may provide information regarding breeding behavior that could be used to explain some of the variability observed in reproductive success.

Fish size may influence redd size (Crisp and Carling 1989), egg burial depth (van den Berghe and Gross 1984; Steen and Quinn 1999), and the habitat, hereafter referred to spawning site, in which a redd was constructed (Crisp and Carling 1989). Because hatchery fish may return as adults at an earlier age or smaller size (Knudsen et al 2006), knowledge of female size constructing a redd would control for any size-related differences in order to determine if any differences in redd structure or spawning site habitat existed between hatchery and naturally produced fish. Our objectives of this study were to 1) describe spawning site and redd characteristics of spring Chinook salmon in the selected reaches; 2) compare spawning site and redd habitat characteristics of hatchery and naturally produced female spring Chinook and 3) explore possible relationships between female size (fork length and weight) and any spawning site and redd characteristics.

\section{Methods}

\section{Trapping and Spawning Ground Surveys}

Female spring Chinook salmon were trapped at Tumwater Dam (rkm 43.7), approximately $30 \mathrm{~km}$ downstream of current and historical spring Chinook salmon spawning habitat (Figure 1). A fish ladder and trapping facility are located on the left bank of the dam. Trapped spring Chinook salmon were transferred from the trap into a sampling tank $\left(0.38 \mathrm{~m}^{3}\right)$ containing MS-222 (88 ppm). Biological data were collected from all spring Chinook. Each fish was identified to gender and scanned for passive integrated transponder (PIT) tags and coded wire tags (CWT). Fork length was measured to the nearest $\mathrm{cm}$ and weight to the nearest $0.01 \mathrm{~kg}$. Scale and genetic tissue samples $(0.5$ $\mathrm{cm}^{2}$ caudal fin clip) were collected from every spring Chinook. The presence or absence of the adipose fin was also recorded. Lastly, a PIT tag was inserted into the dorsal sinus cavity on the left side of the body (age 4 and age 5) or body cavity (age 2 and age 3 ). After sampling, fish were placed into a recovery tank and allowed to fully recover before being released.

Redd size may also be a function of habitat quality and quantity (Burner 1951). We controlled for potential differences in spawning habitat quality and quantity by focusing our analysis specific river reaches in the Chiwawa River (Chiwawa $1=17.0 \mathrm{~km}$; Chiwawa $2=6.1 \mathrm{~km}$ ) and Nason Creek (Nason $1=7.2 \mathrm{~km}$; Nason $2=5.0 \mathrm{~km}$ ) with the most similar proportions of hatchery and natural origin fish based on historical carcass recovery data (WDFW, unpublished data). Each reach was surveyed twice a week by foot. When new redds were found, the origin and fork length of the live female was determined by PIT tag detection when possible (Murdoch et al. 2009). Post spawned females guarding redds were scanned for PIT tags using an underwater antenna mounted on an extension pole. Using this technique, we were able to identify an individual fish and correspond the PIT tag with biological data collected at Tumwater Dam. Redds were identified as locations that had areas of clean gravel which also exhibited the typical redd 
morphological characteristics (e.g., well developed bowl and tail spill). Test redds were identified as locations that had areas of clean gravel, but lacked typical redd

morphological characteristics (e.g., no tail spill). Each redd was assigned a unique waypoint using a handheld global positioning device (GPS), marked with surveyors flagging attached to nearby vegetation, and recorded in a field notebook. Error associated with handheld GPS devices was reduced by orientating the device until the minimum estimated percent error (EPE) was established (i.e., typically no greater than 10 $\mathrm{m})$. Spawning site and redd habitat variables were measured only on completed redds of PIT tagged females detected on redds. 


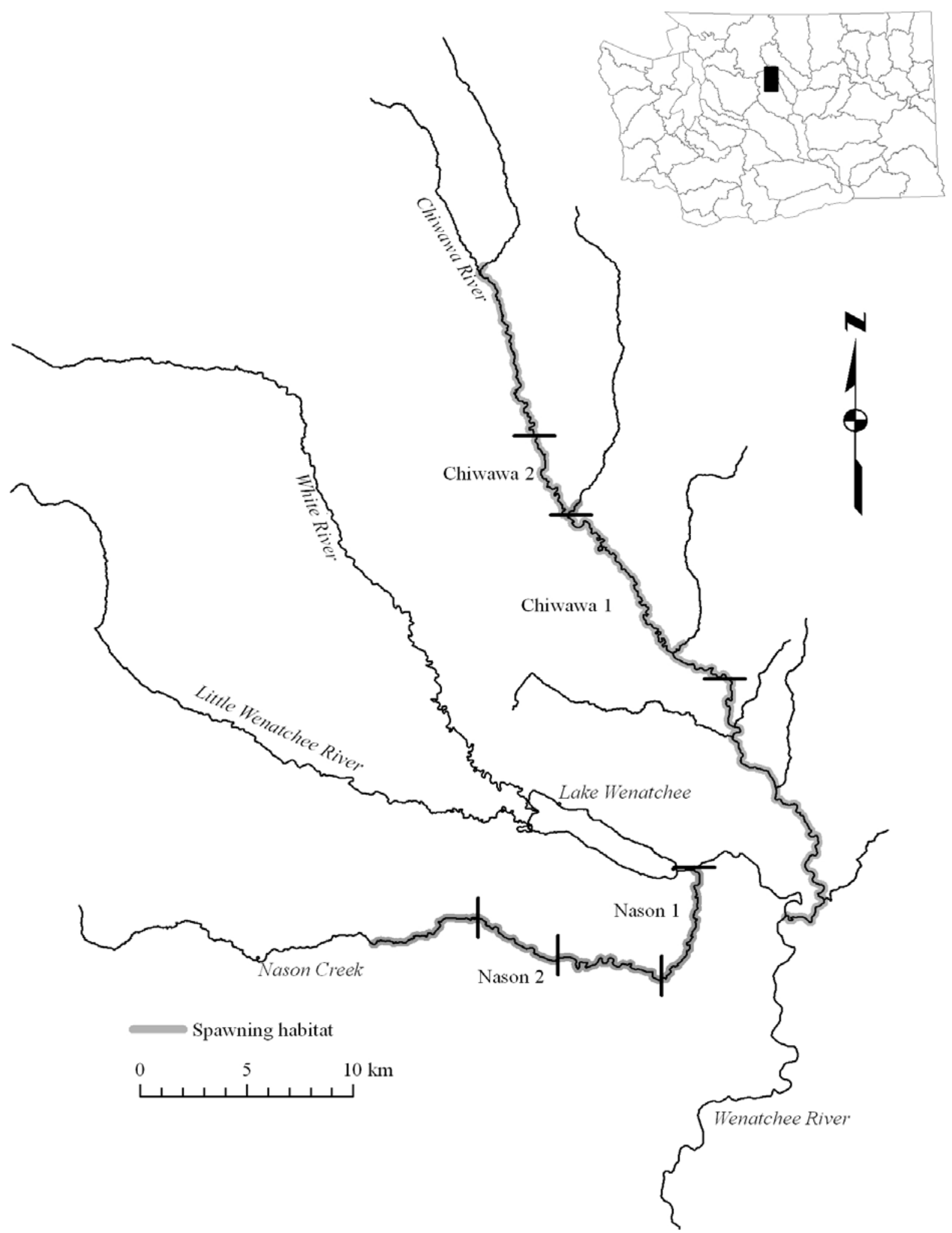

Figure 1. Vicinity map of upper Wenatchee River Basin and selected reaches where microhabitat data was collected on redds constructed by hatchery and naturally produced spring Chinook salmon. 


\section{Spawning Site Habitat}

Selection of a spawning site by a female may be influenced by both the physical habitat as well as biological factors (i.e., competition among females). Hence, spawning site habitat variables were used to describe the general physical habitat in which redds were constructed and some the relationship to other existing redds and are listed in Table 1. Fleming and Gross (1993) reported that as spawner density increased, female hatchery coho salmon constructed redds in the center of the spawning channel while wild females constructed redds along the margins. Because redd location within the channel may influence reproductive success if redds constructed in the middle of channel are more susceptible to scouring, we developed an index of redd location relative to the width of the stream. Redd location was calculated by dividing the distance from the center of the redd to the nearest stream bank by the total wetted width of the stream. For example, a redd constructed in the exact middle of the channel would have a redd location value of 0.5 . Likewise, redds constructed on the edge of the wetted channel would have a redd location value of 0.0 .

Competition between hatchery and wild coho salmon has also been shown to reduce the reproductive success for both males and females (Fleming and Gross 1993). As spawner density increases, egg retention has also been reported to increase, regardless of origin (Fleming and Gross 1992; Schroder et al. 2008). The influence of competition on spawning site selection and redd structure was assessed using an index of spawner density calculated by determining the number of redds within a $5 \mathrm{~m}$ radius that were constructed during the estimated lifespan of the female (WDFW, unpublished data).

\section{Redd Microhabitat}

Water depth measurements (nearest $\mathrm{cm}$ measured at 0.6 times the water depth) were taken at the upstream side of the bowl, the deepest point within the bowl, the upstream end of the tail, the shallowest point of the tail (tail apex), the downstream end of the tail, and left and right side of the redd (Figure 2). Water velocity $(\mathrm{m} / \mathrm{s})$ was measured using a Marsh McBirney Model 2000 or Swoffer Model 2100 flow meters. Water velocity was recorded at the upstream end of the bowl (60\% depth), maximum depth of the bowl $(60 \%$ depth), upstream end of the tail ( $60 \%$ depth, surface, bottom), downstream end of the tail (60\% depth), and the left and right side of the redd (60\% depth). Average redd water depth was calculated from water depth measurements recorded at the left and right side of the redd and the upstream end of the bowl. Average tail depth and velocity was calculated from measurements recorded at the left, right, and center (i.e., tail front) of the tail. The length and width of the redd was recorded to the nearest $0.1 \mathrm{~m}$. As were the length of the bowl and tail. The depth of bowl was calculated by subtracting the average redd water depth from the maximum depth of the bowl. Tail height was derived by subtracting the depth at the tail apex from the average depth measured at the right and left margins of the redd. Substrate composition percentage was visually estimated for the bowl and tail and classified as sand $(<2 \mathrm{~mm})$, gravel $(2-63 \mathrm{~mm})$, cobble $(64-256$ $\mathrm{mm})$, or boulder $(>256 \mathrm{~mm})$. 
Table 1. Spawning site and redd microhabitat characteristics of hatchery and naturally produced spring Chinook redds in the Wenatchee River basin.

\begin{tabular}{|c|c|}
\hline Trait/Symbol & Definition \\
\hline \multicolumn{2}{|r|}{ Spawning site } \\
\hline Habitat type & Pool, riffle, glide (Arend 1999) \\
\hline Stream width & Wetted channel width $(\mathrm{m})$ \\
\hline Left bank & Distance for edge of redd to wetted left bank (m) \\
\hline Right bank & Distance for edge of redd to wetted right bank (m) \\
\hline Nearest bank & Distance for edge of redd to nearest wetted bank (m) \\
\hline Redd position & Position of redd in relation to the center of the channel \\
\hline Nearest cover & Distance to near cover type $(\mathrm{m})$ \\
\hline Cover type & $\begin{array}{l}\text { Overhanging vegetation, large woody debris, deep water, fast } \\
\text { water, boulders, undercut bank }\end{array}$ \\
\hline Nearest redd & Distance to nearest redd at time of construction (m) \\
\hline Redd density & $\begin{array}{l}\text { Number of redds located within a } 5 \mathrm{~m} \text { radius of the redd at time of } \\
\text { construction. }\end{array}$ \\
\hline \multicolumn{2}{|r|}{ Redd dimensions (m) } \\
\hline Redd width & Maximum width of redd \\
\hline Redd length & Maximum length of redd \\
\hline Bowl length & Length of bowl \\
\hline Tail length & Length of tail \\
\hline Bowl depth & Maximum water depth in the bowl minus mean redd water depth. \\
\hline Tail height & $\begin{array}{l}\text { Average tail depth measured at the right and left of the tail minus } \\
\text { the depth at the tail apex. }\end{array}$ \\
\hline \multicolumn{2}{|r|}{ Water depth (m) } \\
\hline Bowl front & Upstream side of the bowl \\
\hline Bowl maximum & Deepest point in the bowl \\
\hline Redd left & Transition point between bowl and tail on left side of the redd \\
\hline Redd right & Transition point between bowl and tail on right side of the redd \\
\hline Tail front & Transition point between bowl and tail center of the redd \\
\hline Tail back & Downstream side of the tail \\
\hline Tail apex & Highest point on the tail \\
\hline \multicolumn{2}{|r|}{ Water velocity $(\mathrm{m} / \mathrm{s})$} \\
\hline Bowl front & Upstream side of the bowl \\
\hline Bowl maximum & Deepest point in the bowl \\
\hline Redd left & Transition point between bowl and tail on left side of the redd \\
\hline Redd right & Transition point between bowl and tail on right side of the redd \\
\hline Tail front & Transition point between bowl and tail center of the redd \\
\hline Tail back & Downstream side of the tail \\
\hline \multicolumn{2}{|r|}{ Substrate (\%) } \\
\hline Bowl & $\begin{array}{l}\text { Sand }(<2 \mathrm{~mm}) \text {, gravel }(2-63 \mathrm{~mm}) \text {, cobble }(64-256 \mathrm{~mm}) \text {, or } \\
\text { boulder }(>256 \mathrm{~mm}) .\end{array}$ \\
\hline Tail & $\begin{array}{l}\text { Sand }(<2 \mathrm{~mm}) \text {, gravel }(2-63 \mathrm{~mm}) \text {, cobble }(64-256 \mathrm{~mm}) \text {, or } \\
\text { boulder }(>256 \mathrm{~mm}) .\end{array}$ \\
\hline
\end{tabular}


(a)

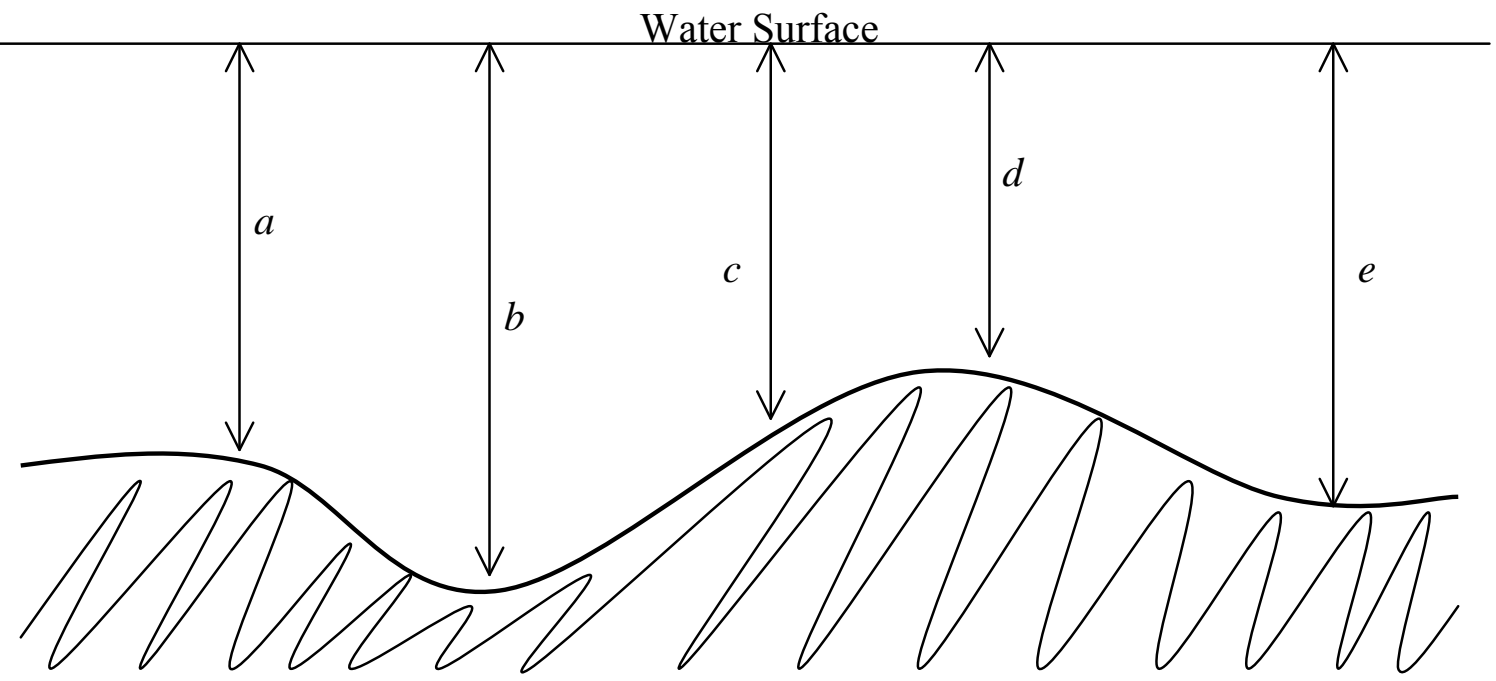

(b)

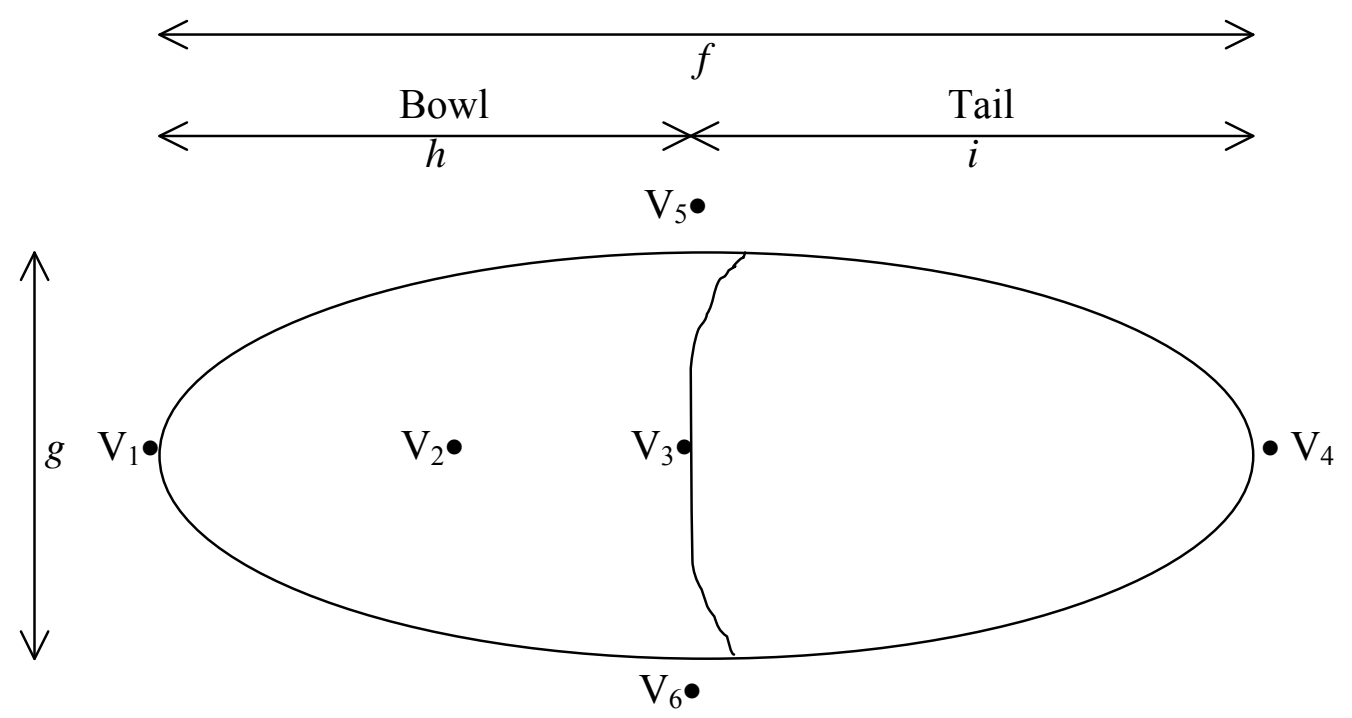

Figure 2. (a) Longitudinal section and (b) plan view of a salmonid redd. Italic letters indicate measurements of water depth and redd dimensions: $a$ is water depth upstream of bowl; $b$ is water depth at the deepest point of the bowl; $c$ is water depth as transition point of bowl and tail; $d$ is water depth at shallowest point of the tail; $e$ is water depth at the downstream point of the tail; $f$ is the total length of the redd; $g$ is the total width of the redd; $h$ is the length of the bowl; $i$ is the length of the tail. Water velocity was measured at 0.6 times the water depth at various locations: $\mathrm{V}_{1}$ is upstream of the bowl; $\mathrm{V}_{2}$ is the deepest point of the bowl; $\mathrm{V}_{3}$ is the transition point between the bowl and tail; $\mathrm{V}_{4}$ is downstream of the tail; $\mathrm{V}_{5}$ is the left side of the redd; and $\mathrm{V}_{6}$ is the right side of the redd. Figure was adapted from Crisp and Carling (1989) and Schmetterling (2000). 


\section{Data Analysis}

Data normality and homogeneity of variances assumptions were examined using the Shapiro-Wilk's $W$ test and Levene's test, respectively. Differences in female fork length and weight (log transformed) among reaches and origins were examined using an analysis of variance (ANOVA). Habitat unit types (i.e., glide and riffle) and associated cover types selected by naturally produced and hatchery female Chinook salmon were tested using a Chi-square goodness of fit test. The frequency distributions of naturally produced females were used as expected frequencies and were calculated by summing the number in each category by river and dividing by the total number. Yates correction for continuity was used for the analysis of habitat unit types because the degrees of freedom equaled one (Zar 1999). Habitat variables and substrate composition data did not meet assumptions of normality or homogeneity of variances. A Kruskal-Wallis ANOVA was used to compare spawning site and redd characteristics of hatchery and naturally produced redds. Substrate classes were analyzed by reach for the bowl and tail separately. When significant differences were detected, multiple comparisons tests were used to determine if the difference was between hatchery and naturally produced redds within the same reach or simply a difference between reaches. Non-normality of data required the use of the Spearman rank correlation coefficient $\left(\mathrm{r}_{\mathrm{s}}\right)$ to examine relationships between biological (length and weight) and spawning site and redd structure variables. All statistical tests were performed at a significance level $(\alpha)$ of 0.05 .

\section{Results}

Between 2005 and 2008, we detected 448 female spring Chinook on redds in selected reaches of the Chiwawa River (70\%) and Nason Creek (30\%). Data were pooled across years (2005-2008) in order to increase samples size. Murdoch et al. (2007) conducted a power analysis of selected habitat variables and reported that a samples size between 150 and 300 may be required to obtain the desired power of 0.8 . Hence, results should be considered preliminary until a larger sample size is obtained over the next several years. Of the female spring Chinook detected on redds, differences in fork length were detected between reaches (ANOVA: $P<0.05$ ) and origins (ANOVA: $P<0.05$ ), but not between origins within a reach (ANOVA reach $X$ origin interaction: $P=0.20$ ). No differences in weight were detected (ANOVA: $P>0.27$; Table 2).

Table 2. Mean fork length $(\mathrm{cm})$ and weight $(\mathrm{kg})$ of female spring Chinook salmon detected on redds in the Wenatchee River Basin between 2005 and 2008.

\begin{tabular}{|c|c|c|c|c|c|c|c|c|c|c|c|c|}
\hline \multirow{3}{*}{$\begin{array}{l}\text { River } \\
\text { Reach }\end{array}$} & \multicolumn{6}{|c|}{ Naturally produced } & \multicolumn{6}{|c|}{ Hatchery } \\
\hline & \multicolumn{3}{|c|}{ Fork length } & \multicolumn{3}{|c|}{ Weight } & \multicolumn{3}{|c|}{ Fork length } & \multicolumn{3}{|c|}{ Weight } \\
\hline & Mean & $\mathrm{SE}$ & $\mathrm{N}$ & Mean & SE & $\mathrm{N}$ & Mean & $\mathrm{SE}$ & $\mathrm{N}$ & Mean & $\mathrm{SE}$ & $\mathrm{N}$ \\
\hline Chiwawa 1 & 82.1 & 0.8 & 40 & 5.66 & 0.18 & 40 & 80.9 & 0.5 & 125 & 5.50 & 0.10 & 125 \\
\hline Chiwawa 2 & 83.7 & 0.9 & 31 & 6.00 & 0.21 & 31 & 80.2 & 0.5 & 117 & 5.38 & 0.11 & 117 \\
\hline Nason 1 & 79.8 & 1.7 & 9 & 5.75 & 0.39 & 9 & 78.7 & 0.6 & 71 & 5.85 & 0.14 & 71 \\
\hline Nason 2 & 80.3 & 1.0 & 27 & 5.78 & 0.22 & 27 & 80.3 & 1.0 & 28 & 5.76 & 0.22 & 28 \\
\hline
\end{tabular}




\section{Spawning Site and Redd Characteristics}

Hatchery and naturally produced female spring Chinook salmon selected spawning sites in similar frequencies in both the Chiwawa River $\left(\chi^{2}=0.18, \mathrm{df}=1, P=0.67\right)$ and Nason Creek $\left(\chi^{2}=0.51, \mathrm{df}=1, P=0.47\right)$. Glides were the dominant habitat type in both the Chiwawa River (75\%) and Nason Creek (80\%) followed by riffles. Nearest cover types associated with naturally produced and hatchery female spawning sites differed in the Chiwawa River $\left(\chi^{2}=0.152 .3, \mathrm{df}=5, P<0.001\right)$, but not in Nason Creek $\left(\chi^{2}=0.5 .8, \mathrm{df}=\right.$ $5, P=0.33)$. The dominant nearest type of cover associated with spawning sites in the Chiwawa River (42\%) and Nason Creek (43\%) for both naturally produced and hatchery females was large woody debris. However, hatchery females in the Chiwawa River selected sites associated with overhanging vegetation and boulders at greater frequencies than naturally produced fish. No difference in spawning site variables between reaches was found for spawner density ( $\mathrm{KW}$ test: $\mathrm{H}=13.8, \mathrm{df}=7, P=0.056$ ), redd position (KW test: $\mathrm{H}=8.7, \mathrm{df}=7, P=0.28$ ), distance to nearest bank ( $\mathrm{KW}$ test: $\mathrm{H}=13.3, \mathrm{df}=7, P=$ 0.065 ), and distance to left bank ( $\mathrm{KW}$ test: $\mathrm{H}=12.0, \mathrm{df}=7, P=0.10$ ). Differences were detected in the stream width of spawning sites between reaches $(\mathrm{KW}$ test: $\mathrm{H}=48.4, \mathrm{df}=$ $7, P<0.001)$, but within each reach no difference was found between hatchery and naturally produced spawning sites (multiple comparison test: $P=1.0$ ). Similarly, differences between reaches were found for the distance to the nearest redd, nearest cover, and distance to right bank, but not between spawning sites of hatchery and naturally produced female spring Chinook within the same reach.

All redd characteristics were significantly different among reaches except for tail length (KW test: $\mathrm{H}=5.7, \mathrm{df}=7, P=0.58)$ and water velocity downstream of the tail ( $\mathrm{KW}$ test: $\mathrm{H}=13.1, \mathrm{df}=7, P=0.07$ ). However, as was the case for spawning site variables, no differences between hatchery and naturally produced redd characteristics were found within the same reach for either the Chiwawa River (Table 3) or Nason Creek (Table 4). Differences between the mean percentage of each substrate class were also found in all reaches (KW Test: $P<0.001)$, but no difference $(P=1.0)$ was detected within each class among hatchery and naturally produced redds (Figure 3 ). In the Chiwawa River, gravel was the dominant substrate class and comprised $56 \%$ and $64 \%$ of the bowl and tail, respectively. Substrate composition of redds in Nason Creek comprised a lesser amount of gravel (35\% bowl and $41 \%$ tail) and a greater amount of cobble (32\% bowl and $45 \%$ tail) compared to the Chiwawa River. Cobble was the dominant substrate class in the Nason 2 reach. 
Table 3. Descriptive statistics (mean, SD) of spawning site and redd variables measured for Chiwawa River spring Chinook between 2005 and 2008 (NP = naturally produced; H = hatchery).

\begin{tabular}{|c|c|c|c|c|}
\hline \multirow{3}{*}{ Habitat variable } & \multicolumn{4}{|c|}{ River Reach } \\
\hline & \multicolumn{2}{|c|}{ Chiwawa 1} & \multicolumn{2}{|c|}{ Chiwawa 2} \\
\hline & $\mathrm{NP}(\mathrm{N}=40)$ & $\mathrm{H}(\mathrm{N}=125)$ & $\mathrm{NP}(\mathrm{N}=31)$ & $\mathrm{H}(\mathrm{N}=117)$ \\
\hline \multicolumn{5}{|c|}{ Spawning site } \\
\hline Stream width (m) & $21.1(8.4)$ & $19.7(7.5)$ & $21.6(7.2)$ & $22.6(6.9)$ \\
\hline Left bank (m) & $8.4(6.8)$ & $7.6(6.8)$ & $7.7(6.7)$ & $9.7(7.5)$ \\
\hline Right bank (m) & $8.2(6.6)$ & $7.65(6.4)$ & $9.8(7.3)$ & $9.1(7.5)$ \\
\hline Nearest bank (m) & $4.1(3.4)$ & $3.4(2.9)$ & $3.8(3.1)$ & $3.9(3.7)$ \\
\hline Redd position & $0.3(0.1)$ & $0.30(0.12)$ & $0.28(0.12)$ & $0.26(0.13)$ \\
\hline Nearest cover (m) & $2.3(3.1)$ & $2.7(4.4)$ & $3.8(8.0)$ & $4.4(4.9)$ \\
\hline Nearest redd (m) & $30(110)$ & $30(70)$ & $60(90)$ & $40(50)$ \\
\hline Redd density & $1.1(0.2)$ & $1.3(0.8)$ & $1.1(0.3)$ & $1.0(0.0)$ \\
\hline \multicolumn{5}{|c|}{ Redd dimensions (m) } \\
\hline Redd width & $4.5(1.4)$ & $4.4(1.2)$ & $4.1(1.3)$ & $3.9(1.0)$ \\
\hline Redd length & $7.4(1.6)$ & $7.0(1.7)$ & $6.3(2.2)$ & $6.5(1.6)$ \\
\hline Bowl length & $3.3(1.2)$ & $3.0(1.0)$ & $2.5(1.0)$ & $2.5(1.0)$ \\
\hline Tail length & $4.1(1.3)$ & $4.0(1.2)$ & $3.8(1.6)$ & $4.0(1.2)$ \\
\hline Bowl depth & $0.18(0.08)$ & $0.17(0.09)$ & $0.16(0.07)$ & $0.14(0.07)$ \\
\hline Tail depth & $0.21(0.11)$ & $0.19(0.09)$ & $0.19(0.11)$ & $0.17(0.09)$ \\
\hline \multicolumn{5}{|c|}{ Water depth (m) } \\
\hline Bowl front & $0.45(0.17)$ & $0.52(0.19)$ & $0.46(0.19)$ & $0.39(0.17)$ \\
\hline Bowl maximum & $0.58(0.17)$ & $0.63(0.18)$ & $0.55(0.18)$ & $0.48(0.15)$ \\
\hline Redd left & $0.40(0.16)$ & $0.43(0.17)$ & $0.35(0.18)$ & $0.33(0.15)$ \\
\hline Redd right & $0.36(0.16)$ & $0.43(0.16)$ & $0.36(0.16)$ & $0.31(0.15)$ \\
\hline Tail front & $0.43(0.12)$ & $0.47(0.14)$ & $0.41(0.14)$ & $0.37(0.13)$ \\
\hline Tail back & $0.32(0.11)$ & $0.38(0.17)$ & $0.32(0.14)$ & $0.28(0.12)$ \\
\hline Tail apex & $0.17(0.09)$ & $0.24(0.12)$ & $0.17(0.13)$ & $0.15(0.10)$ \\
\hline \multicolumn{5}{|c|}{ Water velocity $(\mathrm{m} / \mathrm{s})$} \\
\hline Bowl front & $0.46(0.17)$ & $0.53(0.19)$ & $0.42(0.17)$ & $0.46(0.23)$ \\
\hline Bowl maximum & $0.41(0.15)$ & $0.46(0.16)$ & $0.36(0.16)$ & $0.40(0.21)$ \\
\hline Redd left & $0.44(0.29)$ & $0.48(0.24)$ & $0.35(0.20)$ & $0.44(0.24)$ \\
\hline Redd right & $0.45(0.23)$ & $0.48(0.20)$ & $0.43(0.25)$ & $0.40(0.24)$ \\
\hline Tail front & $0.45(0.16)$ & $0.54(0.19)$ & $0.41(0.17)$ & $0.44(0.24)$ \\
\hline Tail back & $0.50(0.31)$ & $0.57(0.31)$ & $0.41(0.27)$ & $0.54(0.33)$ \\
\hline Tail mean & $0.42(0.14)$ & $0.49(0.16)$ & $0.38(0.14)$ & $0.41(0.19)$ \\
\hline
\end{tabular}


Table 4. Descriptive statistics (mean, SD) of spawning site and redd variables measured for Nason Creek spring Chinook between 2005 and 2008 (NP = naturally produced; $\mathrm{H}=$ hatchery).

\begin{tabular}{|c|c|c|c|c|}
\hline \multirow{3}{*}{ Habitat variable } & \multicolumn{4}{|c|}{ River Reach } \\
\hline & \multicolumn{2}{|c|}{ Nason 1} & \multicolumn{2}{|c|}{ Nason 2} \\
\hline & $\mathrm{NP}(\mathrm{N}=9)$ & $\mathrm{H}(\mathrm{N}=71)$ & $\mathrm{NP}(\mathrm{N}=27)$ & $\mathrm{H}(\mathrm{N}=28)$ \\
\hline \multicolumn{5}{|c|}{ Spawning site } \\
\hline Stream width (m) & $15.2(7.6)$ & $16.8(7.9)$ & $16.2(5.8)$ & $16.6(5.4)$ \\
\hline Left bank (m) & $7.9(8.0)$ & $6.6(7.2)$ & $5.4(3.8)$ & $6.9(5.7)$ \\
\hline Right bank (m) & $3.8(4.4)$ & $6.6(6.1)$ & $6.6(6.2)$ & $5.5(5.3)$ \\
\hline Nearest bank (m) & $1.6(2.0)$ & $2.7(2.5)$ & $2.7(1.9)$ & $2.5(2.0)$ \\
\hline Redd position & $0.24(0.12)$ & $0.29(0.12)$ & $0.31(0.11)$ & $0.30(0.13)$ \\
\hline Nearest cover (m) & $8.3(8.4)$ & $6.0(6.2)$ & $5.6(5.9)$ & $10.1(10.7)$ \\
\hline Nearest redd (m) & $30(40)$ & $90(310)$ & $70(70)$ & $80(90)$ \\
\hline Redd density & $1.1(0.2)$ & $1.9(0.5)$ & $1.3(1.0)$ & $1.0(0.0)$ \\
\hline \multicolumn{5}{|c|}{ Redd dimensions (m) } \\
\hline Redd width & $3.5(0.62)$ & $3.6(1.0)$ & $4.1(0.9)$ & $4.3(1.0)$ \\
\hline Redd length & $5.8(1.4)$ & $5.6(1.3)$ & $6.7(1.1)$ & $6.7(1.4)$ \\
\hline Bowl length & $1.7(0.8)$ & $1.9(0.7)$ & $2.6(0.6)$ & $2.6(0.8)$ \\
\hline Tail length & $4.1(1.0)$ & $3.7(1.0)$ & $4.1(1.0)$ & $4.1(1.1)$ \\
\hline Bowl depth & $0.12(0.07)$ & $0.09(0.04)$ & $0.13(0.03)$ & $0.13(0.07)$ \\
\hline Tail depth & $0.14(0.08)$ & $0.15(0.06)$ & $0.14(0.07)$ & $0.14(0.07)$ \\
\hline \multicolumn{5}{|c|}{ Water depth (m) } \\
\hline Bowl front & $0.29(0.07)$ & $0.33(0.09)$ & $0.34(0.13)$ & $0.32(0.08)$ \\
\hline Bowl maximum & $0.37(0.08)$ & $0.39(0.08)$ & $0.42(0.10)$ & $0.42(0.09)$ \\
\hline Redd left & $0.22(0.09)$ & $0.28(0.08)$ & $0.26(0.12)$ & $0.27(0.10)$ \\
\hline Redd right & $0.26(0.15)$ & $0.29(0.10)$ & $0.26(0.08)$ & $0.27(0.09)$ \\
\hline Tail front & $0.29(0.07)$ & $0.31(0.08)$ & $0.32(0.10)$ & $0.33(0.09)$ \\
\hline Tail back & $0.24(0.13)$ & $0.25(0.08)$ & $0.21(0.08)$ & $0.22(0.10)$ \\
\hline Tail apex & $0.10(0.06)$ & $0.14(0.07)$ & $0.13(0.07)$ & $0.13(0.07)$ \\
\hline \multicolumn{5}{|c|}{ Water velocity $(\mathrm{m} / \mathrm{s})$} \\
\hline Bowl front & $0.40(0.14)$ & $0.39(0.16)$ & $0.37(0.15)$ & $0.41(0.15)$ \\
\hline Bowl maximum & $0.22(0.07)$ & $0.35(0.10)$ & $0.33(0.11)$ & $0.39(0.13)$ \\
\hline Redd left & $0.39(0.21)$ & $0.31(0.17)$ & $0.34(0.12)$ & $0.37(0.18)$ \\
\hline Redd right & $0.34(0.20)$ & $0.32(0.17)$ & $0.41(0.15)$ & $0.31(0.16)$ \\
\hline Tail front & $0.43(0.09)$ & $0.38(0.13)$ & $0.37(0.11)$ & $0.41(0.14)$ \\
\hline Tail back & $0.45(0.21)$ & $0.48(0.24)$ & $0.57(0.22)$ & $0.50(0.26)$ \\
\hline Tail mean & $0.38(0.09)$ & $0.33(0.12)$ & $0.34(0.10)$ & $0.37(0.13)$ \\
\hline
\end{tabular}



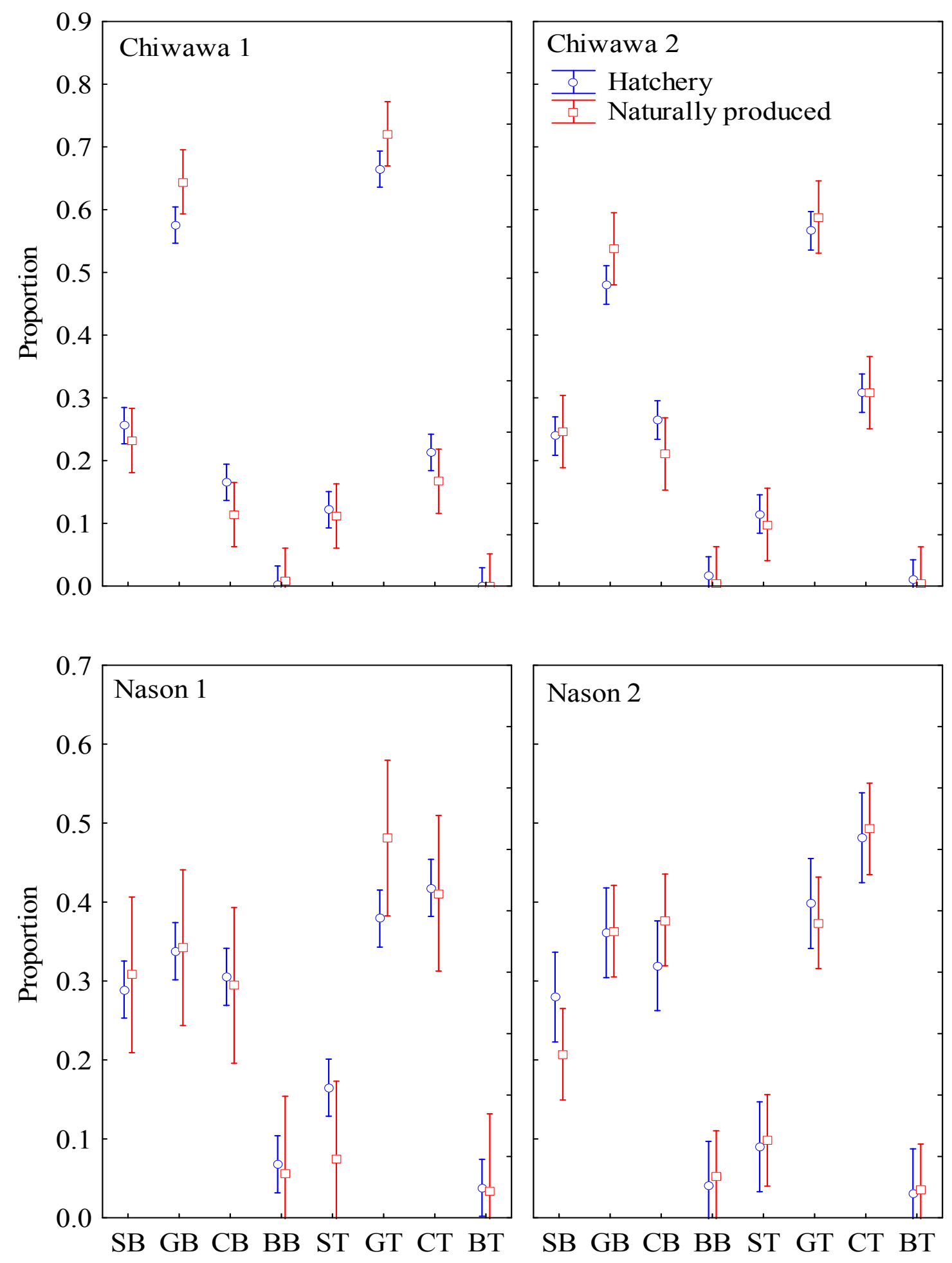

Figure 3. Mean proportion of substrate classes visually estimated in spring Chinook salmon redds in selected reaches of the Chiwawa River and Nason Creek. Error bars denote $95 \%$ confidence intervals $(\mathrm{SB}=$ sand bowl; $\mathrm{GB}=$ gravel bowl; $\mathrm{CB}=$ cobble bowl; $\mathrm{BB}=$ boulder bowl; $\mathrm{ST}=$ sand tail; $\mathrm{GT}=$ gravel tail; $\mathrm{CT}=$ cobble tail; $\mathrm{BT}=$ boulder tail). 


\section{Relationships between Fish Size and Redd Characteristics}

Correlation analysis conducted by reach found no consistent relationships among reaches between fish size and variables examined. Numerous habitat variables were significantly correlated with fork length and weight, but most relationships were weak $\left(r_{\mathrm{s}}<0.50\right)$. In most instances, correlations with fork length were similar to those using weight $( \pm 10 \%)$. The fork length and weight of hatchery female spring Chinook was weakly correlated with bowl length in the Chiwawa 2 reach (fork length: $r_{s}=0.26, P<0.05$; weight: $r_{s}=$ $0.31, P<0.05)$. Similarly, fork length and weight of hatchery females was correlated with tail length in Nason 1 reach (fork length: $\mathrm{r}_{\mathrm{s}}=0.25, P<0.05$; weight: $\mathrm{r}_{\mathrm{s}}=0.35, P<$ 0.05 ), as was bowl depth (fork length: $r_{\mathrm{s}}=0.28, P<0.05$; weight: $r_{\mathrm{s}}=0.25, P<0.05$ ). Water velocity measured at the upstream side of the tail in Nason 2 reach was also correlated with the fork length and weight of hatchery females (fork length: $\mathrm{r}_{\mathrm{s}}=0.41, P<$ 0.05; weight: $\left.\mathrm{r}_{\mathrm{s}}=0.42, P<0.05\right)$.

Correlations coefficients for naturally produced female spring Chinook were generally greater than those with hatchery females. Both fork length and weight were correlated with redd width in the Chiwawa 1 reach (fork length: $\mathrm{r}_{\mathrm{s}}=0.36, P<0.05$; weight: $\mathrm{r}_{\mathrm{s}}=$ $0.36, P<0.05$ ) and Chiwawa 2 reach (fork length: $r_{\mathrm{s}}=0.37, P<0.05$; weight: $\mathrm{r}_{\mathrm{s}}=0.39$, $P<0.05)$. Significant correlations were found in the Chiwawa 2 reach between both fork length and weight and bowl front (fork length: $\mathrm{r}_{\mathrm{s}}=0.40, P<0.05$; weight: $\mathrm{r}_{\mathrm{s}}=0.45, P<$ 0.05 ); tail depth (fork length: $r_{\mathrm{s}}=0.56, P<0.05$; weight: $\mathrm{r}_{\mathrm{s}}=0.52, P<0.05$ ), tail front in Nason 1 reach (fork length: $r_{\mathrm{s}}=0.73, P<0.05$; weight: $\mathrm{r}_{\mathrm{s}}=0.72, P<0.05$ ), and bowl front (fork length: $\mathrm{r}_{\mathrm{s}}=0.44, P<0.05$; weight: $\mathrm{r}_{\mathrm{s}}=0.50, P<0.05$ ), tail front (fork length: $\mathrm{r}_{\mathrm{s}}=0.45, P<0.05$; weight: $\mathrm{r}_{\mathrm{s}}=0.41, P<0.05$ ), and redd depth (fork length: $\mathrm{r}_{\mathrm{s}}=0.41, P$ $<0.05$; weight: $\left.r_{\mathrm{s}}=0.48, P<0.05\right)$ in the Nason 2 reach.

When data were pooled by origin for each river, significant positive correlations were found between both fork length and weight and redd size and water depth for both hatchery and naturally produced females. In the Chiwawa River, only weight was significantly correlated to redd length $\left(\mathrm{r}_{\mathrm{s}}=0.14, P<0.05\right)$, redd width $\left(\mathrm{r}_{\mathrm{s}}=0.18, P<\right.$ $0.05)$, and bowl depth $\left(\mathrm{r}_{\mathrm{s}}=0.16, P<0.05\right)$ for hatchery females. Both fork length and weight of naturally produced females were correlated with redd width (fork length: $r_{\mathrm{s}}=$ $0.34, P<0.05$; weight: $r_{\mathrm{s}}=0.35, P<0.05$ ), and tail water depth (fork length: $\mathrm{r}_{\mathrm{s}}=0.36, P$ $<0.05$; weight: $\mathrm{r}_{\mathrm{s}}=0.34, P<0.05$ ). In Nason Creek, the fork length and weight of hatchery female spring Chinook were weakly related to bowl depth (fork length: $\mathrm{r}_{\mathrm{s}}=$ $0.28, P<0.05$; weight: $\mathrm{r}_{\mathrm{s}}=0.28, P<0.05$ ), maximum bowl water depth (fork length: $\mathrm{r}_{\mathrm{s}}=$ $0.25, P<0.05$; weight: $r_{\mathrm{s}}=0.26, P<0.05$ ), tail length (fork length: $\mathrm{r}_{\mathrm{s}}=0.21, P<0.05$; weight: $\mathrm{r}_{\mathrm{s}}=0.29, P<0.05$ ) and water velocity in the front of the bowl (fork length: $\mathrm{r}_{\mathrm{s}}=$ $0.22, P<0.05$; weight: $\mathrm{r}_{\mathrm{s}}=0.22, P<0.05$ ). For naturally produced fish in Nason Creek, fork length and weight was only positively related to water depth measured at the front of the bowl (fork length: $r_{\mathrm{s}}=0.43, P<0.05$; weight: $\mathrm{r}_{\mathrm{s}}=0.47, P<0.05$ ), maximum depth of the bowl (fork length: $r_{\mathrm{s}}=0.56, P<0.05$; weight: $\mathrm{r}_{\mathrm{s}}=0.57, P<0.05$ ), front of the tail (fork length: $\mathrm{r}_{\mathrm{s}}=0.51, P<0.05$; weight: $\mathrm{r}_{\mathrm{s}}=0.50, P<0.05$ ), tail apex (fork length: $\mathrm{r}_{\mathrm{s}}=$ $0.37, P<0.05$; weight: $\mathrm{r}_{\mathrm{s}}=0.33, P<0.05$ ), and mean redd depth (fork length: $\mathrm{r}_{\mathrm{s}}=0.44$, $P<0.05$; weight: $\left.\mathrm{r}_{\mathrm{s}}=0.48, P<0.05\right)$. 
Relationships between fish size and spawning site variables were analyzed by origin and river. In the Chiwawa River, larger naturally produced female spring Chinook spawned closer to the middle of the river than smaller females (redd position and fork length: $r_{s}=$ $0.37, P<0.05$; redd position and weight: $\left.\mathrm{r}_{\mathrm{s}}=0.31, P<0.05\right)$. The size of hatchery female spring Chinook was negatively correlated with the distance to the nearest redd (fork length: $\mathrm{r}_{\mathrm{s}}=-0.22, P<0.05$; weight: $\mathrm{r}_{\mathrm{s}}=-0.20, P<0.05$ ). We also detected relationships between spawner density and redd size for naturally produced (spawner density and bowl length: $\mathrm{r}_{\mathrm{s}}=-0.24, P<0.05$ ) and hatchery produced (spawner density and redd area: $\mathrm{r}_{\mathrm{s}}=-0.14, P<0.05$ ) females in the Chiwawa River and hatchery females in Nason Creek (spawner density and bowl length: $r_{\mathrm{s}}=-0.31, P<0.05$ ). These results suggest that as spawner density increases redd size may also decrease.

\section{Discussion}

Significant differences among reaches were found for most habitat variables suggesting that habitat quality and quantity does influence spawning site and redd characteristics. If differences in breeding behavior of hatchery and naturally produced females are manifested in where and how redds are constructed, differences may be detected if the natural variation within a reach is not too great and adequate sample sizes are obtained. Because target sample sizes have not been met, conclusions regarding differences in spawning site and redd characteristics of hatchery and naturally produced spring Chinook salmon should be considered preliminary. Although, differences in physical variables or lack there of may not necessarily reflect all differences in breeding behavior. Schroder et al. (2008) found that naturally produced female spring Chinook salmon initially bury their eggs in a shorter time period than hatchery females. Any such differences in behavior during spawning would not be evident in our analysis.

Water depth and velocity of redd sites is consistent with that previously reported for spring Chinook salmon (Burner 1951; Smith 1973). Although redd sizes reported by Burner (1951) appear smaller because of differences in methodology. Burner (1951) measured the length of a redd to the highest point of the tail (i.e., tail apex). Conversely, we measured the entire length of the tail. Relationships between fish size and physical habitat variables while significant were weaker than expected. Interestingly, weight rather than fork length showed a greater correlation with most variables. Because weight was measured during their upstream migration, actual weight at time of spawning was likely lower. We assumed that relative differences in weight over time were similar for hatchery and naturally produced female spring Chinook. An important variable related to reproductive success not measured in this study was egg burial depth, which has been reported as strongly correlated with fish length (van den Berghe and Gross 1984; Crisp and Carling 1989; Steen and Quinn 1999). Crisp and Carling (1989) reported that egg burial depth was not related to bowl depth, but those data were collected from incomplete redds. We expected that bowl depth would be a useful surrogate for egg burial depth (van den Berghe and Gross 1984). Hence, fish size would be related to bowl depth, but lack of a consistent relationship may suggest otherwise. 
As the sample sizes in each reach increases over time, the relationship between redd characteristics and spawner density may provide important information on competition among females on the spawning grounds. Spawner density has already been shown to influence egg retention in artificial streams (Fleming and Gross 1992; Fleming and Gross 1993; Schroder et al. 2008), a relationship that appears to be confirmed in the natural environment. Numerous significant relationships between fish size and habitat variable suggest that spawning site selection is reliant on multiple factors, both physical and biological. Many of the variables measured in this study have not been reported for spring Chinook salmon or any other salmonids and the relative importance of all variables to survival and ultimately reproductive success is unknown. Additional analysis of all data is needed after data regarding reproductive success has been collected and analyzed.

\section{Acknowledgments}

The Bonneville Power Administration and Chelan County Public Utility District funded this study. We thank David Byrnes, Shaun Seaman, Julie Pyper, and Joe Miller for administrative and logistical support. Todd Pearsons provided valuable insight and advice in the early phases of this project. We also thank Beth Brown, Clint Deason, Jay Deason, Nathan Dietrich, Chad Herring, Brain Johanson, Todd Miller, Steve Schonnings, Kayla Truscott, Kirk Truscott, Anthony Zelinski and many other technicians who aided in collecting data on the spawning grounds.

\section{References}

Araki, H., B.A. Berejikian, M.J. Ford, and M.S. Blouin. 2008. Fitness of hatcheryreared salmonids in the wild. Evolutionary Applications 1(2): 342 -355.

Arend, K. K. 1999. Classification of streams and reaches. Pages 57-74 in M. B. Bain and N. J. Stevenson, editors. Aquatic habitat assessment: common methods. American Fisheries Society, Bethesda, Maryland.

Burner, C. J. 1951. Characteristics of spawning nests of Columbia River salmon. U. S. Fish and Wildlife Service Fisheries Bulletin 61:97-110.

Busack, C. A., and K. P. Currens. 1995. Genetics risks and hazards in hatchery operations: fundamental concepts and issues. Pages 71-80 in H. L. Schramm, Jr., and R G. Piper, editors. Uses and effects of cultured fishes in aquatic ecosystems. American Fisheries Society Symposium 15, Bethesda, Maryland.

Busack, C., C. M. Knudsen, G. Hart, and P. Huffman. 2007. Morphological differences between adult wild and first-generation hatchery upper Yakima River spring Chinook salmon. Transactions of the American Fisheries Society 136:1076-1087 
Crisp, D. T., and P. A. Carling. 1989. Observations of siting, dimensions and structure of salmonid redds. Journal of Fish Biology 34:119-143.

Fleming, I. A., and M. R. Gross. 1992. Reproductive behavior of hatchery and wild coho salmon (Oncorhynchus kisutch): does it differ. Aquaculture 103:101-121.

Fleming, I. A., and M. R. Gross. 1993. Breeding success of hatchery and wild coho salmon (Oncorhynchus kisutch) in competition. Ecological Applications 3:230245.

Fleming, I. A., A. Lamberg, and B. Jonsson. 1997. Effects of early experience $\mathrm{n}$ the reproductive performance of Atlantic salmon. Behavioral Ecology 8:470-480

Ford, M. J. 2002. Selection in captivity during supportive breeding may reduce fitness in the wild. Conservation Biology 16:815-825.

Knudsen, C.M., S. L. Schroder, C.A. Busack, M.V. Johnston, T.N. Pearsons, W.J. Bosch, and D.E. Fast. 2006. Comparison of life-history traits between first-generation hatchery and wild upper Yakima River spring Chinook. Transactions of the American Fisheries Society 135:1130-1144.

Lynch, M., and H. O'Hely. 2001. Captive breeding and the genetic fitness of natural populations. Conservation Genetics 2:363-378.

Murdoch, A. R., T. N. Pearsons, T. W. Maitland, C. L. Deason, M. J. Ford, and K. Williamson. 2007. Monitoring the reproductive success of naturally spawning hatchery and natural spring Chinook salmon in the Wenatchee River. Project No. 2003-039-00, Contract No. 00020391. Bonneville Power Administration, Portland, Oregon.

Murdoch, A. R., T. N. Pearsons, and T. W. Maitland. 2009. The number of redds constructed per female spring Chinook salmon in the Wenatchee River basin. North American Journal of Fisheries Management 29:441-446.

Schmetterling, D. A. 2000. Redd characteristics of fluvial westslope cutthroat trout in four tributaries to the Blackfoot River, Montana. North American Journal of Fisheries Management 20:776-783.

Schroder, S. L., C. M. Knudsen, T. N. Pearsons, T. W. Kassler, S. F. Young, C. A. Busack, and D. E. Fast. 2008. Breeding success of wild and first-generation hatchery females spring Chinook salmon spawning in an artificial stream. Transactions of the American Fisheries Society 137:1475-1489.

Smith, A. K. 1973. Development and application of spawning velocity and depth criteria for Oregon salmonids. Transactions of the American Fisheries Society 93:342356. 
Steen, R. P. and T. P. Quinn. 1999. Egg burial depth by sockeye salmon (Oncorhynchus nerka): implications for survival of embryo and natural selection on female body size. Canadian Journal of Zoology 77:836-841.

Van den Berghe, E. P., and M. R. Gross. 1984. Female size and nest depth in coho salmon (Oncorhynchus kisutch). Canadian Journal of Fisheries and Aquatic Sciences 41:204-206.

Zar, J. H. 1999. Biostatistical Analysis, $4^{\text {th }}$ edition. Prentice Hall, Upper Saddle River, New Jersey. 


\title{
Chapter 4 - Influence of habitat and spawner density in the variation of redd microhabitat characteristics of spring Chinook salmon in the Wenatchee River Basin
}

\begin{abstract}
Trends in relative reproductive success of hatchery and naturally produced spring Chinook salmon Oncorhynchus tshawytscha in the Wenatchee Basins suggest females that spawn in the upper reaches of the tributaries produced a great number of offspring compared to females that spawn in the lower reaches of the tributaries. To better understand this trend, redd microhabitat data was collected from spring Chinook salmon that spawned in the Chiwawa River and Nason Creek, the primary spawning tributaries in the Wenatchee Basin. The objective of the study was to examine the influence of habitat and spawner density on spawning site and redd structure characteristics. We analyzed 28 variables of redd microhabitat data collected from the upper and lower most reaches of each study stream. In both streams, we found redds in the upper most reaches to be significantly larger (length and width) and deeper (bowl depth). Spawner density was significantly greater in the lower Chiwawa River compared to the upper reach. No difference in spawner density was detected between reaches in Nason Creek $(\mathrm{P}=0.54)$. Data should be considered preliminary until sample size goals are achieved. In the interim, data from additional stream reaches will be collected to better understand the relationships observed. In the future, redds will also be classified by habitat type and substrate of redds in different habitat types will be compared.
\end{abstract}

\section{Introduction}

Maximizing salmonid egg survival requires optimal habitat variables (substrate composition and cover), hydrological characteristics (water depth and velocity, water temperature), and space (Bjornn and Reiser 1991). Studies too numerous to list have described the criteria for these variables and experimentally determined their influence on survival. However, the influence of spawning site and redd structure on egg survival in the natural environment has not been quantified. Burner (1951) reported that the redd size in two streams supporting populations of spring Chinook salmon Oncorhynchus tshawytscha were different and the stream containing a higher proportion of larger "football" sized substrate producing smaller redds. While substrate size may inversely influence redd size, a positive relationship between redd size and survival may not exist (Steen and Quinn 1999). Natural variation in habitat and the interaction of multiple variables ultimately affect redd structure. Of which, egg burial depth may be of key importance (Crisp and Carling 1989) and has been shown to be positively related to fish length (DeVries 1997; Steen and Quinn 1999). Van den Berghe and Gross (1984) suggested that nest depth is an important factor in brood survivorship and those eggs at a greater depth are less susceptible to mechanical damage due to flooding or redd superimposition. Measuring egg burial depth is an intrusive and potentially lethal procedure. Unfortunately, no relationship between egg burial depth or survival and any 
redd microhabitat variable measured at the surface has been found other than female size. Identifying one or more redd characteristics that can be readily measured in the field that explains a majority of the variation in survival would be useful in both stock assessment and habitat restoration efforts.

Spawner density and competition between both males and females on the spawning grounds is also important in determining individual reproductive success (Fleming and Gross 1993, 1992; Quinn et al. 2007). As spawner density increases, competitively inferior females may be forced to spawn in less than suitable habitat or redds of early spawning females may be disturbed by later spawning females (Quinn et al. 2007). Shirvell and Dungey (1983) found differences in brown trout Salmo trutta redd densities and dimensions between preferred and non-preferred habitats, with larger redds occurring in the non-preferred habitats, which could be the result of competition forcing some individuals into lesser spawning habitats. Egg retention in post-spawned females has also been reported to increase with competition (Fleming and Gross 1993; Quinn et al. 2007; Schroder et al. 2008). Under low spawner densities without restrictions on spawning habitat, all females could choose optimal spawning sites and deposit all their eggs in a redd. Conversely, under high spawner densities females must compete for spawning sites, defend their redd both during and after spawning, and deposit only a fraction of their eggs. Under the high density scenario, early spawning females may still have their redds disturbed from a later spawning female (i.e., redd superimposition) and suffer high mortality. Chinook salmon are not mass spawners like chum $O$. keta or sockeye salmon $O$. nerka and a competition gradient is likely present driven either by habitat availability or spawner abundance. Thus, varying levels of competition may have differing effects on spawning success (Schroder et al. 2008).

The use of artificial propagation to increase spawner abundance has been widely employed and remains controversial. At low densities, hatchery females exhibit similar behaviors as naturally produced fish, but under higher densities have been reported to be competitively inferior (Fleming and Gross 1992, 1993). Schroder et al. (2008) suggested that subtle difference in redd abandonment, egg burial, and redd location may be responsible for the difference in egg to fry survival of hatchery and wild Yakima River spring Chinook. Using a DNA-based pedigree approach, it is now possible to estimate the reproductive success an individual or ability to produce offspring at some predetermined life stage (See Chapter 2). Differences in reproductive success can then be explored and possibly explained by differences in spawning site or redd structure microhabitat characteristics. Williamson et al. (submitted) found a positive relationship between reproductive success and spawning location (river km) for spring Chinook salmon in the Chiwawa River and Nason Creek. While hatchery spring Chinook had a significantly lower relative reproductive success than naturally produced fish, both exhibited a similar relationship with spawning location. Preliminary results found no difference in microhabitat characteristics of redds constructed by hatchery and naturally produced females measured in selected reaches of the Chiwawa River and Nason Creek (See Chapter 3). However, that study only analyzed redds from a limited spatial distribution and did not consider potential variation in spawning site and redd structure across the entire river that could explain the similar trends in reproductive success. The 
objective of this study was to 1) measure spawning site and redd microhabitat characteristics of spring Chinook salmon and determine any relationships with spawning location (river $\mathrm{km}$ ) and 2) estimate the instantaneous spawn density at each redd location and determine the influence on spawning site and redd microhabitat characteristics.

\section{Methods}

\section{Spawning ground surveys}

Spring Chinook salmon were trapped at Tumwater Dam located on the Wenatchee River (rkm 43.7) and tagged with passive integrated transponder (PIT) tags for later identification on the spawning grounds. A PIT tag was inserted into the dorsal sinus cavity on the left side of the body and biological data was collected (fork length, weight, sex, tissue and scale samples). After which, fish were placed into 1,720 L recovery tank with a continuous supply of river water and allowed to fully recover before being released upstream. This study focused on the two major spawning tributaries (Chiwawa River [49.7 km] and Nason Creek [25.3 k]) that were surveyed twice a week (Chapman et al. 1995; Mosey and Murphy 2002). Foot surveys were conducted in an upstream direction so spawning fish would not be disturbed and were scheduled to minimize the number of days $(N=3)$ between surveys. Rafting was conducted on reaches where the flow was too high for foot surveys to be conducted safely (lower Chiwawa River). Two or three person crews surveyed reaches, which were selected for redd microhabitat measurements. Individual observers surveyed the same stream reach throughout the spawning period and in some cases throughout the study period.

Spring Chinook salmon redds were identified by the presence of clean gravel, a depression in the substrate (bowl or pit), and a tailspill or mound of substrate immediately downstream of the bowl (Crisp and Carling 1989; Barlaup et al. 1994). False or test redds were identified as locations that had areas of clean gravel, but lacked typical redd morphological characteristics (e.g., defined bowl or tail spill), were small in size, or had poor substrate quality. Test redds were not included in the analysis if the shape and morphology did not change over repetitive surveys. Surveyors recorded the behavior of the female (i.e., staging, constructing, or guarding) if present. Each redd was assigned a unique GPS waypoint, marked with surveyors flagging attached to nearby vegetation, and recorded in a field notebook. Each flag was labeled with the appropriate reach and redd number, date, redd location, and the surveyor's initials. In addition, a blue flag was used to indicate if the origin of the female was successfully determined. Redd microhabitat variables would later be measured only on completed redds that the female origin was known.

We attempted to identify individual post spawned females while guarding their respective redds by using a portable underwater PIT tag antenna mounted on an extension pole (Biomark, Boise, Idaho). Surveyors carefully approached a female salmon on a redd from a downstream location while minimizing their silhouette and shadow by keeping a low profile. The black triangle antenna was slowly positioned over the dorsal fin of the 
female and the PIT tag was recorded. Using this technique, we were able to identify individual fish on redds and correlate the PIT tag with biological data collected at Tumwater Dam.

\section{Redd microhabitat data}

Microhabitat characteristics of redds were measured in upper and lower most reaches of the Chiwawa River (Chiwawa upper: rkm 36.8 - 42.8; Chiwawa lower: rkm 19.8 - 23.2) and Nason Creek (Nason upper rkm: 14.7 - 19.7; Nason lower: rkm 0.0 - 7.2) between 2004 and 2008 (Figure 1). The maximum length and width of the redd was recorded to the nearest $0.1 \mathrm{~m}$. Lengths were also recorded for the bowl and tail to the nearest $0.1 \mathrm{~m}$. Water depth measurements (nearest $\mathrm{cm}$ ) were taken at the bowl front, the deepest point within the bowl, the tail front, the tail apex, the downstream end of the tail, and left and right side of the redd. Water velocity $(\mathrm{m} / \mathrm{s})$ was measured using a Marsh McBirney Model 2000 or Swoffer Model 2100 flow meters. Water velocity was recorded at the upstream end of the bowl (60\% depth), maximum depth of the bowl (60\% depth), upstream end of the tail ( $60 \%$ depth, surface, bottom), downstream end of the tail $(60 \%$ depth), and the left and right side of the redd (60\% depth). Average redd water depth was calculated from water depth measurements recorded at the left and right side of the redd and the upstream end of the bowl. The depth of bowl was calculated by subtracting the average redd depth from the maximum depth of the bowl. Tail height was calculated using the tail apex minus the average of the left and right redd depths. Mean tail velocity $(\mathrm{m} / \mathrm{s})$ was calculated from measurements $(60 \%$ depth) recorded at the center, left and right side of the front of the tail (Figure 2). The distance to the nearest redd (m), nearest cover type (riffle, pool, large woody debris, boulder, vegetation or bank) and distance to right and left banks was also measured. Redd area $\left(\mathrm{m}^{2}\right)$ was calculated using the maximum length and width of the redd. Substrate composition (i.e., sand, gravel, cobble, or boulder) was visually estimated for both the bowl and tail.

\section{Instantaneous Spawner Density}

Instantaneous Spawner Density (ISD) was used as a measure of competition on the spawning grounds and was calculated for each redd. ISD was defined as the number of redds constructed within a $5 \mathrm{~m}$ radius of a redd. Because spring Chinook salmon die shortly after spawning is complete, we limited the redds included in the calculation only to those females expected to be alive when the redd was constructed. Murdoch et al. (2008) estimated the mean redd residence for each river defined as the number of days between redd construction and the date the carcass was recovered. Redds constructed during the time period both before and after the target redd were included in the ISD calculation.

\section{Data Analysis}

A Shapiro-Wilk test was used to determine if data were normally distributed. MannWhitney U-tests were used to determine if differences existed between microhabitat variables in the upper and lower reaches of both the Chiwawa River and Nason Creek. Spearman rank order correlation analysis $\left(\mathrm{r}_{\mathrm{s}}\right)$ was used to examine the relationship 
between bowl depth and redd structure. All statistical tests were performed at a significance level $(\alpha)$ of 0.05 . 


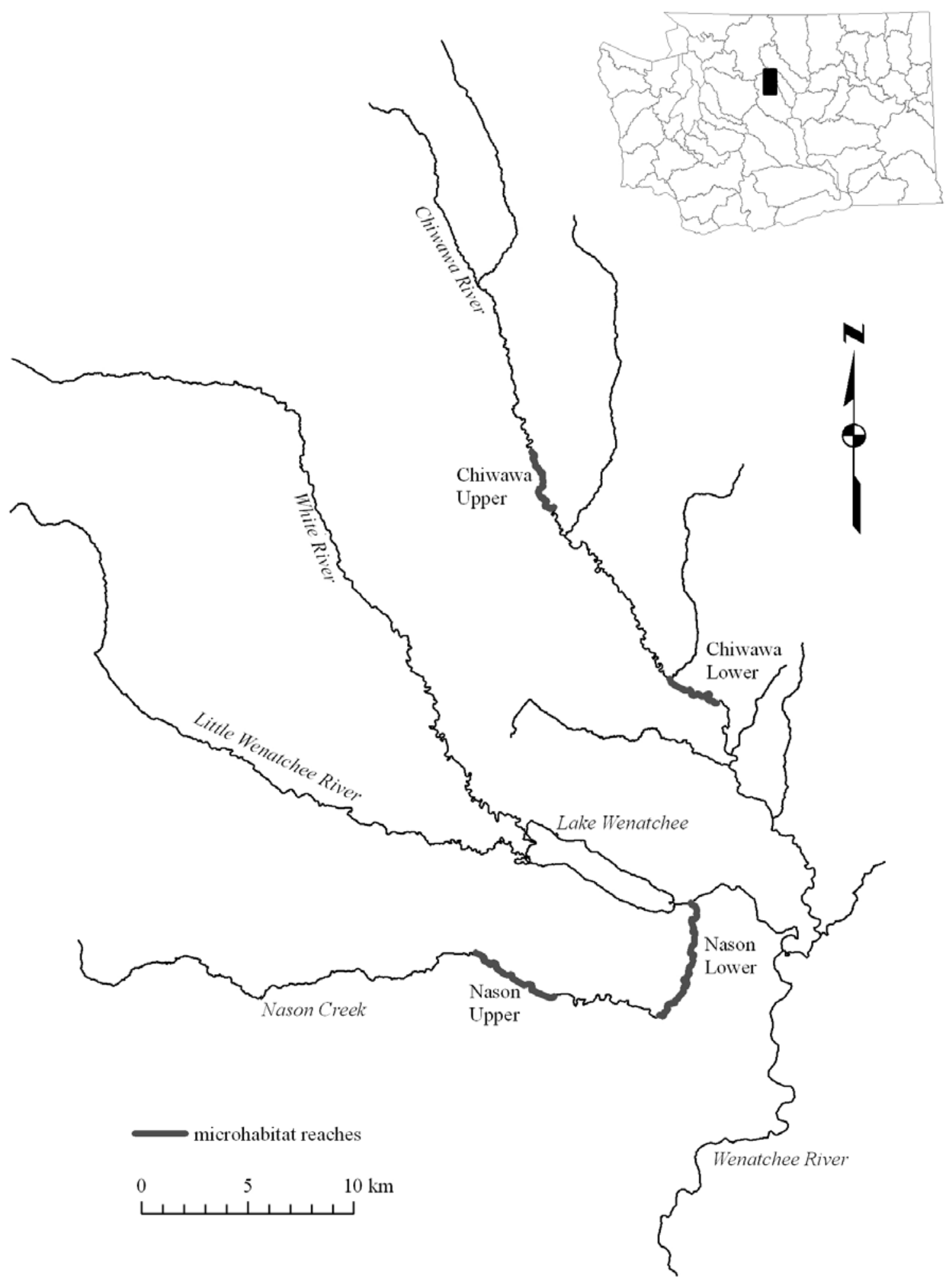

Figure 1. Locations of study reaches for redd microhabitat characteristic measurements. 
(a)
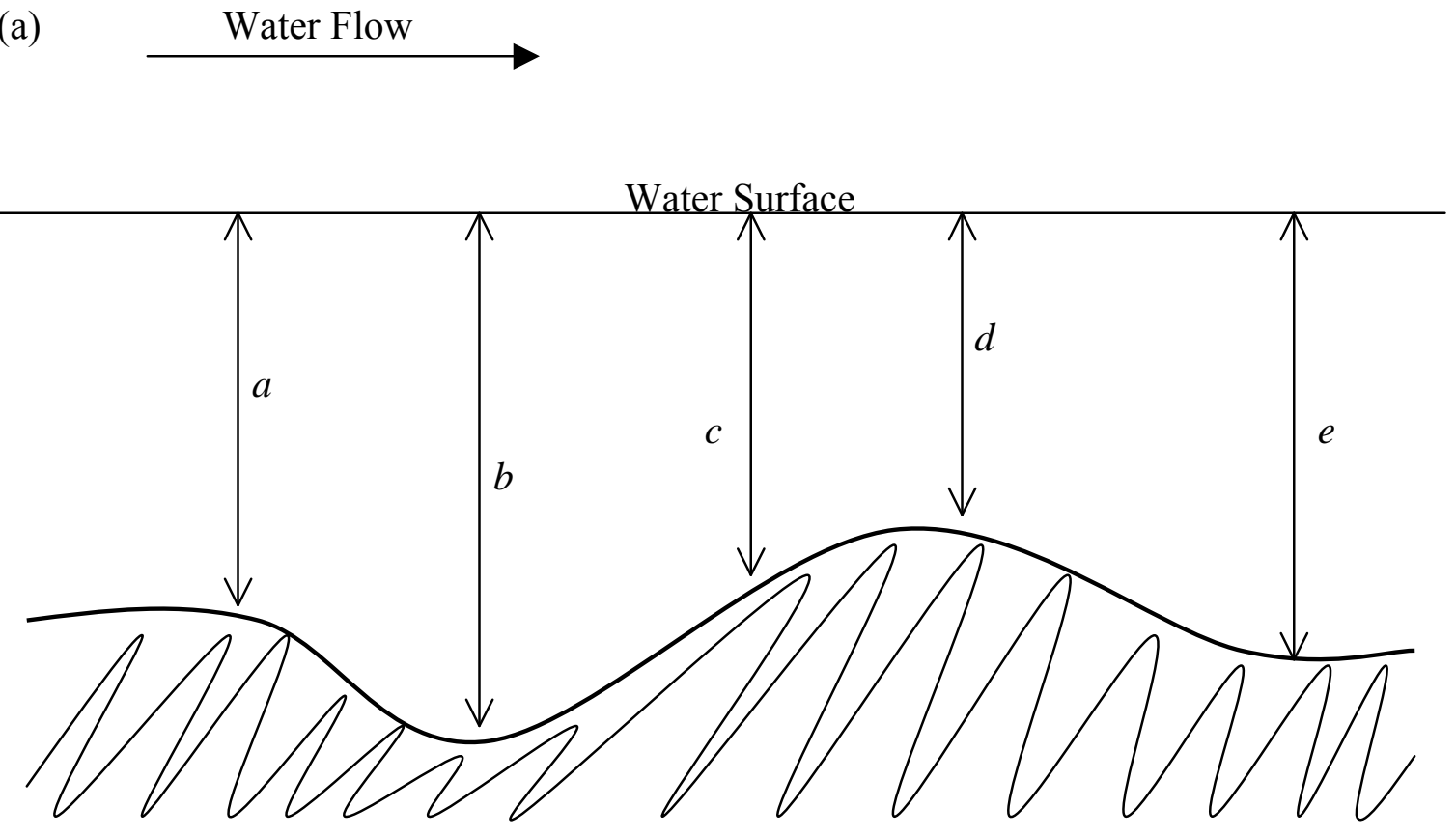

(b)



Figure 2. (a) Longitudinal section and (b) plan view of a salmonid redd. Italic letters indicate measurements of water depth and redd dimensions: $a$ is water depth upstream of bowl; $b$ is water depth at the deepest point of the bowl; $c$ is water depth as transition point of bowl and tail; $d$ is water depth at shallowest point of the tail; $e$ is water depth at the downstream point of the tail; $f$ is the total length of the redd; $g$ is the total width of the redd; $h$ is the length of the bowl; $i$ is the length of the tail. Water velocity was measured at 0.6 times the water depth at various locations: $\mathrm{V}_{1}$ is upstream of the bowl; $\mathrm{V}_{2}$ is the deepest point of the bowl; $\mathrm{V}_{3}$ is the transition point between the bowl and tail; $\mathrm{V}_{4}$ is downstream of the tail; $\mathrm{V}_{5}$ is the left side of the redd; and $\mathrm{V}_{6}$ is the right side of the redd. Figure was adapted from Crisp and Carling (1989) and Schmetterling (2000). 


\section{Results}

Between 2004 and 2008, we collected data from 163 and 173 redds in the Chiwawa River and Nason Creek, respectively (Table 1). Data were pooled by reach across years to increase sample size. The mean stream width of redd locations was smaller in the upper Chiwawa River compared to the lower reach $(P<0.001)$, but not in Nason Creek $(P=$ 0.87). Two major tributaries enter the Chiwawa River between the upper and lower reaches and the corresponding increase in discharge is likely responsible for the increase in stream width. Nason Creek has only minor tributaries within the study area and discharge is likely similar in both reaches. The increase in stream width may also be responsible for the difference in redd position detected in the Chiwawa River. Redds in the lower reach of the Chiwawa River were constructed relatively closer to the stream bank than in the upper reach $(P<0.001)$. No difference was detected in redd position in Nason Creek. Redds in the lower Chiwawa River were also constructed closer to one another than in the upper Chiwawa River $(P<0.001)$, but the opposite trends was observed in Nason Creek $(P<0.001)$. Redd density was also lower in the upper reaches of the Chiwawa River $(P<0.001)$, but not in Nason Creek $(P=0.54)$.

Similar results were found in redd structure variables between upper and lower reaches of both rivers. Spring Chinook salmon redds constructed in the upper most reach of the Chiwawa River and Nason Creek were significantly larger size (length and width) and deeper (bowl depth) than those in the lowest reaches $(P<0.02)$. Bowl depth was significantly positively correlated $(P<0.05)$ with redd length and width in both Chiwawa River (redd length: $r_{\mathrm{s}}=0.31$; redd width $\mathrm{r}_{\mathrm{s}}=0.33$ ) and Nason Creek (redd length: $\mathrm{r}_{\mathrm{s}}=$ 0.27 ; redd width $r_{s}=0.32$ ). Tail length was significantly greater in the upper Chiwawa reach $(P<0.04)$ compared to the lower reach, but no difference was detected in Nason Creek $(P=0.79)$. The height of the tail above the undisturbed surface was the only redd structure variable not different between reaches in both the Chiwawa River $(P=0.27)$ and Nason Creek $(P=0.12)$.

In the Chiwawa River, significant differences $(P<0.05)$ were detected in all of the water depth variables except tail back $(P=0.18)$. Water velocity measured at tail front $(60 \%$ depth), tail back, and right side of the redd was also significantly greater in the upper most Chiwawa reach $(P<0.05)$. No differences were found in any of the water velocity variables recorded in the upper and lower reaches of Nason Creek $(P>0.05)$ and the only difference in water depth was measured downstream of the tail $(P<0.02)$. We attributed differences in water depth and velocity in the Chiwawa River to the increase in discharge and stream width downstream of two major tributaries. 
Table 1. Descriptive statistics (mean, SD) for microhabitat variables of upper and lower reaches in the Chiwawa River and Nason Creek between 2004 and 2008. Significance levels of Mann-Whitney U-Tests comparing upper and lower reaches are also presented. The bowl maximum velocity variable was added in 2005 and sample numbers are as follows: Chiwawa Lower $N=82$, Chiwawa Upper $N=56$, Nason Lower $N=32$, and Nason Upper $N=34$.

\begin{tabular}{|c|c|c|c|c|c|c|}
\hline \multirow{2}{*}{$\begin{array}{l}\text { Microhabitat } \\
\text { variable }\end{array}$} & \multicolumn{3}{|c|}{ Chiwawa River } & \multicolumn{3}{|c|}{ Nason Creek } \\
\hline & $\begin{array}{c}\text { Lower } \\
(N=87)\end{array}$ & $\begin{array}{l}\text { Upper } \\
(N=76)\end{array}$ & $P$ & $\begin{array}{l}\text { Lower } \\
(N=91)\end{array}$ & $\begin{array}{c}\text { Upper } \\
(N=82)\end{array}$ & $P$ \\
\hline \multicolumn{7}{|c|}{ Water depth (m) } \\
\hline Redd depth & $0.30(0.09)$ & $0.41(0.14)$ & 0.00 & $0.32(0.09)$ & $0.31(0.08)$ & 0.46 \\
\hline Bowl front & $0.32(0.11)$ & $0.51(0.18)$ & 0.00 & $0.34(0.11)$ & $0.35(0.11)$ & 0.72 \\
\hline Bowl maximum & $0.42(0.10)$ & $0.59(0.16)$ & 0.00 & $0.41(0.10)$ & $0.43(0.09)$ & 0.14 \\
\hline Redd right & $0.28(0.13)$ & $0.36(0.15)$ & 0.00 & $0.31(0.12)$ & $0.28(0.09)$ & 0.28 \\
\hline Redd left & $0.30(0.13)$ & $0.37(0.17)$ & 0.02 & $0.29(0.11)$ & $0.29(0.11)$ & 0.50 \\
\hline Tail front & $0.32(0.08)$ & $0.46(0.13)$ & 0.00 & $0.33(0.10)$ & $0.33(0.09)$ & 0.46 \\
\hline Tail apex & $0.14(0.08)$ & $0.19(0.12)$ & 0.00 & $0.15(0.09)$ & $0.15(0.08)$ & 0.67 \\
\hline Tail back & $0.27(0.10)$ & $0.30(0.14)$ & 0.18 & $0.27(0.12)$ & $0.23(0.09)$ & 0.02 \\
\hline \multicolumn{7}{|c|}{ Water velocity $(\mathrm{m} / \mathrm{s})$} \\
\hline Bowl front & $0.44(0.20)$ & $0.49(0.22)$ & 0.17 & $0.43(0.19)$ & $0.40(0.15)$ & 0.63 \\
\hline Bowl maximum & $0.37(0.17)$ & $0.43(0.24)$ & 0.13 & $0.33(0.10)$ & $0.36(0.12)$ & 0.30 \\
\hline Redd right & $0.39(0.26)$ & $0.47(0.21)$ & 0.01 & $0.38(0.24)$ & $0.38(0.17)$ & 0.54 \\
\hline Redd left & $0.41(0.23)$ & $0.46(0.24)$ & 0.18 & $0.37(0.22)$ & $0.39(0.15)$ & 0.16 \\
\hline Tail front surface & $0.50(0.22)$ & $0.54(0.21)$ & 0.28 & $0.45(0.21)$ & $0.45(0.15)$ & 0.49 \\
\hline Tail front $60 \%$ & $0.41(0.20)$ & $0.51(0.36)$ & 0.02 & $0.42(0.16)$ & $0.41(0.13)$ & 0.92 \\
\hline Tail front bottom & $0.26(0.14)$ & $0.29(0.19)$ & 0.42 & $0.26(0.15)$ & $0.26(0.12)$ & 0.64 \\
\hline Tail back & $0.49(0.29)$ & $0.63(0.35)$ & 0.00 & $0.51(0.25)$ & $0.54(0.26)$ & 0.46 \\
\hline Tail mean & $0.39(0.17)$ & $0.45(0.23)$ & 0.11 & $0.38(0.16)$ & $0.37(0.12)$ & 0.52 \\
\hline \multicolumn{7}{|c|}{ Redd structure (m) } \\
\hline Bowl depth & $0.12(0.05)$ & $0.18(0.08)$ & 0.00 & $0.09(0.05)$ & $0.12(0.05)$ & 0.00 \\
\hline Bowl length & $2.43(0.99)$ & $2.60(0.96)$ & 0.02 & $1.94(0.77)$ & $2.63(0.76)$ & 0.00 \\
\hline Tail height & $0.15(0.08)$ & $0.18(0.11)$ & 0.27 & $0.15(0.06)$ & $0.14(0.07)$ & 0.12 \\
\hline Tail length & $3.75(1.18)$ & $4.07(1.27)$ & 0.04 & $3.89(1.19)$ & $3.84(1.06)$ & 0.79 \\
\hline Redd width & $3.64(0.98)$ & $4.46(1.08)$ & 0.00 & $3.54(0.95)$ & $4.02(1.00)$ & 0.00 \\
\hline Redd length & $6.18(1.44)$ & $6.67(1.82)$ & 0.02 & $5.83(1.45)$ & $6.47(1.26)$ & 0.00 \\
\hline \multicolumn{7}{|c|}{ Spawning site } \\
\hline Stream width $(\mathrm{m})$ & $26.27(5.39)$ & $17.92(6.07)$ & 0.00 & $17.35(7.97)$ & $17.28(6.58)$ & 0.87 \\
\hline Nearest redd (m) & $32(67)$ & $53(61)$ & 0.00 & $79(28)$ & $76(9)$ & 0.00 \\
\hline ISD & $1.45(0.96)$ & $1.00(0.00)$ & 0.00 & $1.09(0.39)$ & $1.01(0.11)$ & 0.54 \\
\hline Redd position & $0.23(0.13)$ & $0.32(0.11)$ & 0.00 & $0.29(0.13)$ & $0.30(0.11)$ & 0.65 \\
\hline $\begin{array}{l}\text { Dist. nearest } \\
\text { cover (m) }\end{array}$ & $4.86(6.46)$ & $4.57(5.39)$ & 0.90 & $6.33(6.24)$ & $7.38(7.90)$ & 0.42 \\
\hline
\end{tabular}




\section{Discussion}

Differences detected in redd structure variables followed a similar pattern with larger and deeper redds being constructed in the upper most reaches of both Chiwawa River and Nason Creek. Van den Berghe and Gross (1984) found a positive correlation in female coho salmon size and nest depth and suggested that due to a mechanical or energetic advantage, larger females dig deeper nests. Differences in female size may account for some of the difference, but strong relationships between female size (length or weight) and redd structure has not been found in the either the Chiwawa River or Nason Creek (See Chapter 3). Crisp and Carling (1989) reported that fish size is not a significant correlate in spawning site selection and therefore suggests a more complex set of variables must influence individual site selection. Female weight was also not found to be a factor in explaining the differences in reproductive success, but larger females did have higher reproductive success (See Chapter 2).

On the Chiwawa River significant difference in spawner density were found between the two study reaches, with the lower reach having an increased density, which could have negative implications on redd construction, egg burial depth, and eggs retained by the spawned female spring Chinook. Mason and Chapman (1965) found body weight to be an important factor from a competition standpoint between female coho salmon $O$. kisutch, with the smaller fish being dominated by the larger ones. They found competition caused delays in the spawn timing of the smaller females, which lead to an increase in egg retention, and negatively impacted egg fertility and survival of alevins due to later emergence. It is reasonable to assume that in areas of elevated spawner density such as lower reaches of the Chiwawa River, intrasexual competition may explain the construction of shallower, smaller redds and superimposition of redds may result in the decreased reproductive success found in the lower reaches of the Chiwawa River.

Assuming the results do not change as samples size is increased over the next several years, two hypotheses likely explain the variation in redd structure observed: 1) redd structure is related to habitat availability and 2) competition among females influences redd structure. Based on field observations, spawning habitat quality and quantity decreases from the upper to lower reaches in the Chiwawa River, but not necessarily in Nason Creek. Competition on the spawning grounds also appears to increase from the upper to lower reaches in the Chiwawa River, but not in Nason Creek. It is unclear at this time, why trends in redd structure and reproductive success are similar in the Chiwawa River and Nason Creek, but possible factors for the trend (i.e., habitat and competition) are not evident in Nason Creek. One possible explanation is that in lower Nason Creek substrate size is smaller and gradient is lower than upper Nason Creek. The opposite trend observed in the Chiwawa River. Due to differences in habitat, redds in the lower Chiwawa River may be scoured, while redds in the lower Nason Creek may be buried. Both processes would have similar effects in reducing reproductive success.

Results concerning spawning site and redd structure should be considered preliminary until samples sizes are sufficient to achieve statistical power $(\sim 0.80)$. In subsequent years, we will attempt to collect similar data from reaches farther upstream in both the 
Chiwawa River and Nason Creek and in the lowest reach of the Chiwawa River (Figure 3). Redd locations will also categorized by habitat type defined in Montgomery and Buffington (1997) that may provide insight to potential scour depths of eggs in redds. We may also attempt compare substrate composition of redds in different habitats that would also suggest susceptibility to scouring or filling (Kondolf and Li 1992).

\section{Acknowledgments}

The Bonneville Power Administration and Chelan County Public Utility District funded this study. We thank David Byrnes and Shaun Seaman for administrative and logistical support. We also thank Beth Brown, Clint Deason, Jay Deason, Nathan Dietrich, Chad Herring, Todd Miller, Steve Schonning, Kayla Truscott, Kirk Truscott, Anthony Zelinski, Joe Lemoine, John Walter, Tobias Cron, Jamie Hallman, Zeke Simmons, Matt Stillwater, John Frank and many other technicians who assisted in collecting data on the spawning grounds. Chad Herring provided construction of the maps and generated the river kilometer data for calculating various spatial variables. 


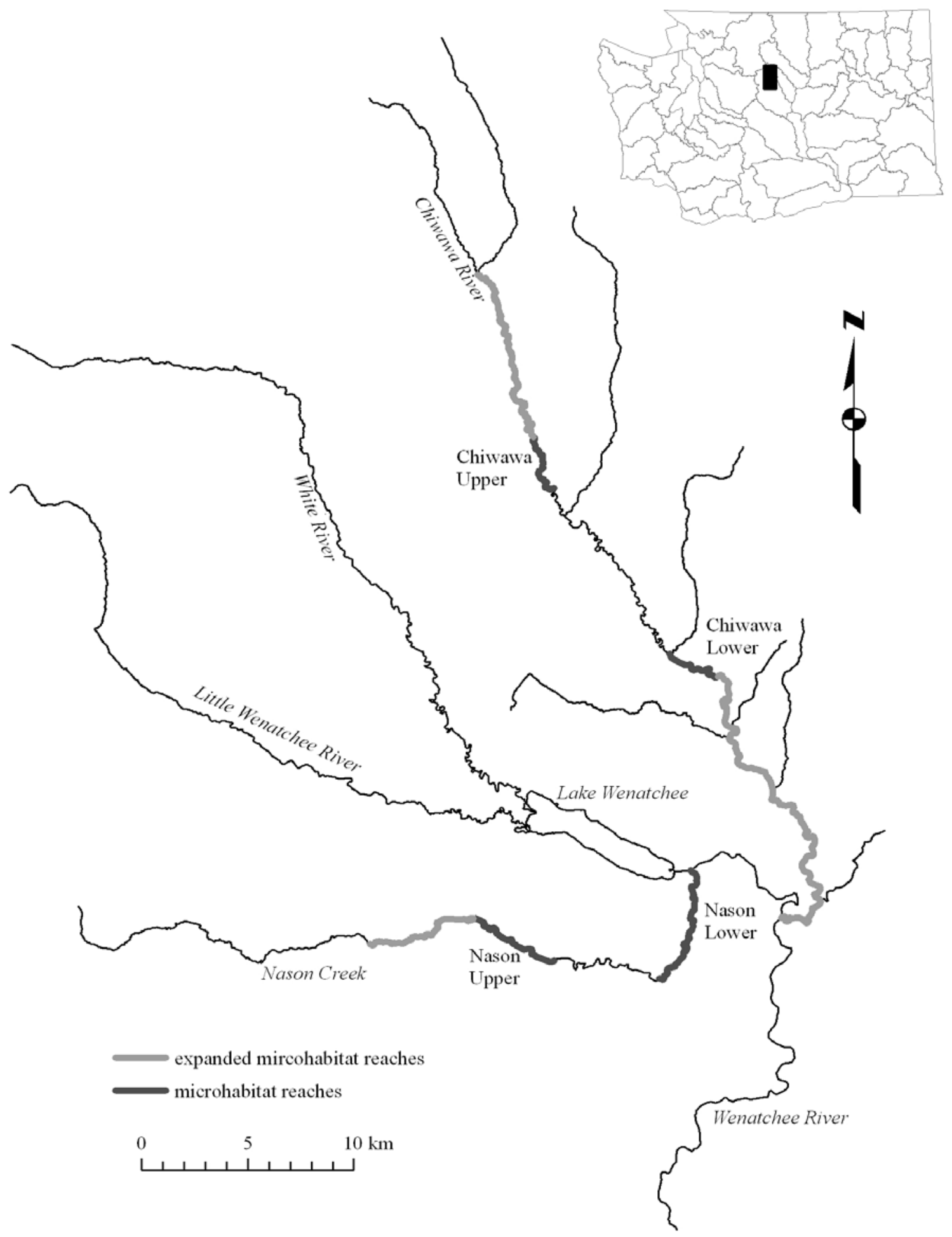

Figure 3. Locations of current and expanded reaches where redd microhabitat measurements will be recorded. 


\section{References}

Barlaup, B. T., H. Lura, H. Saegrov, and R. C. Sundt. 1994. Inter- and intra-specific variability in female salmonid spawning behaviour. Canadian Journal of Zoology 72:636-642.

Bjornn, T. C., and D. W. Reiser. 1991. Habitat Requirements of Salmonids in Streams. Pages 83-138 in W. R. Meehan, editor. Influences of forest and rangeland management on salmonid fishes and their habitats. American Fisheries Society Special Publication 19, Bethesda, Maryland.

Burner, C. J. 1951. Characteristics of spawning nests of Columbia River salmon. U. S. Fish and Wildlife Service Fisheries Bulletin 61:97-110.

Crisp, D. T., and P. A. Carling. 1989. Observations on siting. Dimensions and structure of salmonid redds. Journal of Fish Biology 34:119-134.

DeVries, P. 1997. Riverine salmonid egg burial depths: review of published data and implications for scour studies. Canadian Journal of Fisheries and Aquatic Sciences 54:1685-1698.

Fleming, I. A., and M. R. Gross. 1992. Reproductive behavior of hatchery and wild coho salmon (Oncorhynchus kisutch): does it differ. Aquaculture 103:101-121.

Fleming, I. A., and M. R. Gross. 1993. Breeding success of hatchery and wild coho salmon (Oncorhynchus kisutch) in competition. Ecological Applications 3:230245.

Kondolf, G. M., and S. Li. 1992. The pebble count technique for quantifying surface bed material size in instream flow studies. Rivers 3(2):80-87.

Mason, J. C., and D. W. Chapman. 1965. Significance of early emergence, environmental rearing capacity, and behavioral ecology of juvenile Coho salmon in stream channels. Journal Fisheries Research Board of Canada 22:173189.

Montgomery, D. R. and J. M. Buffington. 1997. Channel-reach morphology in mountain drainage basins. Geological Society and American Bulletin 109:596-611.

Quinn, T. P., D. M. Eggers, J. H. Clark, and H. B. Rich, Jr. 2007. Density, climate, and the processes of prespawn mortality and egg retention in Pacific salmon (Oncorhynchus spp.). Canadian Journal of Fisheries and Aquatic Sciences 64:574-582. 
Schmetterling, D. A. 2000. Redd characteristics of fluvial westslope cutthroat trout in four tributaries to the Blackfoot River, Montana. North American Journal of Fisheries Management 20:776-783.

Schroder, S. L., C. M. Knudsen, T. N. Pearsons, T. W. Kassler, S. F. Young, C. A. Busack, and D. E. Fast. 2008. Breeding success of wild and first-generation hatchery females spring Chinook salmon spawning in an artificial stream. Transactions of the American Fisheries Society 137:1475-1489.

Shirvell, C. S., and R. G. Dungey. 1983. Microhabitats chosen by brown trout for feeding and spawning in rivers. Transactions of the American Fisheries Society. 112:760-771.

Steen, R. P., and T. P. Quinn. 1999. Egg burial depth by sockeye salmon (Oncorhynchus nerka): implications for survival of embryo and natural selection on female body size. Canadian Journal of Zoology 77:836-841.

Van den Berghe, E. P., and M. R. Gross. 1984. Female size and nest depth in coho salmon (Oncorhynchus kisutch). Canadian Journal of Fisheries and Aquatic Sciences 41:204-206.

Williamson, K., A. Murdoch, T. Pearsons, and M. Ford. (submitted). Factors influencing the relative fitness of hatchery and wild spring Chinook salmon in the Wenatchee River, WA.

Wooten, R. J. 1990. Ecology of Teleost Fishes. London: Chapman \& Hall. 